\title{
Enterprising or Enterprise? Sustainable rural training centre models in the Solomon Islands
}

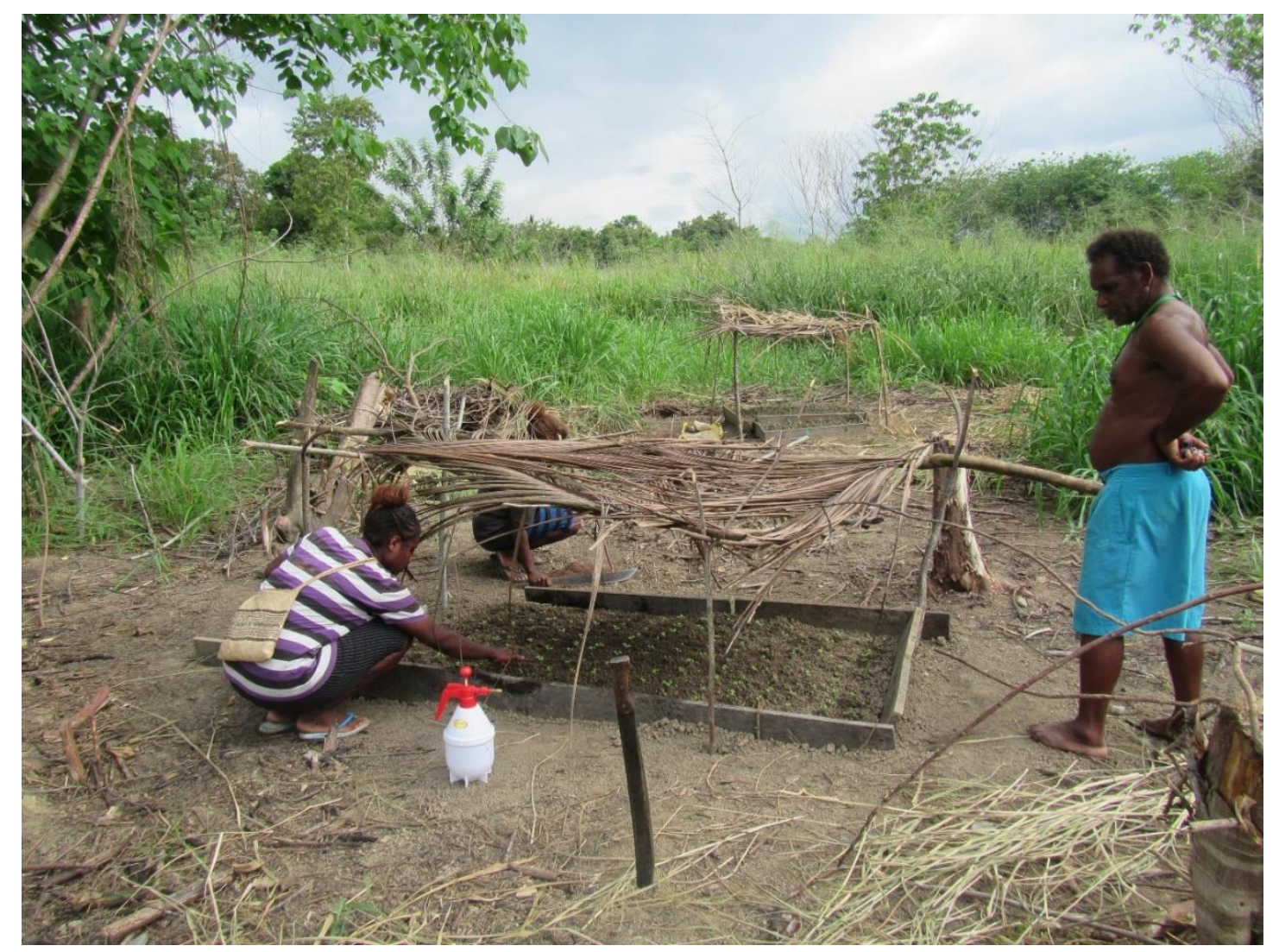

Figure 1. Agriculture students and staff tending to plant nursery at Kaotave rural training centre. (Photo credit: Finn Egan)

\section{Finn Egan}

School of Geography, Environment and Earth Sciences, Victoria University of Wellington, February 2020

Thesis submitted to Victoria University of Wellington in partial fulfilment of the requirements for the degree of Master of Development Studies 
SID: 300294566

Supervisor: John Overton 
"START is a faith-based supervised project that NZ should be acknowledged forrecognising what is important to Solomon Island society and that which provides meaning to the way we do things here."

- Joash Maneipuri, SSEC Education Authority

"What we're trying to do in 5 years in TVET in the Solomon Islands is something that took 25 years to accomplish in Australia, and even then [in Australia] we still haven't got it right" - Interview, 6/6/19, Honiara 


\section{Abstract}

This thesis assesses the educational relevance, impact and operational sustainability, of community rural training centres (RTCs) and external 'development' practice across the Solomon Islands over the last five years. It further legitimises RTCs as effective hubs of 'development' for informal livelihoods and rural community interests.

The thesis adopts a post-development lens in its assessment of insights obtained from qualitative interviews with 87 participants, spanning four RTC locations and in consultation with other stakeholders. Particular attention is given to Escobar's local models of practice (Escobar, 1995) in understanding processes of 'development' at the community level. It assessed the nature and purpose of RTCs for community conceptions of 'development' and 'modernity', identifying their impact in this regard. Alongside this, the thesis assessed the impact of external 'development' programming on the RTC model of practice, including considerations of output relevance and sustainability.

Overall, a social enterprise model (Ridley-Duff \& Bull, 2018) was found to be insufficient to understanding the RTC model of practice. Such a model failed to account for the varied conceptions of 'modernity' at the local level, and instead a more holistic model of RTC operation was proposed. This helps to expand discourses of localised practice in the context of 'development'.

Evidence from participants showed clear positive impacts of the model in supporting different stakeholders' goals for 'development' at the community level. Mainstream discourses of 'knowledge' transfer were challenged by showing the agency and, at times, power, community actors possessed in localising new learnings into current understandings as they saw fit. While external programming played a key part in these processes, its role was as a facilitator of RTC models of practice rather than as the main driver of community 'development'. Rather than simply replacing one set of 'knowledge' with another, this expands discourses of localised 'knowledge' to show community understandings as separate and adaptable domains of knowledge that should be supported rather than replaced.

Finally, this thesis assessed the position of RTCs in wider discourses of Solomon Islands' 'sustainable development', including wider outcomes and implications of this position on their 'sustainability', and for community education. National and global processes of 'development' we found to have great influence on the successes and challenges of RTCs, showing ongoing and evolving challenges to 'informal' livelihoods and practice. External expectations were shown to create a sustainability paradox for rural training centres (Devine, 2003), between conforming to external perceptions to support their 'development' or maintaining their relevance in informal settings with few options for growth. A case is therefore made to expand discourses of 'sustainable development' to conceive of sustainable outcomes in a more holistic way, acknowledging history and community-level intent over external economic 'development' pressures. 


\section{Acknowledgements}

I could not have completed this thesis without the support, guidance and hospitality of the following human beings. You are all awesome and my deepest thanks go out to you:

My Solomon Islands participants and RTC staff - for being open, honest and welcoming in sharing your lives, your hopes and your aspirations with me.

Billy Mai and Shirley Mana - for being fantastic hosts for me in the Solomon Islands and making sure my pidgin was up to scratch!

John Overton - for making sure my practicality stayed grounded in academics and always being a source of positivity.

Mum and Dad - For both powering through my final draft in less than a week and giving me really useful points to consider.

Lauren Hucker - For paying the bills when I struggled to, distracting me from work when I needed it and just generally putting up with me.

Marion Ferguson and Murray Shearer - For seeing a connection and taking a chance on a young guy with a passion for people.

My office buddies - For being much more woke than me, sharing grumbles and being there along the way.

A final thanks to Jules and the team at Caritas Aotearoa New Zealand, who have been amazing to work with, open to change and honest in their approach to development. 


\section{Table of Contents}

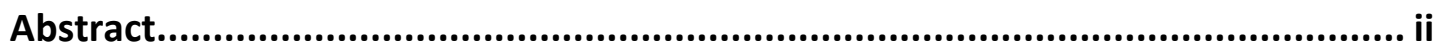

Acknowledgements ........................................................................................................ ii

Table of Contents …...................................................................................................... iv

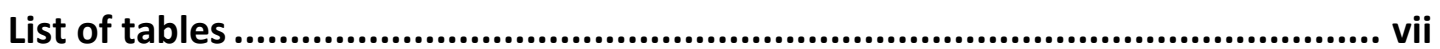

List of figures...................................................................................................... vii

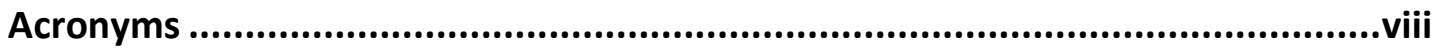

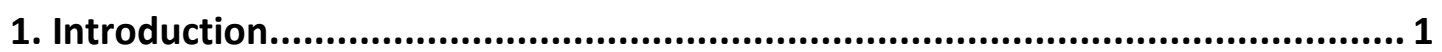

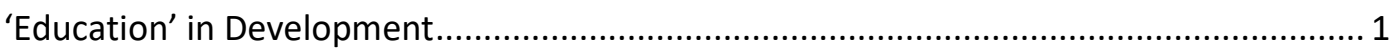

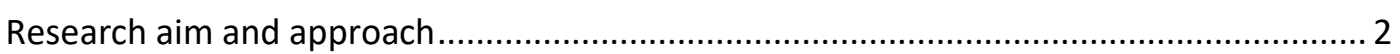

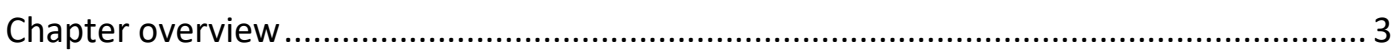

2. Solomon Islands National Context......................................................... 5

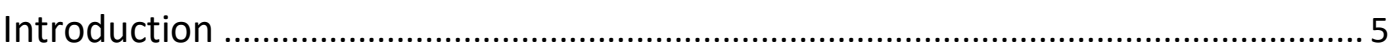

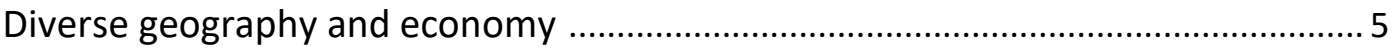

A (colonial) history, a lingering past ......................................................................... 7

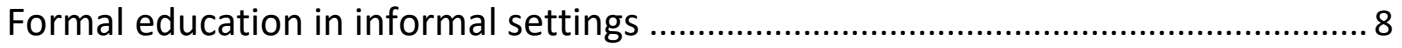

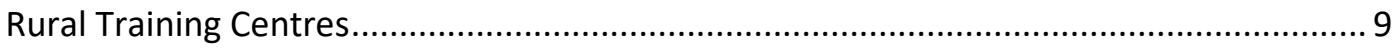

Young people's search for opportunity and employment..................................... 10

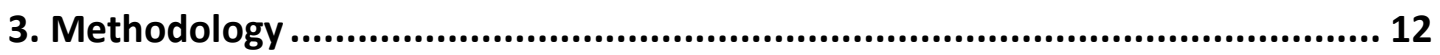

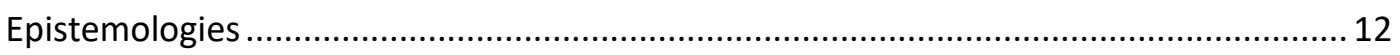

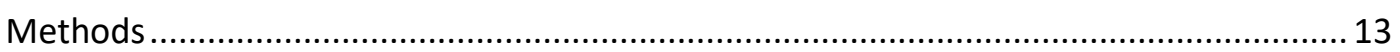

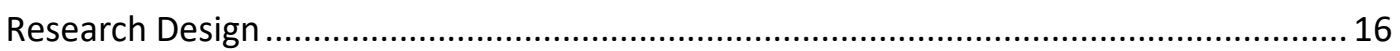

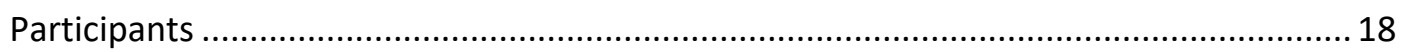

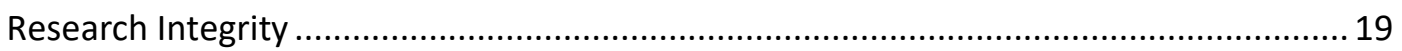

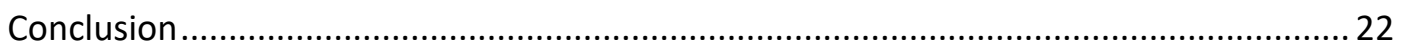

4. A review of Post-development Theory ........................................................ 23

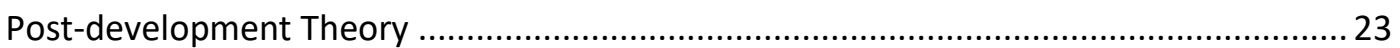

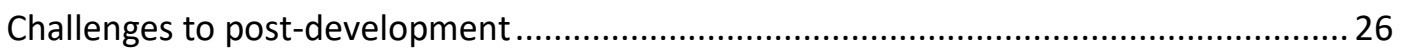

Finding a way forward: Changing the 'development' discourse....................................... 28

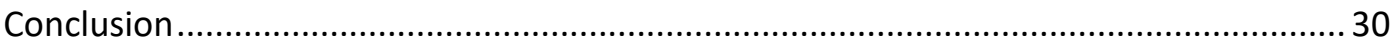

5. Local models of practice: Solomon Islands RTCs as community 'hubs' of diverse

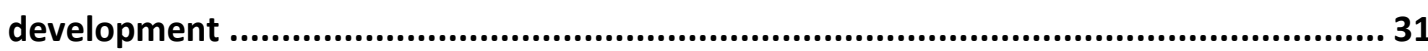

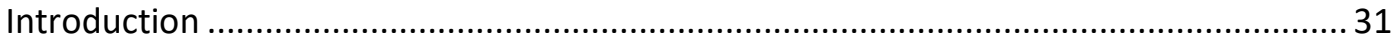




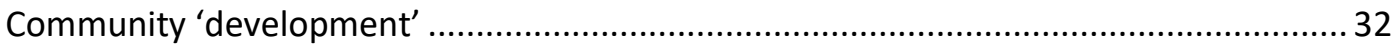

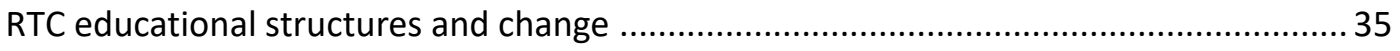

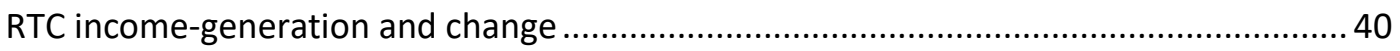

Roles and responsibilities in Solomon Islands Rural Training Centres.............................. 43

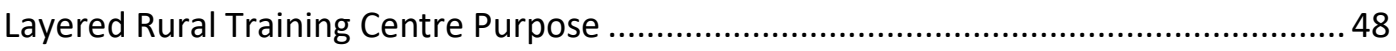

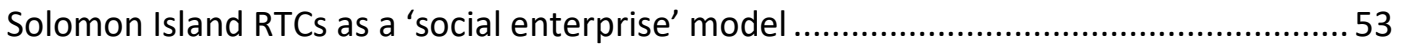

A loose model of Rural Training Centre 'community' practice ...........................................5 55

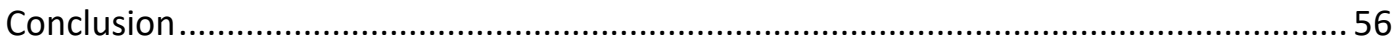

6. Impact of community development hubs: Individual and community development and change in Solomon Islands rural training centres................... 58

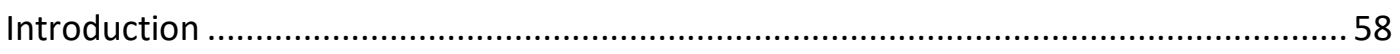

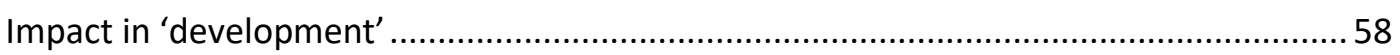

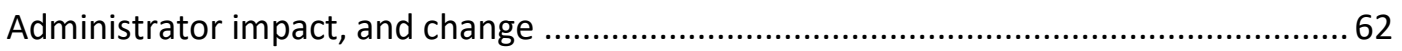

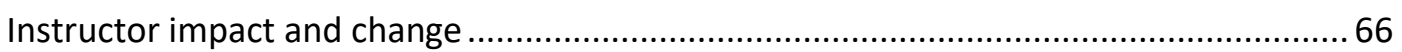

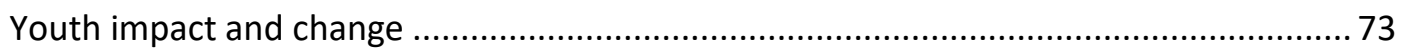

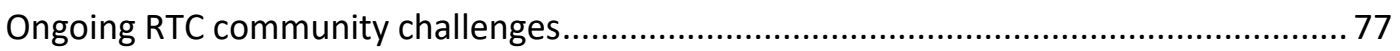

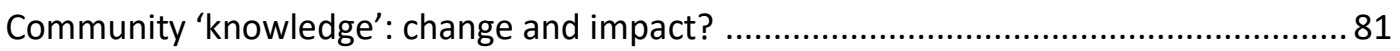

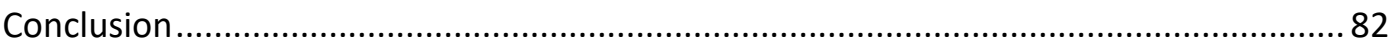

7. Assessing 'sustainable development' practice and impact: Outcomes for Solomon Islands rural training centres in the wider 'development' space ........... 84

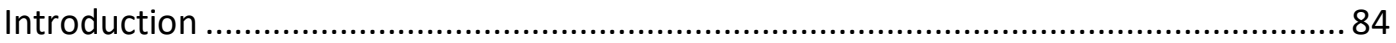

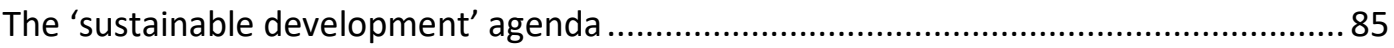

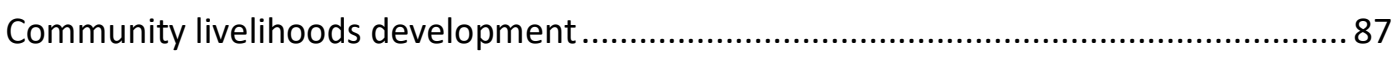

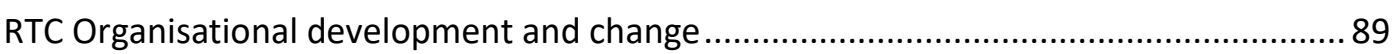

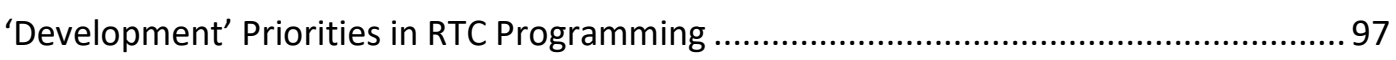

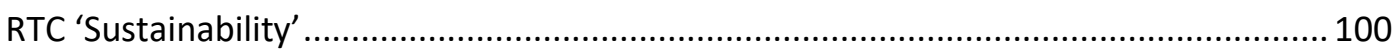

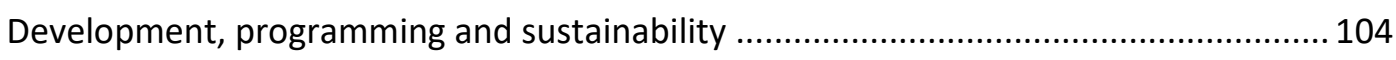

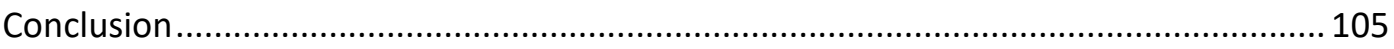

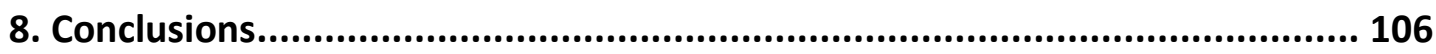

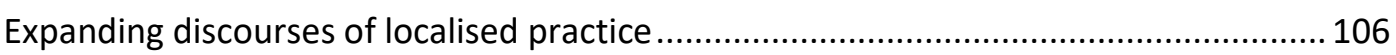

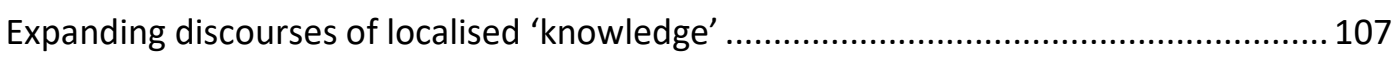

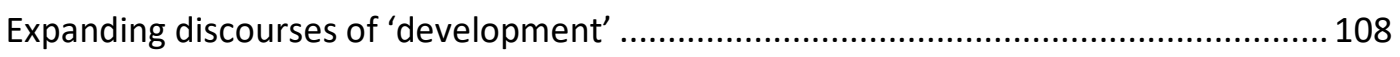

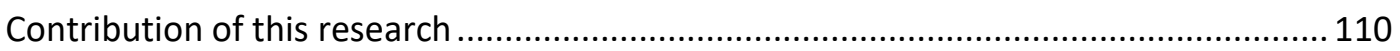

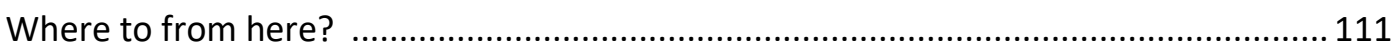

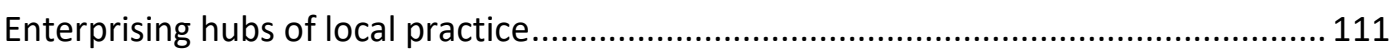

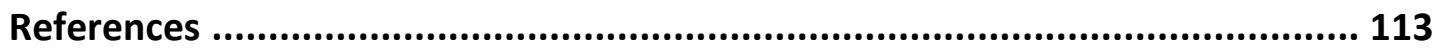




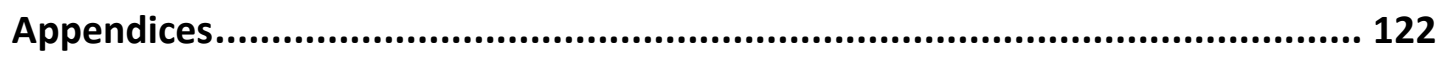

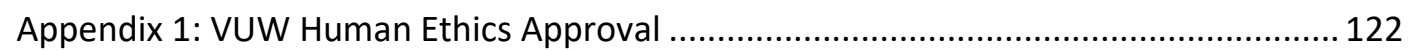

Appendix 2: Solomon Islands Research Permit............................................................. 123

Appendix 3: Participant information sheet and consent form ..................................... 124

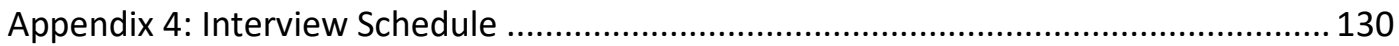




\section{List of tables}

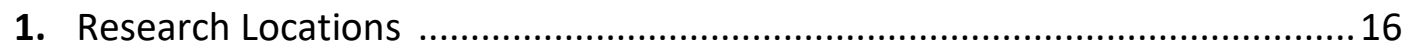

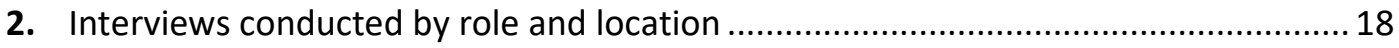

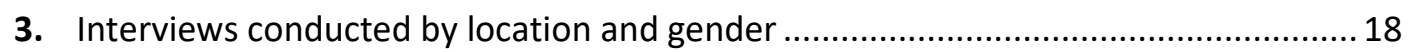

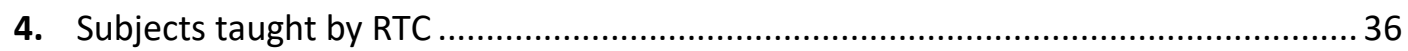

5. Forms of income generation ranked from most to least profitable at each RTC ........ 42

6. Description of Practical placement locations at the RTCs visited ..............................51

7. Instructor learnings from START skills trainings, and their relevance to instructors for

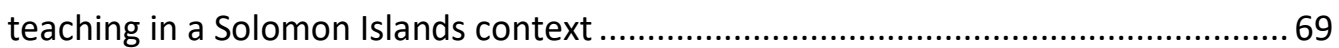

\section{List of figures}

1. Agriculture students and staff tending to plant nursery at Kaotave rural training centre.....

2. Detailed political map of Solomon Islands showing names of capital city, towns, states, provinces and boundaries with neighbouring countries .................................. 6

3. Conceptualising the challenge of social enterprise ethics........................................ 33

4. Above, a staff house constructed as part of START infrastructure at Kaotave RTC. Below, a mechanic class being taken at Vatu RTC in the new START-funded workshop

5. Foundations and timber for new classrooms funded by Kaotave RTC and the Japanese Government. The Kaotave contribution came from profits of the piggery. 38

6. Above, a pig poses for the camera in the piggery facilities constructed as part of the 'Grow Youth Business' component of START at Kaotave RTC. Below, permanent piggery facilities constructed with support under the 'Grow Youth Business' component of START at Vatu RTC .....

7. Building students and their instructor repair staff houses at St Dominic's RTC..........45

8. Students set up profiling for a new boy's dormitory at Kaotave RTC ......................... 49

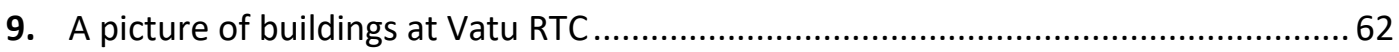

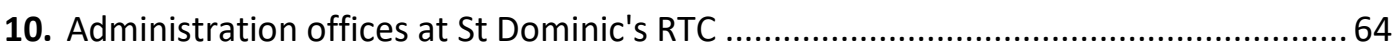

11. Practical learning in the plant nursery at Kaotave RTC ..........................................67

12. Students take notes in a mechanic teaching area at St Dominic's RTC .74

13. Eggs from St Dominic's RTC are transported by staff to a local shop in Gizo to be sold

14. A newly painted, yet non-functioning tractor in the mechanic area at Kaotave RTC. 90

15. Above, the Hospitality and Tourism building constructed under S4EG funding at Tabaka RTC. Below, a model guest house in the Hospitality and Tourism building.... 92

16. A poster promoting RTC education as a pathway to re-entry into formal education and industry

17. Above, textbooks and safety equipment supplied to the Tabaka carpentry teachers under S4EG. Below, a mechanic class being taken in a START-funded workshop at Tabaka.

18. Students and their instructor give water to new-born chicks at St Dominic's RTC..... 99

19. Goods and people bound for Vatu and its surrounding community... 103 


\section{Acronyms}

Caritas - Caritas Aotearoa New Zealand

CEA - Church Education Authority

GNI - Gross National Income

HDI - Human Development Index

MDG - Millennium Development Goal

MFAT - New Zealand Ministry of Foreign Affairs and Trade

NGO - Non-Governmental Organisation

ODA - Official Development Assistance

RAMSI - Regional Assistance Mission to the Solomon Islands

RTC - Rural training centre

S4EG - Skills for Economic Growth Programme

SBD - Solomon Islands Dollar

SDG - Sustainable Development Goal

SIAVRTC - Solomon Islands Association for Vocational Rural Training Centres

SIG - Solomon Islands Government

SINU - Solomon Islands National University

SITESA - Solomon Islands Tertiary Education and Skills Authority

SSEC - South Sea Evangelical Church

START - Strengthening Technical and Agricultural Rural Training in the Solomon Islands Programme

TVET - Technical and Vocational Education and Training

UN - United Nations

VUW - Victoria University of Wellington 


\section{CHAPTER 1}

\section{Introduction}

The initial conception for this research began with a collision of different trajectories, interests and countries. For me, this research grew from a personal desire to contribute in a practical and meaningful way to the lived experience of others. Prior to embarking on my master's studies, I spent two years as a volunteer at a teachers' college in Papua New Guinea, supporting others' education. During this time, I noted the challenges and sacrifices that staff and students navigated in their push towards more secure livelihoods in the education sector. I was particularly interested in how different organisational models, such as 'social enterprise', might be employed to support sustainable development, both internationally and in New Zealand.

Along with my personal experiences, this research engages with Kathryn Fleming's research, "Diverse Education for Diverse Economies: The relevance of Rural Training Centres in the Solomon Islands" (2015). Fleming provided a baseline to a project run by Caritas Aotearoa New Zealand (Caritas), "START", which aimed to strengthen the technical and administrative capacity of eight rural training centres (RTCS) across the Solomon Islands. It did so by raising the quality of teacher training, improving infrastructure and administration, and increasing the availability of basic numeracy and financial management courses. The project has since been extended to a total of 15 RTCS and START is now in its sixth and final year of implementation in 2020.

Where Fleming's work focused on perceptions of RTCs, this follow-up work, carried out on behalf of Caritas, assesses RTC impact and the extent to which external development has contributed to this. It goes beyond 'mainstream' ideas of community development, knowledge and sustainable development to acknowledge local processes and purposes as legitimate within more holistic discourses of education and development practice.

\section{Education in 'Development'}

Education is widely acknowledged as key to processes of 'development', enabling "upward socioeconomic mobility' that helps people 'escape' from poverty (United Nations, 2019, p. 1). Research over the last 30 years has shown education's positive impact on economic, health and learning outcomes, particularly for women and girls, and this has led to significant investment in its access and quality worldwide (King \& Hill, 1993; UNICEF, 2011; Birchler \& 
Michaelowa, 2016; Psacharopoulod \& Patrinos, 2004). However, we need to ask: what is considered 'education', and how do we conceive it? A closer examination of the considerable investment in education for development shows an agenda that has concentrated on promoting education at the primary and tertiary levels, with little support for other areas of learning (Barrett, 2011). Though this provides significant support to the estimated 630 million primary-level students worldwide (United Nations, 2019), it does very little for the further 750 million young people and adults who do not qualify for tertiary education based on their qualifications. The positive impact of funding is therefore insufficiently inclusive for those seeking education.

As well as this focus at early levels of education, there are clear assumptions regarding the style of education practiced and funded. International funding has almost exclusively promoted a formal 'western' style of education, based heavily on one pedagogical tradition, which has been shown to have little relevance for many in 'developing' countries' (Knutsson, 2012). In reality, this 'hegemony' of global understanding on education has silenced other forms of 'informal', 'traditional' or 'indigenous' skills that have significant relevance for local communities and their livelihoods (Connell, 2013). Rather than empowering "people everywhere to live more healthy and sustainable lives" (United Nations, 2019, p. 1), 'western' education serves to promote 'formal' economic growth systems that do little to serve the experiences of the majority of people who live in 'informal' settings (Gibson-Graham, 2005). Expanding conceptions of education to acknowledge and provide support to a more diverse range of skills, goals and approaches is therefore central to this thesis.

\section{Research aim and approach}

The purpose of this research is to examine the impact RTCs, as 'informal' institutions, have on development outcomes for their communities across the Solomon Islands, and the extent to which external programming supports this. Though livelihoods form a component of this research, other purposes are also discussed, and a more holistic approach is taken to understanding their position as education institutions. The research uses qualitative data collected across four RTCs and other stakeholders across Guadalcanal and Western Provinces of Solomon Islands, capturing all phases of the Caritas START programme, along with some institutions that were only partially included in programming outputs. The following question and sub-questions were used to guide the research:

1. How do Rural Training Centres function as development 'hubs' for rural communities? 
a. What is the purpose of Solomon Islands Rural Training Centre models?

b. What is the nature of Solomon Islands Rural Training Centre models?

c. How do Solomon Islands Rural Training Centre models support individual and community development?

d. What are the internal and external outcomes and implications of Rural Training Centre 'development'?

These questions have informed and been adapted into each of the thematic chapters within this thesis.

\section{Chapter overview}

This thesis uses a conventional structure, integrating theory into analysis and discussion from work conducted in the field. A brief review of post-development theory acts as a bridge between separate thematic chapters, which explore relevant literature on models of practice, impact and knowledge, and sustainable development.

Chapter $\mathbf{2}$ gives a contextual overview of Solomon Islands geography, economy, history and education, exploring key factors that have contributed to young people's livelihood opportunities and experiences. It also introduces the relevance of RTCs at the community level in the Solomon Islands.

Chapter 3 covers research methodology, exploring the qualitative approach that was selected, its grounding in social constructivism, and the processes that emerged through the use of interviews and observation. Attention is also given to processes of responsive research design, participant selection and integrity in conducting research for both academic and practical purposes.

Chapter $\mathbf{4}$ explores foundational literature on post-development theory and mainstream discourses that have, along with challenges to these critiques, informed this research. It goes beyond critique to engage with constructive post-development thought, introducing Escobar's (1995) work on local models of practice as a means of informing 'better' development.

As the first integrated discussion chapter, Chapter 5 provides a community-level overview of RTC education and income generation systems. In doing so, it explores how we might understand the RTC model of practice in the context of wider community development discourse. Particular attention is paid to the relevance of a 'social enterprise' framework to understanding the process and purposes of an RTC, showing the limitations of external 
discourses to community systems and instead suggesting a more holistic 'community' model that legitimises local practice within wider discourses.

Having discussed the RTC 'community' as a model of practice, Chapter 6 explores the impact of these communities as 'development hubs' for local Solomon Islands communities. 'Development' outputs are discussed, showing the successes in supporting local RTC purposes along with areas that could be improved to create more impact for participants and their communities. Impact and 'knowledge' transfer literature is used to show local agency in integrating external information into established knowledge where it supports individuals' own purposes, expanding discourses of 'knowledge' to include RTC actors.

Chapter $\mathbf{7}$ considers the place of RTCs in wider processes of 'development' in the context of Solomon Islands education. The focus in this chapter is on external discourses of 'sustainable development' and the extent to which these align with and inform RTC priorities. Opportunities for young people, changes in the Technical and Vocational Education and Training (TVET) sector and processes of engagement with external donors are discussed, showing challenges for RTCs in engaging with external conceptions of 'sustainable development'. A case for more holistic understandings is put forward that engages more effectively with community-level priorities in 'sustainable development'.

Chapter 8 concludes by reflecting on the way in which this thesis has expanded discourses of localised practice, localised 'knowledge' and 'development' to further legitimise the RTC model of practice. It discusses the contribution of this theory and research to better future RTC-centred practice, as well as potential areas for further research. 


\section{CHAPTER 2}

\section{Solomon Islands National Context}

\section{Introduction}

This chapter explores contextual factors that influence livelihoods for young people, and the rise of the rural training centre (RTC) education model in the Solomon Islands. It explores geographical settings, historical integration within the world system and national conflict, as well as economic and educational structures which continue to impact livelihood opportunities for many young people. This information grounds the later findings of the research in the lived experience of RTC workers and the young people they support. Key to this is that lived experiences and values change across place, and this is particularly noticeable in the diversity of nature, purpose and impact of RTC models across the Solomon Islands. This chapter therefore introduces a post-development mentality to this thesis, acknowledging those that are often overlooked in 'development' and providing a postdevelopment evaluation of those who do so. This shows how more holistic understandings of the world, that acknowledge the differences that exist, can lead to better and more relevant practice and outcomes in community settings.

The primary grounding of this thesis in community structures means that focus is only given to factors in the Solomon Islands that have a direct correlation with the thesis topic. Locallevel contextual factors do not form a part of this chapter and are instead integrated in more depth within chapters 5, 6 and 7. This provides a richer understanding of the research findings, given there are others who the reader may refer to that have already explored the Solomon Islands context in detail (Bennett, 2000; Gegeo \& Watson-Gegeo, Whose knowledge? Epistemological collisions in Solomon Islands community development, 2002; Jones, 2018).

\section{Diverse geography and economy}

\section{Geographic spread}

Geographically, the Solomon Islands has a dispersed, but relatively large, population in comparison with most Pacific Island states (Figure 2). Its population of approximately 650,000 people are spread over 347 of the 992 islands that make up less than $5 \%$ of the total area of the Solomon Islands (UNDP, 2018a). Whilst this leaves the Solomon Islands incredibly resource rich, it also poses various challenges for government in the provision of core 


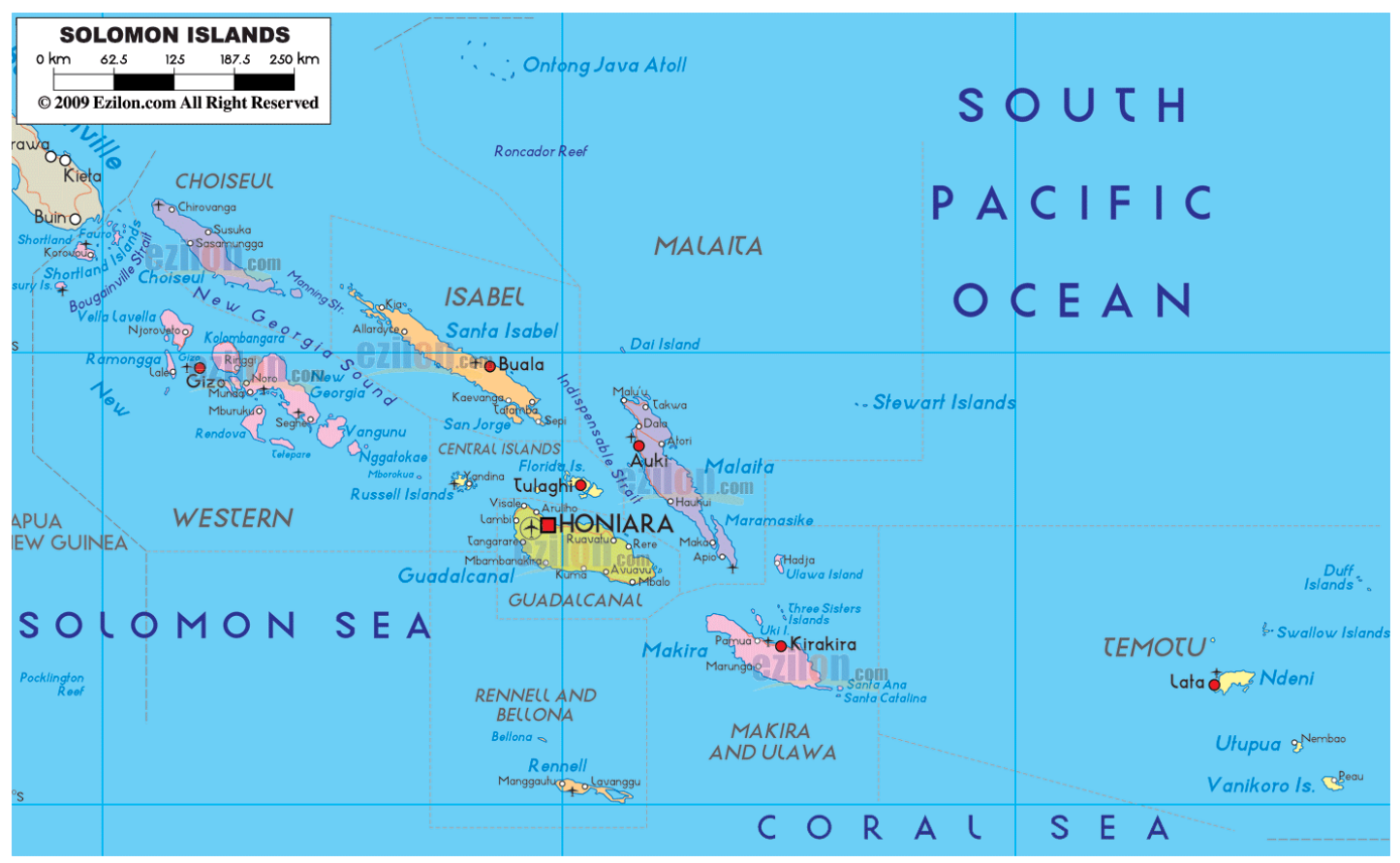

Figure 2. Detailed political map of Solomon Islands showing names of capital city, towns, states, provinces and boundaries with neighbouring countries (Ezilon Maps, 2015).

services, such as education, and formal employment opportunities for its population. Services, such as health, are concentrated in provincial capitals to reach as many people as possible, with those in remote areas having to travel a day or more at times to access these. The primary mode of transport between most provinces is by boat, with some communities operating small dinghies with an outboard motor commonly referred to as 'banana boats'. Transport by sea is expensive relative to the average person's income and dangerous, with boats regularly capsizing, running out of fuel or becoming lost at sea during bad weather. On larger islands, such as Guadalcanal where the capital Honiara is found, community-owned trucks and vans service travel between remote communities and provincial centres. Individual ownership of transport is uncommon outside of Honiara, with communities often pooling resources to meet collective costs.

\section{Economic position}

The Solomon Islands' small population and geographic spread have led others to view it as on the 'periphery' of the global economy (UNCTAD, 2019). External financing is low and nearly all of this comes in the form of 'Official Development Assistance' (ODA). Like other Pacific island countries, challenges related to scale and demand limit economic competitiveness at the global level, with population size and spread being too small to compete with other countries (CDP, 2018). Gross National Income (GNI) per capita is USD 1,872 , which remains low relative to neighbouring countries in Melanesia and Micronesia 
(UNDP, 2018a). At the national level, the Solomon Islands economy is largely reliant on temporary government outputs and agriculture to drive its economic growth (ADB, 2019). ODA still represents over $50 \%$ of government income, though this has reduced significantly since 2008, with a focus on sustainable transport, energy and tourism in recent years targeted at boosting international investment (UNCTAD, 2019). This has yet to materialise significantly internationally as exported goods, such as timber, cocoa, palm oil, tuna and copra, are considered vulnerable to fluctuations in price and supply. As a result, the Solomon Islands ranks low on the Human Development Index (HDI), at 152 out of 189 countries based on indicators of health, education and economy (UNDP, 2018a) and is categorised as one of the 'Least Developed Countries' in the world (UNCTAD, 2019).

While this external depiction paints a negative economic image of the Solomon Islands, this is only representative of formal economic perspectives. Demand for goods locally is low due to the majority of people practicing small-scale subsistence agriculture, allowing them to live external to formal 'western' structures (Fleming, 2015). Food is generally plentiful, meaning there is little need to be reliant on formal employment. Instead, Bray notes that "[small countries] are highly personalised societies in which people know each other in a multitude of settings, and in which relationships are longlasting [sic]" (1991, p. 21). In the Solomon Islands, these relationships are key, with extended family, or 'wantok', groups supporting each other in times of need (Gegeo \& Watson-Gegeo, Whose knowledge? Epistemological collisions in Solomon Islands community development, 2002). Therefore, while the country is seen as disadvantaged economically at the global scale, this perception has little relevance for the livelihoods of most Solomon Islanders.

\section{A (colonial) history, a lingering past}

The Solomon Islands boasts thousands of years of diverse local history that is often and unfortunately overshadowed by its more recent colonial past, which saw the country placed into the global system as a colony. Rather than representing a homogeneous cultural group, the 80 different language groups have been referred to as "disparate communities... [where] primary identities and allegiances remain implanted in local languages and kin-based groups" (Dinnen, 2010, p. 285). This negative portrayal again masks the strength and diversity of culture and embedded knowledge that is often overlooked in international systems. Though beneficial in supporting each other, this diversity creates challenges in responding to the diverse interests and values of communities across the Solomon Islands. The country's systems of governance are reflective of its recent past, with a constitutional monarchy and 
representative parliamentary government in place since independence in 1970 . These systems of governance, more reflective of global influence rather than local relevance, have also been key to maintaining power imbalances across the provinces (Jones, 2018). Colonists saw Guadalcanal and Western provinces as key areas of opportunity, with services and trade concentrated in these areas whilst neglecting other regions. This created a system of inequality across the Solomon Islands which Fito'o (2012) argues remains in place in modern times.

This inequality came to a head in the early 2000s, with ethnic tensions between provinces leading to the collapse of government systems due to 'uneven' development across the country (Jones, 2018). These tensions began on Guadalcanal, with the local population becoming increasingly angry over urban migration from Malaita province pushing them off their traditional land in their search for employment (Dinnen, 2010). The inability of the government to contain the crisis led to a request for international intervention in July 2003, with the Regional Assistance Mission to the Solomon Islands (RAMSI) led by Pacific nations, being formed to restore order (Jones, 2018). This was achieved relatively quickly, with a transition in late 2003 from military control to rebuilding of infrastructure, government and relationships. Though RAMSI was credited with stabilising the country, and officially concluded in 2017, this history is key to the disengagement and alienation of many, particularly youth, which still exists at a national level in the Solomon Islands.

\section{Formal education in informal settings}

Access to formal education in the Solomon Islands is often dependent on location and means. The impact of geographic spread, coupled with low economic capital, is that government cannot support formal education systems across the provinces (Sanga \& Maneipuri, 2002). The cost of education is therefore placed on families, with annual school fees contributing to the maintenance of most schools in remote communities. These fees are high relative to average incomes and mount up quickly given the average household size of 5.7 (SIG, 2015). Fees also increase significantly from primary to secondary education, with the added cost of transport to urban centres. The impact of this is a discrepancy between expected, 10.2, and mean, 5.5, years of schooling, showing the challenges of providing formal education access across the Solomon Islands. However, Fleming challenges the relevance of this education for local needs, suggesting that it supports the implementation of external 'knowledge' rather than passing on relevant knowledge and skills (2015). As a 
consequence, many in rural areas choose not to access these services, with $48 \%$ of the population leaving education prior to secondary school (UNESCO, 2019).

The structure of the Solomon Islands education system also pushes many out of school as early as primary school. Until recently, this system has involved examinations for Standard 6, Form 3 and Forms 5-7, which students are required to pass in order to advance in the formal education system (Fito'o, 2012). A primary driver of this was the limited capacity to provide secondary education for the Solomon Islands population, with exams helping to limit enrolment past primary school (Interview, 17/5/19, Honiara). Concentration of services in urban centres means that remote communities are most impacted by this, given the variations in support for teachers and administrators across provinces (Sanga \& Houma, 2004). This impacts significantly on girls, with recent figures showing that $93 \%$ do not complete formal education compared to the already high $79 \%$ of the population as a whole (Plan International Australia, 2019). The government has announced that Standard 6 examinations will no longer be administered from 2020 (Laungi, 2019), but economic and access challenges are likely to mean that remote communities still struggle to access the formal education system.

\section{Rural Training Centres}

In response to the challenges of formal systems catering to the needs of Solomon Islanders, rural training centres (RTCS) arose through church networks as a way to support young people in 'informal' community settings (Interview, 6/5/19, Honiara). RTCs offer young people, those between 15 and 34 years of age (SIG, 2017b), another avenue for skills development through 'informal' skills and livelihoods in agriculture, building and various other courses. Key in this is a focus on skills that are relevant to local experience and teaching based on culturally accepted practice (Apffel-Marglin \& Marglin, 1996). There are currently 60 RTCs managed by different denominational Church Education Authorities across the Solomon Islands, with the Solomon Islands Association for Vocational Rural Training Centres (SIAVRTC) acting as a collective representative body for them (Interview, 6/5/19, Honiara). Despite the high percentage of people leaving formal education, government constraints and priorities have meant that Technical and Vocational Education and Training (TVET) receives very little financial support in the Solomon Islands. Recent figures show TVET only directly receives about $0.004 \%$ of the education budget (SIG, 2018), while the rest is mostly channelled into overseas scholarships for a select few. This funding has primarily contributed to teacher salaries, which are low compared to their colleagues in formal education (SIG, 
2017a). Opportunities to develop RTCs are therefore currently based on external avenues of funding. Recent development projects, through Caritas and the Australian government, have created increased government interest in TVET, with a separate government entity known as the Solomon Islands Tertiary Education and Skills Authority (SITESA) being formed to directly support RTCS alongside other TVET entities (SIG, 2017a). However, this has yet to create tangible change for most RTCS, who remain significantly underfunded in remote areas of Solomon Islands.

\section{Young people's search for opportunity and employment}

The economic, historical and educational factors highlighted in this chapter have all had significant impacts on opportunities for young people in the Solomon Islands. While domestic livelihoods are diverse across country, they are also highly dependent on provincial resources, skills and markets (IMF, 2018). Industry and formal employment remain concentrated in urban centres, most notably Honiara, the capital, and Noro, in Western province, and opportunities outside of these are limited, with many young people feeling pressure to move for employment (Fleming, 2015). Infrastructure and service development remain concentrated in urban centres, further exacerbating challenges and frustrations for many (Fito'o, 2012). However, historic challenges related to education quality and access also mean that many are judged to not have the skills required for formal employment opportunities (Interview, 6/6/19, Honiara). The impact of this is an increasingly large bubble of young unemployed Solomon Islanders who are concentrated in key urban areas of the Solomon Islands. While the crisis ended in 2003, many of the lingering inequalities that contributed to it remain, especially for young people.

In the face of potential unrest, RTCs are seen by local Solomon Islands communities as a vital and successful avenue for livelihoods development (Fleming, 2015). Fleming's work legitimised the 'informal' education RTCs provide for the wide field of economic experience in the Solomon Islands. Subsequent 'development' practice since 2015, notably the work of Caritas, has aimed to improve infrastructure and teaching quality in RTCS, focusing on promoting relevant education and economic 'hubs' for young people in community settings. This work is key to counterbalancing what Fito'o has referred to as "systemic privileging of a few young people who are able to access educational opportunities" $(2012$, p. 73), instead giving others access to culturally-embedded knowledge.

This thesis therefore further legitimises the multi-layered purpose, nature and impact of RTCs at the community level, and explores the extent to which processes of 'development' 
have supported this model to create livelihoods opportunities for young people. It emphasises local experience whilst challenging and expanding on dominant discourses that silence this, helping to promote a system in which the Solomon Islands is not just pigeonholed as a 'Least Developed Country', but is acknowledged as a fountain of diverse understanding and opportunity. 


\section{CHAPTER 3}

\section{Methodology}

This chapter details the processes undertaken in exploring Solomon Island rural trainings centres (RTCs). It examines the steps, including epistemological conception, research design, implementation, analysis, ethical considerations and limitations, that impact on the final work. As noted previously, this research has been conducted in partnership with a number of different groups of people in Guadalcanal and Western Provinces, meaning consideration has been given to the ways in which I engaged with them.

\section{Epistemologies}

The conceptual framework of this research is critical, in its discussion of how the world is, but also constructive, in suggesting how things might be more reflective of the experiences of a wider group of society.

\section{Social constructivism}

This research is grounded in ideas of social constructivism and acknowledges the historical, political and geographic injustices that have allowed inequality to flourish and diversity to be consistently marginalised to the 'peripheries' of society. Sumner and Tribe's suggestion that "multiple realities exist which are intangible, local and specific in nature" $(2004$, p. 5) lends itself to the diversity of experience and approach that is visible at the global scale. These experiences and approaches are occurring alongside each other yet have materialised in so many different ways across place. This social and cultural construction of the world by people (Gredler, 1997) means there is a need to understand processes of knowledge and learning that occur in different contexts where people live, rather than simply using a universal theory of understanding (McMahon, 1997). A major implication of this social constructivist perspective is that there is no set truth that guides all human interactions, just multiple realities that require consideration (Kim, 2001). A social constructivist lens is both appropriate and useful in the Solomon Islands context due to the diversity of culture and experience across different parts of the country.

Despite this varied view of the world promoted under a social constructivist lens, dominant discourses have consistently overshadowed others in a 'one size fits all' model of knowledge and development. As noted by Santos, "the possibility of alternatives is discredited precisely for being utopian, idealistic and unrealistic" (2004, p. 236), yet this is only true for those whom the mainstream suits; those who are comfortable and inflexible in their own views of 
the world. In the Solomon Islands context, even the creation of the RTCs has come about due to the failure of colonial and post-colonial education structures and priorities to cater to the needs of rural communities. Fleming's work shows that a national focus on formal education structures has been unresponsive to the needs of most Solomon Islanders at the community level (2015). While this research does not claim to produce "a de-colonized [sic], postcolonial knowledge" (McEwan, 2008, p. 1), it is an attempt to support rural communities in their own decolonisation of knowledge by distinguishing their experience from that of others.

\section{A qualitative approach}

A qualitative approach lends itself well to social constructivism's emphasis on multiple realities, and even more so for this research due to my focus on individual community impacts and national-level influencers of Solomon Islands RTCs. As noted by Robson (1993) this approach allows for flexibility in the research process. Various variables, including time, my limited experience in a Solomon Islands context and limited feedback in the design phase from some stakeholders, meant that there was ambiguity in how my methodology would work in a practical sense. In response to this, I adopted broad questions that would allow more specific themes to emerge and inform my work as the research progressed (Petty, Thomson, \& Stew, 2012). This allowed individual experiences, perceptions and aspirations to come to the forefront, showing the level of diversity even at a community level. Although my themes were informed by previous work, the contexts in which I was conducting this research were noticeably different in ways from those described in 2015 by Fleming, which required a high level of adaptation on my part. In these ways my own processes of observation and learning, as well as that of others, informed my approach in an ongoing process of knowledge construction and interpretation (Maxwell, 2013). Being adaptive to changing circumstances in this approach was therefore beneficial to the process as a whole.

\section{Methods}

Two methods, observation and interviews, were used for this research. This combined both qualitative and participatory ideologies, using a mixture of 'one-on-one' and 'group' interviews as part of the process. Doing this gave my research a more balanced and contextspecific appreciation of individual RTC 'communities' (Mayoux, 2006), and a greater understanding of the RTC network's influences as a whole. I tried to adopt an open and strength-based approach to research, which gave participants freedom to share about their own experiences. Although influenced by a strengths-based 'appreciative inquiry' style of research (Cooperrider \& Whitney, 2000), it would be disingenuous of me to say that I 
practiced this effectively or consistently. I occasionally found myself in discussions with others where ideas were framed in a negative way that was not reflective of this approach to research. My research style was therefore flexible, with listening, follow-up and storytelling between myself and others being key, giving depth to the research in an empowering way for my participants.

\section{Observation}

Observation refers to a process of immersion where the researcher lives and works amongst the community to understand their perspectives and ways of life (van Donge, 2006). This involved me staying in various settings at the RTCs, including with staff and their families or in other RTC accommodation that was typically used as part of practical teaching. Doing so allowed me to be part of everyday activities and spend more time with others in an informal capacity across the institutions. I noticed that this was often viewed positively but with surprise and concern that, as a foreigner, the facilities and food would not meet my 'standards'. I kept a record of observations within a notebook over the duration of my trip and regularly updated this as new information and perspectives materialised (Gray, 2004). Most of the RTCS I visited asked me to give feedback to the administration at the end of my trip on my main observations of their strengths and challenges. In doing so, I tried to maintain the same strengths-based approach of the research, framing feedback in a constructive way while also not dictating a particular way forward (Cooperrider \& Whitney, 2000).

Alongside this, I undertook observation of 'non-community'-based activities and people related to the RTCs during my time in the Solomon Islands. This was primarily within Agriculture and Leadership trainings facilitated by Caritas and SIAVRTC that coincided with my trip, and which took place in and around Honiara. Being present at trainings and events surrounding them, such as graduation ceremonies, gave me access to many stakeholders who would otherwise have been hard to reach. As well as this, I was also privy to some discussions and meetings of and with NGO, government and civil society groups due to my links to Caritas and SIAVRTC. These perspectives and knowledge give my findings more depth and context, particularly regarding wider patterns and priorities that impact on the RTCs. As per the confidentiality of my research, organisations have not been directly named where my research was not the primary focus of discussion. 


\section{Interviews: 'one-on-one' and 'group'}

As well as notes and observations, I conducted semi-structured interviews with administrators, teachers, students and a wide range of stakeholders related to the RTCs. Interviews ranged from 10 minutes to 1 hour and 20 minutes and involved a mixture of preprepared topics that would then feed into other areas that were raised by participants (Longhurst, 2010). Interviews took place in participant-chosen locations, including personal offices, classrooms or in outdoor areas. Giving agency to participants in this way created a more relaxed and familiar environment in which they were more comfortable to share (Gray, 2004). Most interviews were audio-recorded, with summaries being prepared following the interview and presented to participants if requested; in some cases, participants asked for a copy of the interview summary or audio file which I provided. Some were not comfortable being recorded and in these cases I would take notes during the interview and give them the chance to amend these as they saw fit; some offered to sign these notes as a form of credibility and consent to what was said.

Another form of interview which I employed with students at some RTCs was a collective format, with groups ranging from 2 to 12 people. Although similar topics were covered in these interviews, the primary focus was on student experience, prior to, during, and after education at their RTC. These interview sessions lasted approximately 40 minutes and were not recorded at the request of participants. Overall, I found their effectiveness varied from place to place based on the rapport I had built with students prior to the session and the types of questions posed to them. Following my first session I noted that the topics we discussed were relevant, but that students were not involved in all aspects of the RTC. As an example, students had little to say on their role in generating income for their RTC but could openly talk about the work they did in and out of class time. I had therefore been unprepared in my consideration of the different perspectives and preparation required for different groups in my research (Valentine, 2005). I consequently changed the questions I asked students, which allowed them to contribute in a more meaningful way.

\section{'Mi garem sumfela Pijin nomoa'}

I conducted interviews in a mixture of English and Solomon Islands Pijin, which was possible due to my prior experience with Tok Pisin in Papua New Guinea. While not exactly the same, I found learning the distinctions between the two pijins to be a good way to make connections with participants and my host communities. Despite good comprehension, I found that many participants were uncomfortable or shy about speaking in English, which 
was a challenge that had been identified by Caritas and SIAVRTC as I was preparing to travel to the Solomon Islands. Although there was the option of having a translator, I was conscious of situations where a researcher is left "side-lined and alien" (Bujra, 2006, p. 173) within their own research process, and I wanted to avoid this within formal interview settings. Giving participants the option to speak in one of their native languages gave me a lot more freedom to explore the topics with them, and my experience in a similar Melanesian context helped me understand variances in language use that may have stopped others understanding nuances in some responses. It also led to an interesting linguistic pattern, in which I asked questions in English, received a response in Pijin, and then translated this into English notes as we talked. Being able to conduct interviews without the use of a translator also allowed me to avoid some of the potential biases of an external party (Longhurst, 2010), who may have further blurred understanding in the communication chain from participant to researcher.

\section{Research Design}

In order to more deeply understand the lived experiences of different RTC communities, a case study design was chosen for this research. The five sites selected are shown in Table 1 as follows:

Table 1. Research Locations

\begin{tabular}{|c|c|c|c|}
\hline Name & Location & Demographic & RTC size \\
\hline $\begin{array}{l}\text { Kaotave Rural } \\
\text { Training Centre }\end{array}$ & Tetere, Guadalcanal & Semi-urban & $\begin{array}{l}120 \text { students } \\
15 \text { staff }\end{array}$ \\
\hline $\begin{array}{l}\text { DIVIT Rural } \\
\text { Training Centres }\end{array}$ & Visale, Guadalcanal & Semi-urban & N/A \\
\hline $\begin{array}{l}\text { Vatu Rural Training } \\
\text { Centre }\end{array}$ & $\begin{array}{l}\text { Northeast } \\
\text { Guadalcanal }\end{array}$ & Rural & $\begin{array}{l}24 \text { students } \\
8 \text { staff }\end{array}$ \\
\hline $\begin{array}{l}\text { St Dominic's Rural } \\
\text { Training Centre }\end{array}$ & $\begin{array}{l}\text { Kolombangara, } \\
\text { Western Province }\end{array}$ & Rural & $\begin{array}{l}110 \text { students } \\
13 \text { staff }\end{array}$ \\
\hline $\begin{array}{l}\text { Tabaka Technical } \\
\text { Institute }\end{array}$ & $\begin{array}{l}\text { Noro, Western } \\
\text { Province }\end{array}$ & Semi-urban & $\begin{array}{l}400 \text { students } \\
15 \text { staff }\end{array}$ \\
\hline
\end{tabular}

The locations chosen act as a sample of the 15 RTCs that participated in Caritas programming, with attention given to include institutions that were part of all phases of the project. There was some initial discussion between me and Caritas about the sample size in order to balance my focus with the interests of Caritas and SIAVRTC. The five case sites were therefore purposefully chosen in order to reflect evaluation interests, while also giving my research 
depth and scope beyond what had already been researched. Whilst five sites were selected as part of this original sample, only data from four of these forms the basis for this research. The primary reason for this is that logistical issues meant that I was unable to develop a holistic picture of DIVIT RTC, with most staff being away when I visited.

\section{Accessing 'community'}

My initial proposal included a focus on engaging with communities surrounding the various RTCs that was similar to previous research. However, I decided early into my fieldwork that this was not feasible for several reasons. Firstly, the time limitations of my fieldwork meant that I was only spending a week at each RTC. Seeking to obtain a 'balanced' view of each RTC was incredibly valuable, but equally time-consuming, meaning I spent much more time with those actively engaged in day-to-day RTC operations. This left very little time to approach people who were 'external' to the RTC and would have been done in an ad hoc and inconsistent way.

Secondly, I had some concerns about my access to local communities; something which was only made possible through RTC administrators and staff, and local community leaders. Although this was not a concern in of itself, I noted barriers in the interview process regarding impartiality, confidentiality and participant comfort that had been highlighted previously by others (Desai \& Potter, 2006). In terms of impartiality, community 'leaders' made decisions around who I would talk to and, therefore, who I also would not talk to. In terms of confidentiality, community and RTC leaders knew who I was speaking to and the differences in different contexts meant that it would have been easy to distinguish who had said what in any research I produced. In terms of participant comfort, I found community leaders and RTC staff would often stay during interviews and, at times, speak on others' behalf. Although the conversations I had with 'community members' were overwhelmingly positive regarding their relationships to the RTCs, I was left uncertain whether this was an indication of actual sentiments or if this was what people thought I or leaders wanted to hear. This impression was also not something I experienced when talking with RTC instructors and students which led me to make a distinction between internal and external 'community' as the focus.

Finally, and most importantly, was the realisation that the nature of training centres being 'rural' meant that a 'surrounding community' in the way that I had imagined was not often visibly present in day-to-day RTC operations. This assumption on my part came partly from the emphasis on local community and youth outcomes of the Caritas programme, but it became evident quickly that this assumption was not accurate or easily measurable. 
Students often came from across the Solomon Islands, meaning measurable impact was more 'dispersed' than I had realised. In some cases, the closest students' 'community' was an hour of travel away. The logistics of reaching them would have been time-consuming for both myself and the RTC and would have impacted on student learning given they would have most likely accompanied me had I gone. My ultimate decision was, therefore, to change my focus from 'surrounding communities' to what emerged as an RTC 'community' instead.

\section{Participants}

A total of 87 participants contributed to this research, including 43 one-on-one interviews and 5 group interviews. Tables 2 and 3 breakdown participants by role, location and gender. While similar numbers of administrators and instructors were interviewed across all four of the RTCs, student numbers ranged from 6 (Kaotave) to 18 (St Dominic's). This is reflective, as noted previously, of student preferences between one-on-one and group interviewing in different settings and is the main variance in interview numbers across the RTCs. The majority of interviewees being male (72\%) is also reflective of the make-up of most RTCs, with fewer female students enrolled in all the case sites selected except DIVIT RTC. If St Dominic's, an all-boys school, is excluded from the data the representation of women in my interviews is $37 \%$, which is a more reflective sample split.

Table 2. Interviews conducted by role and location

\begin{tabular}{|l|l|l|l|l|l|l|}
\hline $\begin{array}{l}\text { Location } \\
\text { Role }\end{array}$ & Kaotave & Vatu & St Dominic's & Tabaka & Honiara & $\begin{array}{l}\text { Total } \\
\text { interviews }\end{array}$ \\
\hline $\begin{array}{l}\text { Administrators } \\
\text { Instructors }\end{array}$ & 2 & 2 & 2 & 3 & & 9 \\
\hline $\begin{array}{l}\text { Students } \\
\text { Community }\end{array}$ & 6 & 6 & 9 & 6 & & 26 \\
\hline $\begin{array}{l}\text { leaders } \\
\text { Officials }\end{array}$ & 13 & 18 & 7 & & 44 \\
\hline $\begin{array}{l}\text { Total } \\
\text { participants }\end{array}$ & 13 & 21 & 30 & 1 & 2 & 3 \\
\hline
\end{tabular}

Table 3. Interviews conducted by location and gender

\begin{tabular}{|l|l|l|l|}
\hline $\begin{array}{l}\text { Gender } \\
\text { Location }\end{array}$ & Male & Female & Total \\
\hline Kaotave & 9 & 4 & 13 \\
\hline Vatu & 14 & 7 & 21 \\
\hline St Dominic's & 27 & 3 & 30 \\
\hline Tabaka & 9 & 8 & 17 \\
\hline Honiara & 4 & 2 & 6 \\
\hline Total & $63(72 \%)$ & $24(28 \%)$ & 87 \\
\hline
\end{tabular}


I tried to capture a fair representation of RTC 'community' members. Where possible, interview participants represented an accurate balance of gender, provincial background, courses offered, participation in external development training and levels of personal and organisational leadership. This last distinction was used to acknowledge the different experiences of those in leadership positions, such as heads of department or student leaders, compared to others with no official leadership position, such as entry-level staff or students.

\section{Recruitment}

Participant recruitment was done in a way that relied on the in-country connections of Caritas and SIAVRTC. I met five RTC tutors as part of START Agriculture training, and two leaders as part of Leadership training at the beginning of my trip; these people usually acted as the initial contact when I visited their RTC. The trainings also acted as a trial phase, giving me scope to test the relevance of different questions for participants. Tabaka was the only RTC where staff were not present at any trainings and in this case Caritas and SIAVRTC made first contact on my behalf while conducting their own monitoring prior to my arrival. From initial introductions, I worked in partnership with leaders and tutors to identify a representative interview list, that included as many perspectives as possible. Longhurst notes that this method of recruitment is open to bias from external parties (2010), but this would have been difficult to avoid given my limited previous experience in targeted RTCs. In cases where the original interview list left out certain groups, I was able to approach others to build a greater picture of the RTC communities.

\section{Research Integrity}

My personal experiences, as a volunteer and a 'development' worker, greatly supported the research process' integrity. As noted previously, I spent two years as a Volunteer Service Abroad Univol at a teachers' college in Papua New Guinea. This gave me a firm grounding in wider aspects of Melanesian culture prior to entering the Solomon Islands, making engagement with participants and stakeholders comfortable from arrival. Alongside this, my role as a Programme Assistant at Caritas meant that I already had an understanding of the START programme and RTC network stakeholders. This allowed me to engage in more indepth discussions around processes, as well as facilitating a smooth recruitment process.

\section{Balancing academic and development priorities}

Despite this, my relationship with Caritas and SIAVRTC was a key consideration for the integrity of this research, and the distinction between my role as a development worker and 
researcher. Mercer (2006) notes that working with NGOs poses several ethical and political challenges in development research. The most obvious of these in my case was a potential conflict of interest, given Caritas were my employer and their funding of the research was subject to its connection to the START programme. Although this had the potential to place limitations on my research (Mercer, 2006), I found Caritas to be open to points of learning outside the boundaries of this as well, alongside areas that focussed on START. I also took a leave of absence from Caritas during my time in the Solomon Islands in order to ensure there was separation between my two responsibilities. The limitations were therefore only in the openness of communities in presenting their reality as they truly saw it.

Although existing Caritas and SIAVRTC relationships helped in accessing communities and arranging meetings with local groups, there were some challenges in my role as an independent researcher. I grappled internally with the balance between my own academic priorities and those of Caritas and other RTC stakeholders (Sumner \& Tribe, 2008). Distinguishing myself from other development workers, for example, was particularly difficult in the first two weeks because I was introduced as a Caritas staff member. Many participants were concerned about the confidentiality of their responses, particularly regarding negative feedback about START. This was perhaps reflective of traditional relationships in development, where ongoing funding is often reliant on the success of programming (MacLean \& Brass, 2015). After asking SIAVRTC to introduce me as a university researcher I noticed this concern was less common, even when making people aware of my role as a part-time staff member at Caritas.

Despite these challenges, the involvement of multiple stakeholders across the RTCS highlighted a range of local knowledge and counteracted any central 'development' priorities that my own biases may have caused (Sumner \& Tribe, 2008). Research participants and external bodies were informed of the contribution of the research to wider Caritas and SIAVRTC projects, to avoid any conflict of interest in this regard. In reality, I found this connection to the NGOs was more beneficial than not, giving me easy access to communities than I would not have had as an independent researcher (Mercer, 2006). There is also a tendency for research to be extractive in the way that findings only benefit the researcher (Campbell \& Groundwater-Smith, 2007). Working with an NGO that was invested in the RTCS long-term helped ensure clear impacts for the RTC network from my research.

\section{Cross-cultural 'consent'}


Another area in which I had to adapt my approach to research was in receiving informed consent as part of the Victoria University (VUW) ethics process. This was important to give confidentiality to protect my participants from any potential backlash, such as if they were critical of the RTCs or members of the community. Preparing and presenting information sheets to participants was welcome and appreciated, but the concept of written consent was regularly misunderstood and met with distrust. This is not a new phenomenon, with Shamin and Qureshi (2013) highlighting 'consent' as a major divide in research engagement between global 'North' and 'South' countries. While presenting consent forms, I also offered an oral option, and this eventually became the default alongside what was expected as part of the VUW ethics guidelines. Most people preferred the oral option and gave it at the beginning of my audio recordings. It was my impression that this form of consent was more appropriate and credible in the Solomon Islands due to the oral-based nature of relationships. Another consideration in relation to consent was that literacy levels differed across participants (Campbell \& Groundwater-Smith, 2007). Many of my participants asked to be taken through the consent form verbally because they could not understand what was written, either in the Pijin or English versions that were presented. Being flexible to the needs of my participants in these ways created a positive and supporting environment in which they felt comfortable to share their own experiences and perspectives.

\section{Analysis of data}

I conducted data analysis using a thematic approach, as opposed to using some form of discourse analysis. Although relevant in certain research situations, the lack of recorded conversations for some key groups meant that qualitative discourse analysis would have been inconsistent (Wodak \& Meyer, 2016). Instead, a thematic approach was used to explain processes I observed in and around the various RTCs. These themes are:

- The nature and purpose of community RTCS as development 'hubs' (focused on organisational models)

- Impact of community development 'hubs' (focused on RTC knowledge and impact)

- Development outcomes and impact (focused on wider Solomon Islands education development)

These themes have been adapted from my original research questions and are used as evaluative lenses for Caritas' work and my own research. This analysis is supported by partial transcriptions of interviews, and frameworks, such as Ridley-Duff's Social Enterprise Ethics Framework (2018), which are discussed within later chapters. 


\section{Research Limitations}

Although this thesis highlights patterns and processes across different RTCs, it should be noted that there are some potential limitations to its use in this way. The research is limited, as noted previously, by location due to its focus on RTCs in Guadalcanal and Western Provinces. This neglects the potential diversity of experience for RTCs elsewhere, such as Makira and Malaita provinces. This is particularly important due to historical prioritisation of some provinces over others in the Solomon Islands context. While I encourage those working with RTCs in other contexts to learn from my findings, I suggest that these findings are not taken as a definitive representation of RTC experience across the whole Solomon Islands.

My research is also constrained by its primary focus on RTCs operating in what I would describe as 'semi-urban' rather than 'rural' settings. This raises various debates over definition due to the contested nature of what is considered 'rural' (Scott, Gilbert, \& Gelan, 2007), with population density, extent of land use, types of employment and economic activity being some differentiating factors. For the purposes of this discussion on the Solomon Islands context and given that it is not a focus of my thesis, my primary 'rural vs urban' consideration is in access to formal services and employment, such as hospitals, markets and industry. With this limited definition in mind, Vatu is the only RTC visited which I would classify as 'rural', with the other RTCs visited having relatively close, although not direct, access to main centres, services or industry in comparison. Part of the reason for this limitation is my reliance on others for guidance in the RTC selection process, and the fact that most of the original Caritas-targeted RTCs were close to urban areas. I am conscious that not all RTCs operate in this type of setting and there may therefore be differences for them that are not fully discussed in this research.

\section{Conclusion}

In summary, this chapter outlined a qualitative approach to research in the Solomon Islands that was grounded in social constructivist epistemologies and allowed me to explore individual perceptions and experiences in a more meaningful way. The breadth and depth of this research, involving interviews with 87 participants across several locations in the Solomon Islands, gives me a solid understanding of community experiences on this topic. This adds to the legitimacy of my findings in later chapters, helping to show the diversity of experience present and the need for a post-development lens, covered in the following chapter. 


\section{CHAPTER 4}

\section{A review of post-development theory}

This chapter outlines the key points of post-development theory in academic literature, which underpin the following chapters of this thesis. It expands on the roots and distinct strands of post-development thinking, as well as the key criticisms and gaps in using this type of approach to Development Studies. My exploration of education and context in the Solomon Islands reinforces these challenges to the 'mainstream' discourses that have often dominated thinking in this regard. Given the diversity of thought amongst scholars in postdevelopment, this chapter suggests a way forward that challenges current practice whilst not completely rejecting 'development'. In line with Escobar's suggestion of diverse local models of practice, I set the scene by suggesting a need for more holistic understandings in 'development' practice that are relevant to differing community contexts.

In keeping with a post-development mindset and challenging the status-quo, this chapter is not intended as a traditional literature review but instead serves as the foundation to a series of integrated, but separate, analysis/discussion chapters that follow. Each chapter has its own body of literature that it draws on in a multi-faceted discussion of Solomon Islands rural training centres. This review therefore acts as an overarching guide of tone and purpose for the thesis, linking each chapter's distinct body of literature together.

As a final prelude to this chapter, the use of different terminology going forward must be briefly touched on. The use of vocabulary and terms for those who are the primary target of practical 'development' programming is often highly charged and disputed, both in different parts of the world and across different eras of 'development' literature. My use of quotations for terms like 'developing' and 'Third World' is an attempt to acknowledge the power imbalances that such terms create. It is my intention to not legitimise any of these terms, and I use them interchangeably throughout this thesis only as a reflection of the field I am a part of.

\section{Post-development theory}

The history of post-development theory is multifaceted, grounded in a range of critiques related to the approaches and impacts of 'development' practice. Post-development arose as a field of discussion in the 1980-90s, with scholars from both 'developed' and 'developing' nations challenging the nature, impacts and underlying assumptions of the "hegemonic 
mainstream development project" (Gibson-Graham, 2005, p. 4). Where other forms of critical theory criticise the way in which the discipline is practiced, post-development theory has also gone further at times, challenging the notion of 'development' altogether (Sachs W. , 2013). The framing of processes of 'development' has been done in a way that perpetuates an ordered and uniform sense of 'progress' that benefits the 'elites' of the world (Gupta, 1995). Post-development theorists therefore seek to highlight assumptions of this singular approach to 'development', breaking down and challenging the power imbalances that these discourses create (Sidaway, 2014). By doing so they place agency in the values and experiences of those in 'developing' countries who, despite being the supposed focus, have been seemingly overlooked by the mainstream discourse (Escobar, 1995). Although postdevelopment theory draws on ideas from many fields, and is therefore broad in its scope, there are some key points of similarity which connect its theorists.

\section{Development as 'Discourse'}

A key criticism in post-development literature refers to the way practitioners of 'development' have used language to construct and normalise one particularr set of ideas. This process of normalisation creates a discourse in which assumptions related to power and hierarchy become internalised by society as a whole and are ultimately taken to be universal 'truths' (Foucault, 1980). In the case of post-development, criticisms centre on the way in which language has been used by institutions and practitioners to co-opt the nature, means and goals of 'development' (Sumner \& Tribe, 2008). Theorists, such as Escobar (1995) and Santos (2004), point to United States President Harry Truman's 1949 inaugural speech as a key point of departure for this, with his labelling of the majority of the world as 'underdeveloped'. Doing so instantly created a binary between the nations of the 'West', seen to be the bastions of 'progress' and 'enlightenment', and the rest of the world, who required external intervention to 'better' themselves. Although terminologies used in 'development' have changed in response to criticisms of the discourse over time, power relations and positive-negative associations between 'developed' and 'underdeveloped' remain in place (Swart \& Bob, 2004). In the context of education, 'western' discourses were pivotal in shaping distinctions between 'formal' and 'informal' conceptions of education, with the latter being globally viewed as lesser to the former (Apffel-Marglin \& Marglin, 1996).

\section{Development as 'Violence'}

Many in post-development thinking go as far as saying that the 'development' discourse has created violence in its destruction of places, cultures and, in some cases, people. Santos 
(2004) notes how mainstream discourse, which he terms 'Enlightenment thinking', has produced absences of thought through its narrow focus on 'western' values. These 'monoculture' values paint the picture of a global, economically-driven, efficient, modern and scientific world as the be-all of success (Gibson-Graham, 2005). The impact of these inflexible descriptions of the world are that other forms of thinking that may conflict with these 'monoculture' values are silenced and, over time, lost. Pieterse (2010) notes that the 'monocultural project' of development "has often required the loss of 'indigenous' culture, or the destruction of environmentally and psychologically rich and rewarding modes of life" (Sidaway, 2014, p. 147). In the context of education in the Solomon Islands, this violence plays out in the silencing of local knowledge and practice through a focus on formal structures and learning priorities. In some cases, such as deforestation, a formal approach to education has led to loss of traditional knowledge about what forests offer, instead focussing on its short-term economic value and displacing people as a result (Kabutaulaka, 2017). Drivers of 'development' have therefore been successful, rather than failed, in their aims and goals for educational homogenisation (Esteva \& Prakash, 2014). 'Development' is therefore violent in its silencing of the 'other', its impacts on places and people, and its encouragement of uniform 'progress' at all costs.

\section{Development as 'Neo-Colonialism'}

The discourse of 'development' has also been described as a neo-colonial construct by those who see it perpetuating similar power relationships and hierarchies to those that were present before decolonisation. The construction of a narrative of the 'West', like 'development', has created a group of 'others' who do not conform to the mainstream discourse (Hall, 2018). This process of 'othering' (Said, 1985) was one of the foundations of colonial dominance, with 'western' colonial powers using their own 'global truths' to dictate how everyone should act. For post-development thinking, issues with the 'development' discourse arise when we consider the question of who truly profits from processes of economic growth, cultural uniformity and global institutional control. Desai and Potter (2014) note that the incorporation of 'developing' countries into the global capitalist economy has had the effect of sustaining economic production in 'developed' countries, given the greater access to raw materials and markets this has provided them with. 'Formal' education structures founded during Solomon Islands' colonial past, are arguably perpetuating mainstream discourses. In these ways, 'development' is merely the neocolonial tool by which economic powers continue to control their former colonies. 


\section{Development as 'Failure'}

These key points that are highlighted by post-development theory have led to the suggestion that 'development' has ultimately failed, and impressively so, in addressing the needs of the global 'poor'. The same processes which benefit 'developed' countries have had little to no positive impact in many 'developing' countries (De Ferranti, et al., 2003). Though growth has occurred in places, it has created greater inequality at the national level than what was present prior to 'development'. Given this failure, post-development thinkers suggest that a new way forward is needed, either away from or within current 'development' systems and institutions. At the extreme are proponents of antidevelopment, who see no value in the practice or principle of 'development' (Simon, 2007; Sachs W. , 2013). Ferguson notes that 'development' projects "have consistently failed to achieve their stated objects... [while] expanding the field of bureaucratic state power in people's everyday lives" (1994, p. 176). Ferguson suggests we resist and transcend the institutions and power relationships that have been sustained by 'development' through active political opposition to its practice.

While antidevelopment advocates see 'development' as unsalvageable others have suggested that its ideas may still have merit, and that there may be alternatives that could address people's needs. Some suggest that there may be more effective alternatives to development (Escobar, 1995; Rahnema \& Bawtree, 1997; Esteva \& Prakash, 2014). These theorists suggest that systemic change must take place in how global inequalities are perceived and, where needed, addressed. Esteva and Prakash (2014) suggest the global focus of 'development' has been one of its greatest drawbacks due to its unresponsiveness to the community level. They highlight the work of grassroots organisations in developing a 'commons' mindset, "not an alternative economy, but an alternative to the economic society" (Esteva \& Prakash, 2014, p. xviii). Finding ways in which institutions and workers of 'development' may support, and not hinder or drive, these movements could be the way forward.

\section{Challenges to post-development}

Although post-development offers a useful and in-depth critique of 'mainstream' thinking, it is not short of its own critics. Despite being critical of discourses that homogenise experience, critics suggest that it does exactly that to 'development' practice, ignoring the diversity in approach taking place in the field (McGregor, 2009). To do so also ignores the tangible improvements to health, education and livelihoods that have occurred for many people in 'developing' countries (Corbridge, 1998). These achievements imply that 'development' 
practice has not been as complete a failure as post-development thinkers suggest. Curry (2003) notes that to reject 'development' implies that there is no chance for the 'impoverished' to improve their overall wellbeing, be it in health, education or livelihoods. Sachs, a major advocate for antidevelopment, notes that "[elites of] the South ... emerged as the staunchest defenders of development" $(2013$, p. 25). Not only is this taken as a sign that 'development' is something that is wanted, but to deny this opportunity to others, as postdevelopment seems to do, is its own form of cultural imperialism (McGregor, 2009).

Along with this, post-development has been criticised for the way in which it romanticises 'poverty' in rejecting 'development' (Sidaway, 2014). McGregor notes that many postdevelopment writers have created a binary "between an 'evil West and a Noble South"' (2009, p. 1694), that idealises the 'traditional' society that has been lost due to the 'modernisation'. Many critics question the validity of this previous society because it overlooks many of the negative aspects of 'traditional' societies that, in many cases, were just as hierarchical, inequitable and difficult as current structures (Corbridge, 1998; McGregor, 2009). As well as this, some suggest the post-development binary sees 'traditional' society as a static entity that is at the mercy of 'development' (Pieterse J. , 1998). However, more established work in the field of 'community development' suggests that this is a false representation, given the agency communities have in influencing and reinterpreting 'development' knowledge at local levels (Curry, 2003). Post-development thought therefore perpetuates 'mainstream' discourses due to its own underlying assumptions of the world.

Finally, the most traditional criticism of the original post-development thinkers was that they offered no tangible ways forward from the 'development' discourse they were quick to criticise (Corbridge, 1998). Although the critical nature of post-development has since evolved to incorporate potential ways forward, these are either rejected as idealistic and unattainable (Curry, 2003), or as ideas that are already part of the 'development' discourse they seek to transcend (Corbridge, 1998). Grassroots 'development' has been suggested, if not adopted, in participatory development thinking since the 1970s, meaning that postdevelopment is not a new critique in its own right. Corbridge is also critical of postdevelopment thinkers for failing to acknowledge the contribution 'western' thinking has to offer in facilitating "the 'pluriverses' they wish to celebrate at the grassroots" (1998, p. 144). Cutting ties with 'development' not only has the potential to hinder some communities, negatively impacting on their human rights or access to external support, but also allows 
traditional hegemonic powers to wash their hands of any responsibility for the inequalities that have been created over time (Corbridge, 1998).

\section{Finding a way forward: Changing the 'development' discourse}

Despite the points highlighted above, post-development's criticisms of 'mainstream' discourse still hold weight in wider discussions. Post-development has been valuable in widening the 'development' landscape, highlighting and challenging how and why 'development' practice is done (Gibson-Graham, 2005). The strong backlash from many writers is evidence of this, forcing them to address their assumptions and, ironically, giving them something to reinvigorate their own academic writing. Some thinkers have maintained a staunch antidevelopment stance in their writing (Esteva, Babones, \& Babcicky, 2013; Sachs W. , 2017), with others fervently opposing them (Corbridge, 2007).

What is important to consider is that post-development thought has not been stagnant in its approach to 'development'. While Ziai notes that the criticisms above were warranted for the original post-development texts, this has given rise to "a neo-populist PD discourse" (2015, p. 837), which is less sceptical of 'development'. This has led others to suggest alternatives of 'development' that put institutions, official development assistance (ODA) and other development co-operation to better use. These theorists suggest there may be more acceptable forms of 'development' that are either more inclusive in their approach or less 'western' in their focus (Gibson-Graham, 2005; Sidaway, 2014). Others have also noted the incorporation of post-development criticisms into more 'mainstream' development discussions (Ziai, 2015). Matthews (2004) noted that opposing aid priorities at the time often led to the failure of 'development' practice, and that adopting contextually relevant values at the community level would be more likely to create positive change. Murray and Overton also highlight, as a fault in the priorities of 'development', "the downgrading and sometimes outright dismissal of poverty reduction as a guiding principle for aid" (2016, p. 443). The shift in institutional discourse towards 'sustainable development', discussed further in Chapter 7 , is an instance of economic and political co-option of discourse, yet they do not reject 'development' outright. Although 'development' may not be perfect in practice or principle, there may be ways to re-align it to be more effective for a wider group of people (Ziai, 2015). This is the theoretical position I take as part of this thesis, suggesting how we might conceive of different ways forward in understanding and practice. 


\section{Escobar: Towards local models of practice}

Given this position, I have taken Arturo Escobar's local models of practice as a basis from which to consider Solomon Islands rural training centre experiences in and alongside 'development' practice (Escobar, 1995; Escobar, 2001; Escobar, 2004). Escobar's main concern is the fixation on 'modernity' as a goal in 'development' discourse, which he believes is rarely relevant to local priorities (2001). This is due to the ingrained assumptions of the purposes of 'development', only pushing a singular form of 'modernity' that is more representative of a 'developed' worldview than it is of a 'developing' one (Escobar, 2004). This leads to the creation of an "under-developed subjectivity endowed with features such as powerlessness, passivity, poverty and ignorance" (Escobar, 1995, p. 8), with the 'developing' requiring external intervention from the 'developed' to achieve uniform 'modernity'. The impact of this is twofold, with local communities having their own priorities and practice marginalised while also having to adopt an external framework.

In response to these challenges, Escobar proposes a 'development' environment in which local models of practice and understandings of 'modernity' are legitimised in different contexts (2004). The use of 'local' here and throughout this thesis is problematic because it implies some sense of unified locality. The 'local' in reality changes across and within place, which is the inherent challenge for 'development' practice responding to diverse, and often varied, needs and processes. To work effectively with, in and across diverse places requires time, openness and a relinquishment of power and direction on the part of external actors. Supporting and responding to local models of practice in this way gives credibility to a wider range of experience and value, in which processes of 'development' may be explored more inclusively (Gibson-Graham, 2005). Three thematic points of thought have been drawn from Escobar for the chapters that follow in this thesis:

1. How local models of 'development' practice might be conceived, and what purposes they serve.

2. Understanding the impacts of local models of 'development' practice on community development, and local agency in these processes.

3. Highlighting the external forces that impact on and, at times, threaten local models of 'development' practice, and the agency of local actors to resist.

These themes have been chosen because they provide a framework where local experiences, understandings and agency can be explored whilst also acknowledging how this practice fits (or does not) into wider discourses of 'development'. Chapter 5 explores what local models 
of practice look like in the context of RTC 'community development', as well as how this differs from a 'western' conception of seemingly similar models. Chapter 6 explores how we might challenge mainstream conceptions of 'modernity', 'knowledge' and 'development', highlighting how these are navigated in Solomon Islands settings. Chapter 7 examines the wider forces, priorities and assumptions of 'education development' in the Solomon Islands, as well as the implications of these for the RTC network.

\section{Conclusion}

This chapter has outlined the foundational ideas of post-development, challenging the ways that dominant discourses have been used to co-opt the purposes, processes and priorities of 'development'. The monocultural silences that a neo-colonial discourse has created have not only led to many failures of 'development' promises and outcomes for those termed 'developing', but also to ongoing cultural, environmental and physical destruction of diversity at local levels. Post-development thinking is therefore vital to widening credible experience, facilitating and advocating for diverse conceptions and practices in 'development' that are more representative of people's lived experiences and values. The following chapters will use the critical but constructive post-development lens established in this review to explore local models of practice in Solomon Islands RTC contexts, drawing on a diverse range of concepts in discussions of how 'development', despite its flaws, can be done differently. 


\section{CHAPTER 5}

\section{Local models of practice: Solomon Islands RTCs as community 'hubs' of diverse development.}

\section{Introduction}

This chapter explores the people, processes and purposes that contribute to local models of 'development' practice at Kaotave, Vatu, St Dominic's and Tabaka rural training centres (RTCs), to understand the model of practice that is being run in these local contexts. It begins with an overview of literature on 'social enterprise' as a driver of community development, focussing on 'community development hubs' as facilitators of mainstream 'development' and 'modernity'. Key contextual education and income-generation processes that relate to these ideas are then discussed, highlighting the roles and responsibilities that contribute to ongoing RTC operations. In line with post-development critiques of uniform understandings, I challenge the validity of external assumptions of nature and purpose that have driven external RTC support. The perspectives of local community administrators, instructors and students are instead highlighted as an alternative and multi-faceted understanding of what community 'development' is in a Solomon Islands context. I propose a loose model of interdependent Solomon Islands RTC 'communities' with diverse conceptions of 'development' and 'modernity' that do not fully conform to 'western' understandings of these terms. These 'communities' are linked but distinct from the external communities with whom they operate, both by geography and connectivity.

The practical and constructive component of the thesis is reinforced by discussion throughout of how START programming has influenced the RTC community model over the past five years. Regular references are made to the context in which Fleming's work (2015) was conducted, and the changes to that context in 2019. I use extracts from interviews, as well as observational notes, to reflect on how direct outputs of START have both supported, and at times hindered, this growth. Doing so encourages positive aspects of programming to be continued while suggesting adaptations for areas that have been less successful, based on the local model of practice put forward. With a greater appreciation of how and why RTCS operate, it is possible to then later discuss their community impacts, as well as how external parties might affect this. 


\section{Community 'development'}

Community development and empowerment have an important place in wider discourses of 'development' and 'modernity'. At its core, community development seeks "to build [local] assets that increase the capacity of residents to improve their quality of life" (Green \& Haines, 2015, p. 10). Across different contexts and industries, effective 'grass-roots' participation is seen as a major driver in successful programme outcomes (Ohmer, Meadowcroft, Freed, \& Lewis, 2009; Sebele, 2010). As noted by Gross et al. (2002), community-level initiatives can be more flexible and responsive to local needs, mobilise communities in their own 'development' and avoid top-down styles of programming. Despite this, community development initiatives have often been shown to make little impact on their target communities for those same reasons (Korten, 1980; Cavaye, 2001; Garikipati, Johnson, Guerin, \& Szafarz, 2016). A major part of this is the historical framing of communitylevel actors as subservient benefactors of external 'development' programming, with the goal being to create 'positive' change in 'underdeveloped' communities towards capitalist 'modernity' (Arensberg \& Niehoff, 1971). Early discussions of community development considered how external 'development' workers might better understand community processes to have their work more widely accepted at the local level, rather than understanding the interests at that level (Edwards \& Jones, 1976). Edwards and Jones (1976) viewed the primary agents of change in community development as external workers, whose goal it was to impart 'western' values to others. In this discourse, community action is an external process, where external agents of 'western' change promote a 'better' value system that is more conducive to economic growth than the 'traditional' one. This narrative supports discourses of 'underdevelopment', with communities being expected to be rewired to a uniform system of action and purpose.

More recent work in community development has been critical of this old approach, noting how it marginalises the priorities and agency of community members in their own 'development'. Participatory development, for example, criticises 'top-down' approaches that practitioners take in 'development' practice, giving 'local people', as the intended 'targets', little say in their own 'development' (Chambers, 1983; Leal, 2010). Community development theory therefore tried to evolve to involve 'development' recipients in the process to better understand the 'actual needs of the poor' and incorporate this into the overall process (Chambers, 2007). While positive in its placement of the 'community' at the centre of 'development', many still challenge this view of community development, given that the focus remains on sustaining external 'development' goals. Cooke and Kothari note 
participatory development is facilitator-focussed, which has the potential to overlook the perspectives of those, such as women, children and people with disabilities, who may be excluded from community discussions (2001). Where cross-gender discussion is seen as a norm in 'western' discourse this is not always true for other communities, who utilise different processes (Pearson, 2005). In this way we see the co-option of community development into a uniform discourse of 'development'.

\section{'Social enterprise' as a model of community development}

An organisational model that lends itself well to processes of community hub development is 'social enterprise'; a "hybrid organisational form, or forms, blending mission and market logics that are coined variously as 'business with social purpose' or 'in business for good'" (Ridley-Duff \& Bull, 2018, p. 4). Similar models to this have been put forward in development practice as facilitators of rural community development (Cavaye, 2001; Amir, Ghapar, Jamal, \& Ahmad, 2015; Castro-Sitiriche, 2015). As noted by Cavaye (2001), including community priorities and interests as part of a mixed social and economic approach to community development can foster effective change. Despite this, a major difficulty in the wider literature is the variety of ways in which social enterprise is conceptualised, with writers using terms like 'social enterprise' and 'hybrid organisation' interchangeably to mean different things (Austin \& H Stevenson, 2006; Nyssens, 2007; Lyon \& Jackson, 2015; RidleyDuff \& Bull, 2016). Even then, these associations fail to capture internal organisational differences and complexities. Recent research has centred on the internal ethics of different 'social enterprise' models. Ridley-Duff and Bull (2018) have suggested that the internal political motivations of social enterprises and their staff affects how they balance their social and commercial goals. Figure 3, on the following page, helps illustrate these "diverse political foundations" (Ridley-Duff, 2018, p.2), highlighting three main ways these organisations prioritise their values:

1. 'Charitable Trading Activities' (CTAs) prioritise the social and charitable goals of the organisation and its community.

2. 'Cooperative and Mutual Enterprises' (CMEs) seek to develop financial and social goals simultaneously to their mutual benefit.

3. 'Socially Responsible Businesses' (SRBs) are primarily grounded in financial goals but seek to do so in ways which positively benefit the communities with whom they operate. 


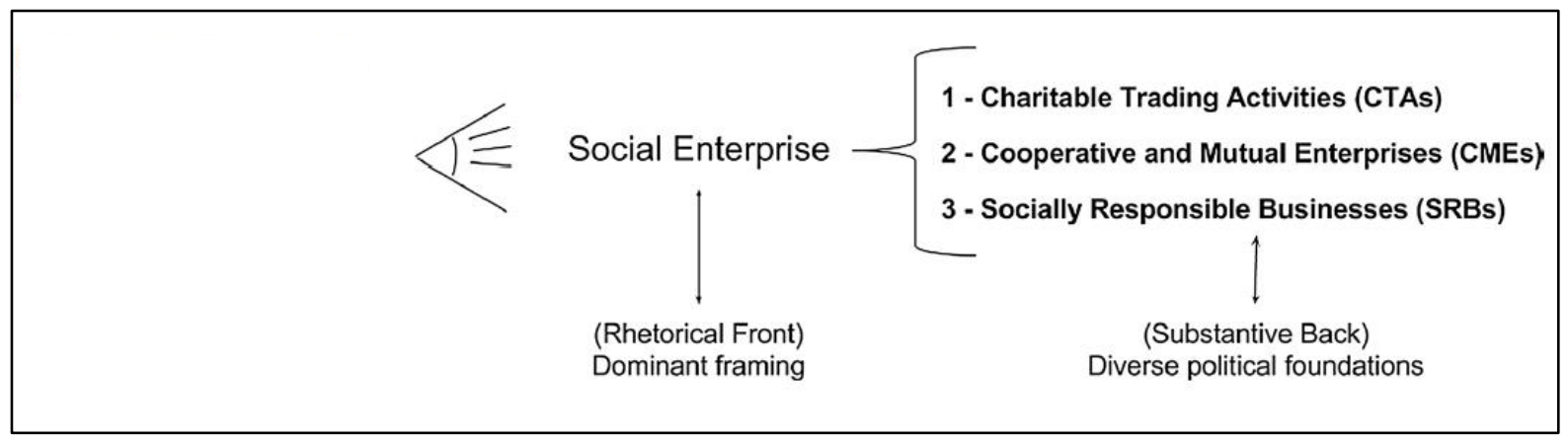

Figure 3. Conceptualising the challenge of social enterprise ethics (Ridley-Duff \& Bull, 2018, p.4).

Ridley-Duff and Bull suggest that a social enterprise's foundations, its people, purpose and place, greatly influence which of the categories it will fall into, and how it operates as an organisation.

\section{Dangers of co-option for community organisational models}

From a post-development standpoint, these social enterprise categories are dangerous in that they are reflective of how a community organisational model can be co-opted into wider capitalist discourses of 'development'. Community-level institutions are increasingly pushed through external programming into models that are more aligned with mainstream 'development' discourse, with a recurring theme in much of the literature relating to the changing nature of aid priorities as a driver of the 'social enterprise' model. Maclean and Brass (2015) examined processes of NGO organisational model change in Kenya and Uganda to sustain renewable energy provision for local communities. They highlight "decreasing donor funding to more traditional NGO programming [and] an ideological shift... among donors... toward funding profit-oriented or financially sustainable organisations" as causes (MacLean \& Brass, 2015, p. 75).In this way, we see how wider discourses can co-opt community development initiatives into wider frameworks that are not necessarily indicative of their own nature and purpose.

\section{'Decolonising' community development}

Given the opportunities to co-opt community development initiatives, a more holistic definition of the term is needed which prioritises the potential for diversity in interpreting 'community' and 'development' across contexts. Green and Haines' definition of 'communities of place' and their capital seeks to show how value systems might extend beyond an economic discourse, including to the "physical, human, social ... environmental, political and cultural" $(2015$, p. 10$)$. Also key to this is that people and organisations within a community are placed as the main creators of their own 'development' goals and processes 
(Sen, 1999). These processes are open to contextual differences, not always conforming to a discourse that promotes uniform function or purpose across place. Agency is therefore taken from external parties and given to local actors and institutions to decide what is best for them (Green \& Haines, 2015). Although even this has the potential to only be representative of local-level proponents of wider discourses, this is at least a first step in promoting communities as agents of their own understandings, change and 'modernity' (Escobar, 2004). This gives space for community models of 'development' to form in response to the direct needs and interests of local communities, in a way that is not completely overshadowed by external discourse.

\section{'Hubs' of community development}

Where space is given for these models to grow there is evidence to show they can be more relevant and impactful for communities long-term. A similarity in many of these community development models is in creating 'hubs' of practice (Green \& Haines, 2015). These hubs are diverse in nature, but can include local institutions, people or organisations that support the needs and interests of communities with whom they operate. In urban settings, universities may be examples of this in how they can promote innovation and relevant skills for people (Hansen \& Lehmann, 2006). However, the same is relevant in rural settings, where 'development' programming is often channelled through an organisational focal point that is accessible for surrounding areas (Green \& Haines, 2015). In the context of the Solomon Islands, RTCs have been shown to be key hubs of contextually-relevant livelihoods development for their communities. Fleming's work (2015) showed that students and communities perceived RTCs as a key avenue for their own skills and livelihoods development. Given the capacity of education institutions to be hubs of 'development' in other settings, identifying the nature and purpose of the RTC organisational model is vital to understanding how external programmers might better support them as community development initiatives in the Solomon Islands. Given the ways in which START programming has tried to foster a social enterprise model as part of RTC community 'development', it is from this starting point that I begin considerations of the nature and purpose of the Solomon Islands RTC organisational model.

\section{RTC educational structures and change}

The following three sections serve as a grounding to the operational model of the education institutions visited. Their purpose is to give context to the reader on the people and places within the RTC communities that are discussed in this and following chapters. Table 4 on the 
following page presents all the courses taught at the four RTCs and how these compare to each other. As can be seen, there are five courses that all institutions teach: agriculture, building/carpentry, mechanic, New Testament studies (NTS) and 'business' or 'marketing'. These last two terms are used in the Solomon Islands to separate the selling of goods at community-level markets from industry-level financial skills and management that reflect an external discourse of business. It should be noted that life skills are also widely taught at RTCs for female students, with St Dominic's being an outlier here due to it only taking male students.

As well as this, some RTCs offer context-specific courses, such as St Dominic's forestry course due to the surrounding logging industry on Kolombangara island. Students either learn a mixture of all the courses offered (Vatu and St Dominic's) or select one main course which is learnt alongside either New Testament Studies (Tabaka), or core financial skills (Kaotave). Vatu runs a similar education model to formal education systems, with students taking a range of courses simultaneously, while St Dominic's uses cycle systems, where students move to different courses in three-week blocks. The education system is similar in these ways to the situation outlined by Fleming (2015), but there are noticeable developments in some places.

Table 4. Subjects taught by RTC

\begin{tabular}{|l|c|c|c|c|}
\hline $\begin{array}{l}\text { Location } \\
\text { Subject (tick, if taught) }\end{array}$ & Kaotave & Vatu & St Dominic's & Tabaka \\
\hline $\begin{array}{l}\text { Agriculture } \\
\text { Building/Carpentry }\end{array}$ & $\checkmark$ & $\checkmark$ & $\checkmark$ & $\checkmark$ \\
\hline Mechanic & $\checkmark$ & $\checkmark$ & $\checkmark$ & $\checkmark$ \\
\hline Life Skills & $\checkmark$ & $\checkmark$ & & $\checkmark$ \\
\hline Electrical & $\checkmark$ & $\checkmark$ & & $\checkmark$ \\
\hline Hospitality/Tourism & & & $\checkmark$ & $\checkmark$ \\
\hline $\begin{array}{l}\text { Forestry } \\
\text { Business/Marketing } \\
\text { Skills }\end{array}$ & $\checkmark$ & $\checkmark$ & $\checkmark$ & $\checkmark$ \\
\hline $\begin{array}{l}\text { New Testament Studies } \\
\text { /Personal Development }\end{array}$ & $\checkmark$ & $\checkmark$ & $\checkmark$ & $\checkmark$ \\
\hline
\end{tabular}

\section{Courses taught}

One of the changes is in courses offered at the RTCs, with all but St Dominic's having introduced a new subject in the last five years. Vatu offers a community-level electrical course, focussed on domestic wiring and solar units. At Kaotave, resources and training from START's financial capability training have encouraged a more in-depth financial course to be 

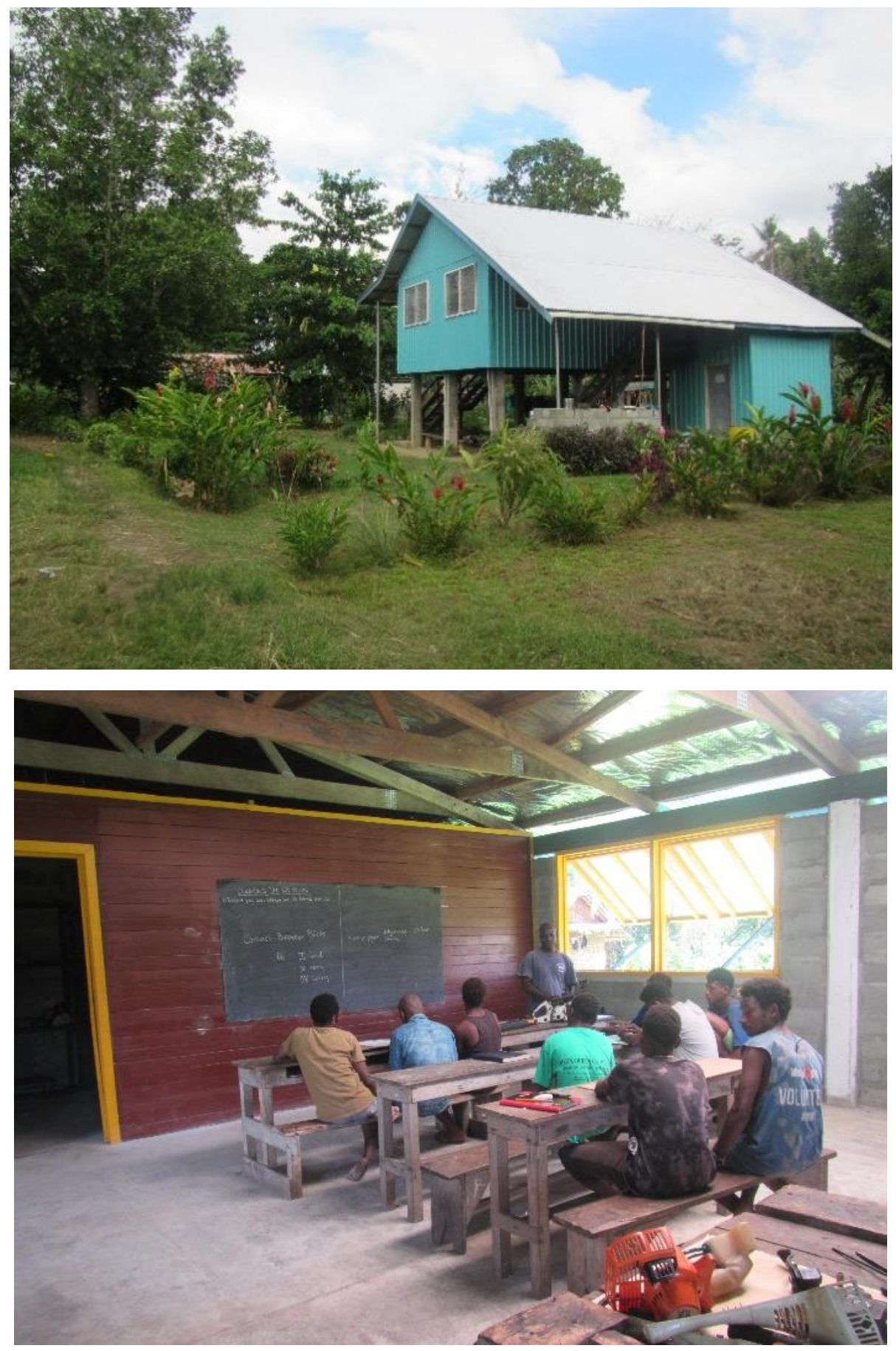

Figure 4. Above, a staff house constructed as part of START infrastructure at Kaotave RTC. Below, a mechanic class being taken at Vatu RTC in the new START-funded workshop (Photo credit: Finn Egan).

developed which is compulsory for students. This focuses on promoting financial capability and autonomy, with students taught budgeting and saving skills that are applicable to various settings. Finally, Tabaka is piloting a hospitality and tourism curriculum as part of an Australian Government 'Skills for Economic Growth' (S4EG) Programme. Although there have been no changes in courses offered at St Dominic's, there are impacts on the style and quality 
of teaching within its current courses, which will be discussed in the next chapter of this thesis.

\section{Infrastructure}

There are noticeable differences in the level of infrastructure at RTCs targeted under START. At Vatu, this is visible in the construction of a shared carpentry, mechanic and electrical workshop (Figure 4), and a classroom/dormitory for the life skills course and female students. Remaining funds have been used to construct a permanent concrete piggery building for the agriculture department. All permanent structures at Vatu will also soon have a solar power system, which was to be installed by a volunteer at the time of writing. This is noticeably different from five years ago when there was only one permanent administration and teaching structure at Vatu. Alongside permanent structures, temporary structures using local materials continue to be constructed and used for staff housing and communal and religious spaces.

At Kaotave, START funding has been used to construct two staff houses (Figure 4) and to begin a broiler project as a form of income generation. Extensions were also being made by the carpentry department to the boys' dormitory, and a new piggery has also contributed to income generation for the agriculture department. Finally, a new classroom building was in

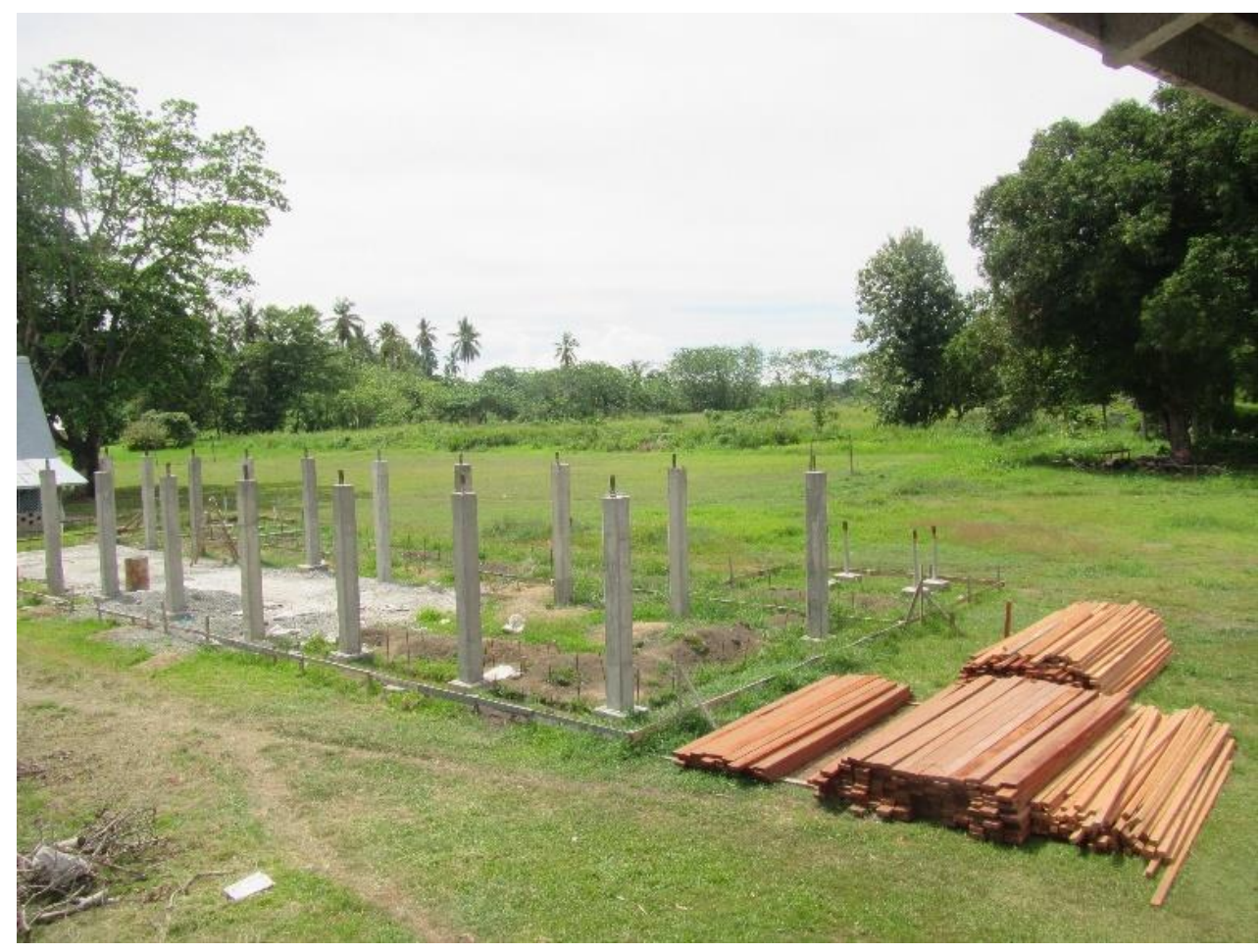

Figure 5. Foundations and timber for new classrooms funded by Kaotave RTC and the Japanese Government. The Kaotave contribution came from profits of the piggery (Photo credit: Finn Egan). 
the process of being constructed in partnership with the Japanese Government at the time of my visit (Figure 5). Prior to this, only some courses had dedicated classroom or workshop areas, which many interviewees described as a challenging learning environment.

Tabaka is where the most noticeable changes have taken place over the last five years. The institution has effectively been rebuilt from the ground up, with external funds used to construct staff housing, a mechanic workshop and new girls' dormitories; there is now a separate classroom for all courses taught at Tabaka. A new solar power system funded by the S4EG Programme in recent years is connected through all these buildings. S4EG has also contributed to the construction of classrooms and demonstration facilities (guest rooms, bathrooms and a kitchen) to support the hospitality and tourism department. In these ways Tabaka is the most obvious example of the impact of increased 'development' funding over the last five years.

St Dominic's is the only institution visited where current infrastructure has remained the same since 2015 , although maintenance has taken place. The quality of this infrastructure, as noted by interview participants, varies, with some courses having classrooms whilst others are taught outdoors. An example of this was the piggery course, which was taught in an openair structure that was formally used for pig holding prior to the construction of concrete pens. Foundations were being laid out for a new staff room at the time of visiting but this had yet to eventuate. Coincidentally it is also the only RTC visited that was not allocated funding for infrastructure under START, although there is not a direct correlation between these two points. The impact that external 'development' can have can therefore be seen in the speed of change over a five-year period in the RTC setting.

\section{Teaching resources}

There has been some increase in access to practical teaching equipment at the RTCs over the last five years, although there is a discrepancy between courses in this regard across the sites visited. Life skills courses at all relevant RTCs remain severely under resourced, although this is less impactful at Vatu due to small student intakes. Practical resources at Kaotave and Tabaka, such as sewing machines, material and cooking facilities, are present but not in enough quantity to meet learning needs for all. START-targeted courses, such as agriculture, building and mechanic, are not exempt from this either, with access to practical materials dependent on the geographic differences previously described. The impact of these changes, or lack thereof, at the various institutions visited is discussed in more detail in the following chapter. 


\section{RTC income-generation and change}

RTCs employ various income-generating models to sustain their operations, some longstanding and others newly created. These models compensate for the ongoing disparity in government funding between RTCS and other Solomon Islands education institutions. One staff member of Tabaka noted this government contribution is only " 400 [Solomon] dollars... per head student contribution per year... compared to secondary school 1-3000 maybe, per child" (Interview, 2/6/19, Tabaka). Administrators at all sites said that this was not enough to effectively contribute to the running of their RTC, although they appreciated that staff salaries were still paid separately by the Solomon Islands Government (SIG). At Vatu, the SIG grant is so small due to their student intake that it would cost them more to travel to Honiara to access it through their Education Authority than simply not accessing it at all. Tabaka receives a larger per-student grant (SBD 10,000 per student) for its Tourism/Hospitality students under the S4EG Programme, although there is no guarantee of this continuing after 2020. RTCs therefore find other means to support themselves in the long-term.

Although RTCs generate income in diverse and context-specific ways, there are similarities in the forms of models employed. Table 5 on the page 42 lists the forms of income generation employed at each of the sites visited from most profitable to least. The main forms of income generation across all RTCs are agricultural, with selling pigs and vegetables through local networks the most profitable and consistently practiced. Piggeries, like those supported through the START Programme at Kaotave and Vatu (Figure 6, below), generated a minimum profit of SBD 2,000 for a fully-grown pig or up to SBD 300 for a new-born piglet, with six piglets per litter on average. The cultural significance of pigs as part of Solomon Islands celebrations means that there is a consistent demand for them at RTCs with a piggery (Kaotave, Vatu and St Dominic's) whilst also catering to the school's own needs. While Vatu already had a piggery prior to external support, the construction of a concrete structure has improved stock capacity and management.

At Kaotave and Vatu, selling crops created a monthly profit of SBD 300-400 (SBD 3,200-4,800 annually), but also significantly reduced food costs by catering to RTC needs throughout the year. A similar profit was made by the Tabaka agriculture department, but this was sold to the administration for department resource costs, thereby not generating income for the institution itself. Tabaka's internal income generation was minimal, being reliant on external funding grants from the S4EG Programme for $50 \%$ of its annual budget. Some internal 

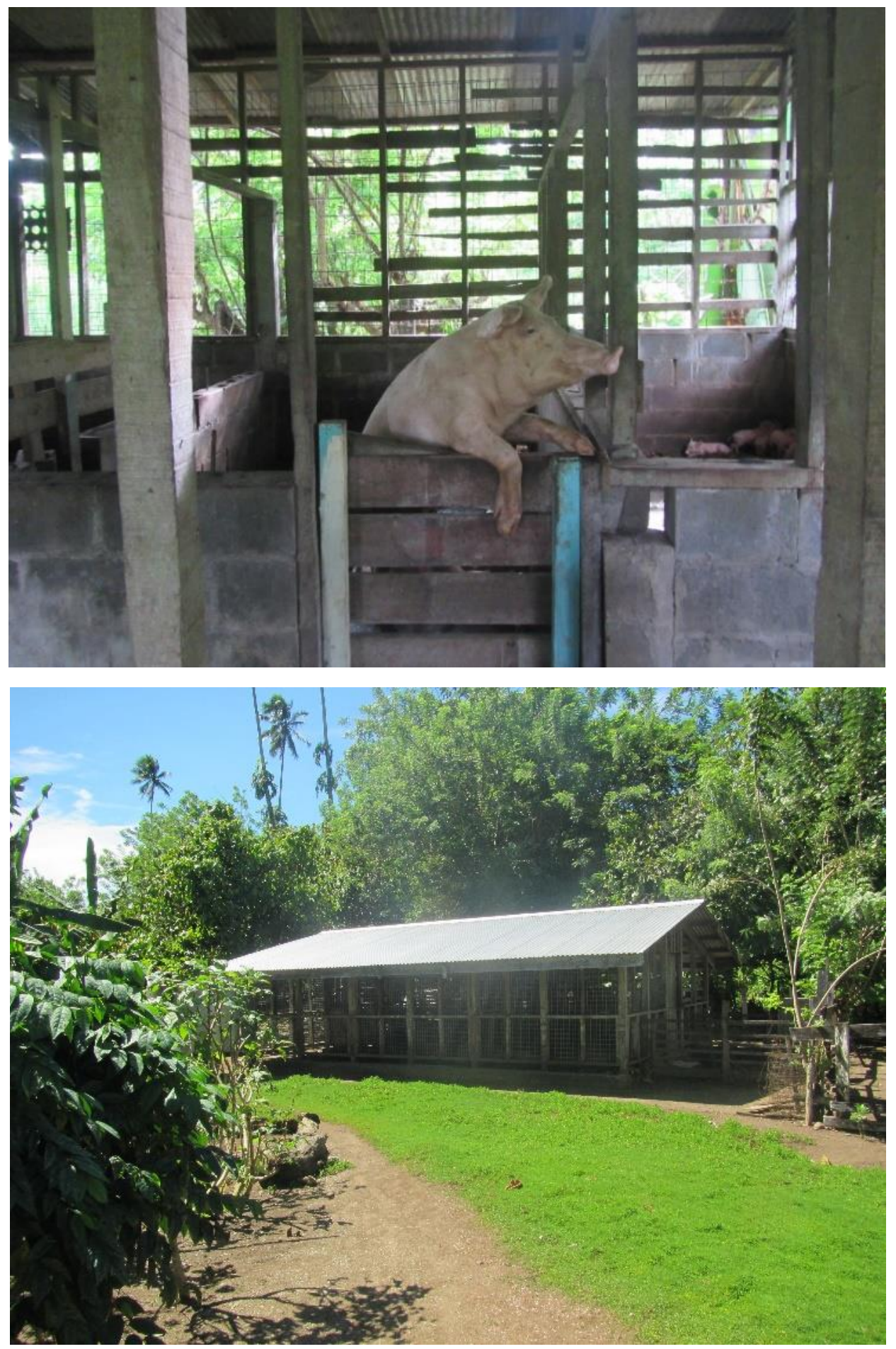

Figure 6. Above, a pig poses for the camera in the piggery facilities constructed as part of the 'Grow Youth Business' component of START at Kaotave RTC. Below, permanent piggery facilities constructed with support under the 'Grow Youth Business' component of START at Vatu RTC (Photo credit: Finn Egan).

projects were planned, including bungalows (tourism), a piggery (agriculture), a canteen (administration), wiring and installations (electrical), clothing racks (life skills) and broiler raising (agriculture), but these were in their infancy when visited. St Dominic's did not have consistent crop rotation, meaning food substitution or income generation was inconsistent. 
This is significant because $50 \%$ of St Dominic's annual budget was spent on student food, despite having the largest agricultural capacity of any of the RTCs visited (Interview, 28/5/19, St Dominic's).

Table 5. Forms of income generation ranked from most to least profitable at each RTC.

\begin{tabular}{|c|c|}
\hline Location & Forms of RTC income-generation (relevant department) \\
\hline Kaotave & $\begin{array}{l}\text { 1. Piggery (agriculture) } \\
\text { 2. Cassava and Kumara (agriculture) } \\
\text { 3. Broiler raising (agriculture) } \\
\text { 4. Ice lollies and cakes (life skills) } \\
\text { 5. Vehicle servicing (mechanic) } \\
\text { 6. Metal chair and desks (mechanic) } \\
\text { 7. Lava lavas (life skills) }\end{array}$ \\
\hline Vatu & $\begin{array}{l}\text { 1. Cocoa/copra plantations (agriculture) } \\
\text { 2. Piggery (agriculture) } \\
\text { 3. Vegetable gardens (agriculture and life skills, separately) } \\
\text { 4. Broiler raising (agriculture) } \\
\text { 5. Chairs and scrapers (carpentry) } \\
\text { 6. Basket weaving (life skills) } \\
\text { 7. Building/generator wiring (electrical) }\end{array}$ \\
\hline St Dominic's & $\begin{array}{l}\text { 1. Timber (forestry) } \\
\text { 2. Piggery (agriculture) } \\
\text { 3. Egg laying (agriculture) } \\
\text { 4. Furniture (carpentry) } \\
\text { 5. Housebuilding (building) }\end{array}$ \\
\hline Tabaka & $\begin{array}{l}\text { 1. Vegetable growing (agriculture) } \\
\text { 2. Furniture (carpentry) } \\
\text { 3. Clothing racks (life skills) } \\
\text { 4. Motor servicing (mechanic) }\end{array}$ \\
\hline
\end{tabular}

Along with general patterns of income generation, some RTCs employed contextuallyspecific forms of income generation. For example, there was a longstanding relationship between St Dominic's and the KPL logging company on Kolombangara to cut timber from RTC land to meet any quota shortfalls that occasionally arose. This took place every 2-5 years, with a recent harvest in 2018 earning SBD 194,000 for St Dominic's. This is a significant amount, allowing the RTC to support its operating costs and infrastructure development when needs arose. Alongside this St Dominic's staff managed 300 laying hens, supplying a 
local business in Gizo with 20-40 trays of eggs weekly. At SBD 31 per tray, this contributed to a weekly profit of SBD 620-1,240 to ongoing operating costs. Cocoa and coconut plantations at Vatu raised SBD 10,000-14,000 per harvest, with the potential for three harvests a year. However, these were not done consistently, only being harvested as short-term operating needs required. These and other activities were made possible by the work of multiple stakeholders contributing together towards the running and maintenance of the RTCs.

\section{Roles and responsibilities in Solomon Islands Rural Training Centres}

Along with key education and business operations, it is important to understand the roles and responsibilities of different stakeholders at the RTCs, including how these people work together to support RTC operations.

\section{Administrators: RTC leadership and accountability}

The role of administrator staff in income generation varies across the RTCS, with some notable patterns. Their leadership positions mean they have general oversight over various activities in the RTCs, including financing, staffing and direction, but the extent to which this was practiced varied in different places. A key area of this was in the management of financial resources, with some administrators taking full responsibility over this and others delegating it to others. Delegation was visible at many of the RTCs visited, with administrators giving others the primary responsibility over financial records and receiving regular updates on income. This appeared to create a much more positive relationship between staff due to more transparency around profits and spending. An example of this is in the following comments made by an agriculture instructor:

"Our principal he's opening the new account for the piggery project for itself ... for now our school is building a new classroom ... our grant is late for coming in, so my principal said [to me] we will use half of this money while waiting for the grant to come in" (Interview, 6/5/19, Tetere).

From my observations, the important aspect of this was clear communication in using funds. In this case, the administrator had open dialogue around how funds would be used, leading to less resentment and a more positive organisational culture. In this way, community development systems at the RTC were better integrated and inclusive of all relevant stakeholders.

Although some administrators were able to balance accountability needs with internal transparency, there were also cases in which staff would become frustrated due to limited 
control over the income-generation process. An example of this was an instructor who had full oversight over the operations of their designated responsibility at St Dominic's except financial recording. This created frustration for them because they felt cut out of the process, despite being the driving force behind the success of the activity and having the financial skills to manage this aspect of the work. When I talked to the RTC's administration about this activity, they were aware of some challenges faced in this regard:

"There's some few things that we need to really put it very clearly for in terms of recording and spending ... the teachers might need for us to report back on how we spend ... for us especially as the admin because when the records are well-kept, it should be really good so that we can report back to the teachers" (Interview, 28/5/19, St Dominic's).

Despite the information being available, the administrators had yet to make it accessible to the relevant staff members or involve them in the process. The effect of this was a division that, as seen in other cases, could have easily been avoided. There were therefore many important considerations for administrators in navigating in their roles within the RTCs.

\section{Instructors: RTC facilitators}

Along with administrators, instructors play a key role in RTC operations, both academically and financially. A main reason for this is the integrated nature of income generation at RTCS being closely linked to the courses that are taught. An example from Table 5 is the production of furniture at Kaotave, Tabaka and St Dominic's, which is used to also teach core carpentry, welding and marketing skills to students. Instructors are therefore efficient with their time, teaching while also supporting RTC operations. Instructors in some RTCs took an active role in financial recording related to income generation. Although this was sometimes for personal knowledge and accountability, it served as an integrated check on other parts of the RTC system.

Despite the benefits to this integrated income generation system there are some limitations to its viability as a consistent income strategy in certain RTC contexts. With the previous example of furniture, a major challenge was the need to teach other course components. Once students had learnt to make a chair or a scraper, instructors then needed to move on to other subjects rather than simply repeating the process as would take place in a business. This particularly affected Kaotave and Tabaka, where students only took one course, because instructors had more content to cover. St Dominic's cycle system was the best equipped for 


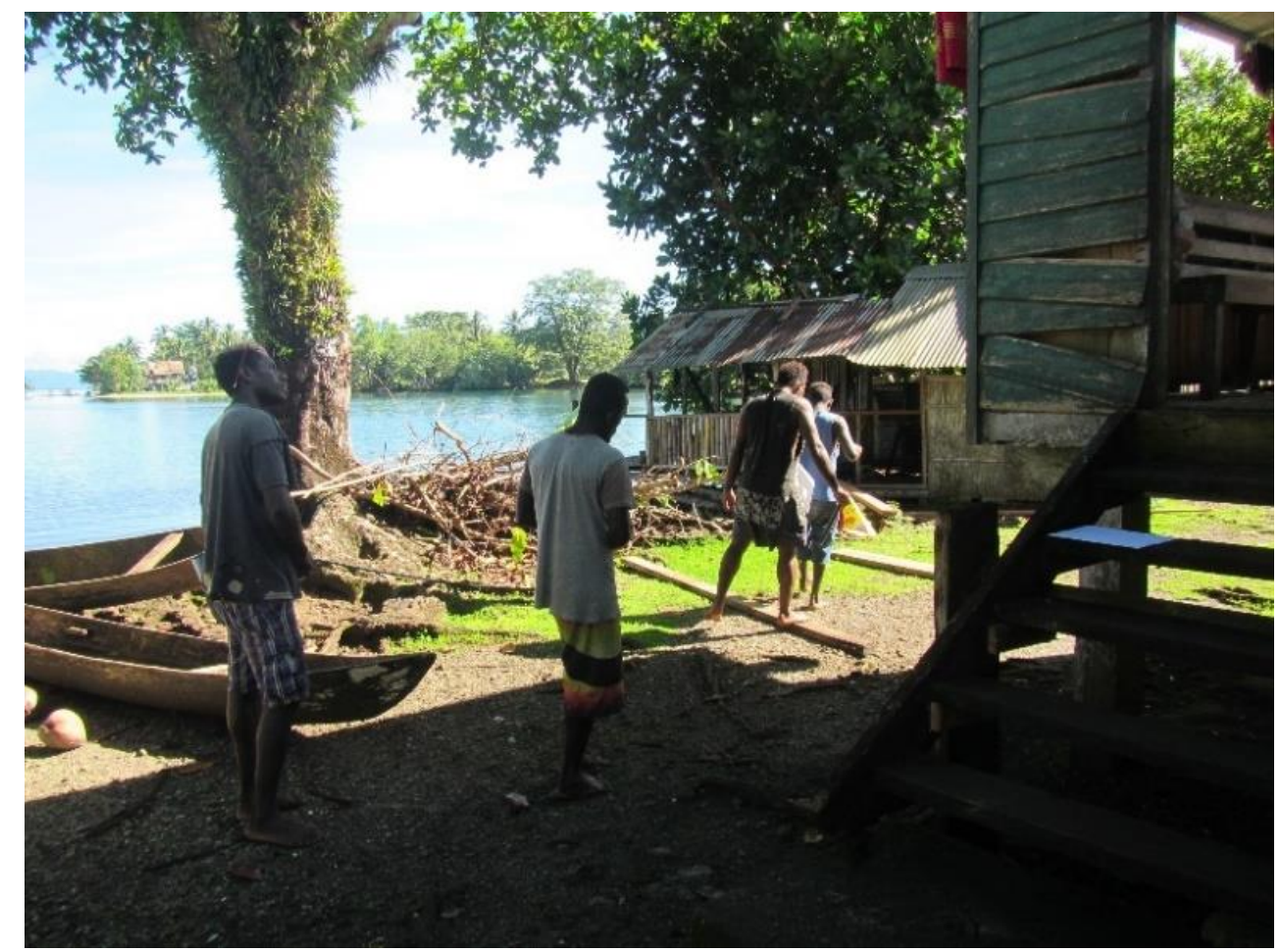

Figure 7. Building students and their instructor repair staff houses at St Dominic's RTC (Photo credit: Finn Egan).

consistent production, with new groups of students learning the same skill from one instructor across the year. However, no set curriculum meant that the changing RTC needs (housing maintenance, instead of furniture production, for example) often took precedence.

As well as this active role in income generation, instructors took part in other work that contributed to RTC operations. The instructor role extended to overseeing school upkeep and maintenance (Figure 7), subsistence gardening, and extracurricular activities related to students' wellbeing, such as liturgy, sports and music nights. Many instructors had strong religious connections to the denominations that their RTCs were associated with. As noted by a staff member at Kaotave, "I think because of Christian church, I guess school first" (Interview, 11/6/19, Kaotave). They were therefore willing to devote most of their time to working and supporting others in the RTC. Working alongside students and administrators meant that instructors were key to facilitating connections between other groups within the RTCs.

\section{Students: RTC workforce}

Students are unique in the RTC 'community' because they not only work but pay to be in the system, with RTC fees ranging from SBD 1,500-3,600 per year depending on the institution. For some unable to afford these fees, RTCs employed other systems of remuneration so that students could take part. At Vatu, one student did extra maintenance work over the course 
of the academic year and summer, with hourly wages deducted out of his school fee balance. Most RTCs, especially those with limited operating costs, were not strict on the payment of school fees, but would withhold final completion certificates from students until they had fully paid their fees. This meant there was accountability for students whilst also giving them flexibility to stay engaged in education.

Where instructors were often the facilitators of income generation and other activities, students were the main source of labour to sustain RTC operations. This practical work was expected of students both during and outside of class time, with both included separately within weekly timetables. St Dominic's students would spend half an hour in the morning on school maintenance, cutting grass or moving building materials before going into morning classes. Classwork varied across courses but included maintenance of school gardens, motors and building RTC infrastructure. Some students noted that the expectations on them were hard to become accustomed to, but most accepted it as part of their education and contribution to the RTC 'community'. This extended to student 'free time', with expectations to be involved in religious and social activities as part of education. In some RTCS, student leaders ran these events alongside staff.

\section{External community: RTC 'market'?}

While other groups had a direct relationship to RTC operations, external community had a more complex underlying relationship with, and in, the RTC communities. On the surface this relationship was primarily transactional, with the surrounding community often serving as the market for RTC income activities and vice versa. This was evident at Tabaka, with students and staff regularly visiting the surrounding community to purchase food and timber for their own needs. Instructors were sometimes engaged in contract work by community members, such as the wiring of a local shop in the nearby town of Noro. However, there was also a more entrenched social relationship in the way RTCs engaged with surrounding communities. At St Dominic's, staff saw a distinction between the 'local' and 'business' communities they operated with, with companies, like KPL logging, having the means to pay for their services. In contrast, local-level villages were not always able to do so. As noted by a St Dominic's instructor,

"One of the important things is that we try to contribute to the people outside the school ... they come and ask us, and the building students go there, build their house. Now we're building one house from the village for an old man ... [he 
provides] all the materials... and he just provides food for the students and we build it" (Interview, 7/5/19, Tetere).

An important reason for this is that RTCs are not only set up at the discretion of their denominational church, but with the permission of local communities as traditional land owners. One staff member at Tabaka noted the presence of an education institution gave the community prestige, but this also required reciprocity. As part of the surrounding community, RTCs could draw on others for support but were also obliged to support in kind.

External community members rarely took part in RTC operations, either in an education or income generating capacities. This is noteworthy because START's 'Grow Youth Business' component, which supported many of the income generating activities described, aimed to promote community employment opportunities. Kaotave, for example, could not find graduates who wanted to be employed, with a staff member noting that they had offered the piggery management role to one of their 'trustworthy' graduates, but she had wanted to start her own business instead; Agriculture staff therefore maintained primary responsibility over the piggery. From an income-generation perspective therefore, the external community remains separate from RTC operations despite being important to the system as a whole.

\section{Carers and support staff: 'silent' RTC contributors}

As a final note, it is important to acknowledge the unpaid 'informal' work that goes on, often behind the scenes, in RTC operations. This work, as noted in the literature on postdevelopment theory, is usually overlooked despite evidence that it is a valid part of wider social and economic systems of operation. Fleming (2015) primarily focussed on highlighting similar forms of 'silent' labour that occur in informal contexts. It is also important to acknowledge this group given that the majority were women, who have comprised a large proportion of those overlooked in wider discourses.

All the sites visited had people that contributed to the ongoing running of the RTC 'community', either formally or otherwise. Formally, this included staff that were directly paid to support school activities, while informal networks included spouses and other staff family members, and external community members who contributed to the RTCs. This group's roles were diverse, including school maintenance and cooking for students, and transporting people and goods to and from the RTCs. This also extended to childcare activities for RTC staff, freeing others to perform their own RTC community roles. Carers and support workers therefore play a key, if often overlooked, role in RTC operations. 


\section{Layered Rural Training Centre Purpose}

Having explored the nature of the RTC operational model, the following section explores the layered meanings for those in the RTCs that view the institutions as key promoters of theirs and others' 'development' and 'modernity'. This helps show the diversity of purpose that sits behind what may be viewed externally as a standard educational-business model. Exploring these purposes helps reinforce the separation of RTC models of practice from a homogenised view of education provision, but also shows layered understandings of 'development'.

\section{Community Livelihoods}

The original purpose for the creation of RTCs is and, in most places, remains facilitating community livelihoods for early school leavers. These livelihoods are diverse across locations and take place in both formal and informal areas of the economy (Fleming, 2015). Courses offered at the RTCs cater to community-level needs and outcomes. These needs form part of RTC educations, including using agriculture projects in the second-year at Vatu and St Dominic's to help students purchase tools in preparation for their return home. At Vatu, staff were very clear about their teaching being for a community setting:

"Successful outcomes for myself are the students have done something in their communities. When I see something in the community, in the village, improving through the students, graduates from Vatu, that's successful" (Interview, 21/5/19, Vatu).

This response was important in showing distinctions between rural and semi-urban settings. Vatu's remote location from formal sectors of employment, its integrated role in the community and local staff and student bases make its work vital to supporting community outcomes. Most Vatu staff and students came from the local Guadalcanal area, showing the mutual benefits that derive from the RTC operational model. It not only gave students the skills to work within a community context, but equipping students could then benefit the RTC itself in creating a pool of future staff later.

The community-livelihoods purpose was also evident in Vatu and St Dominic's holistic education system, where students studied many different topics over the course of their studies. This meant students could gain relevant knowledge in many different fields, making 


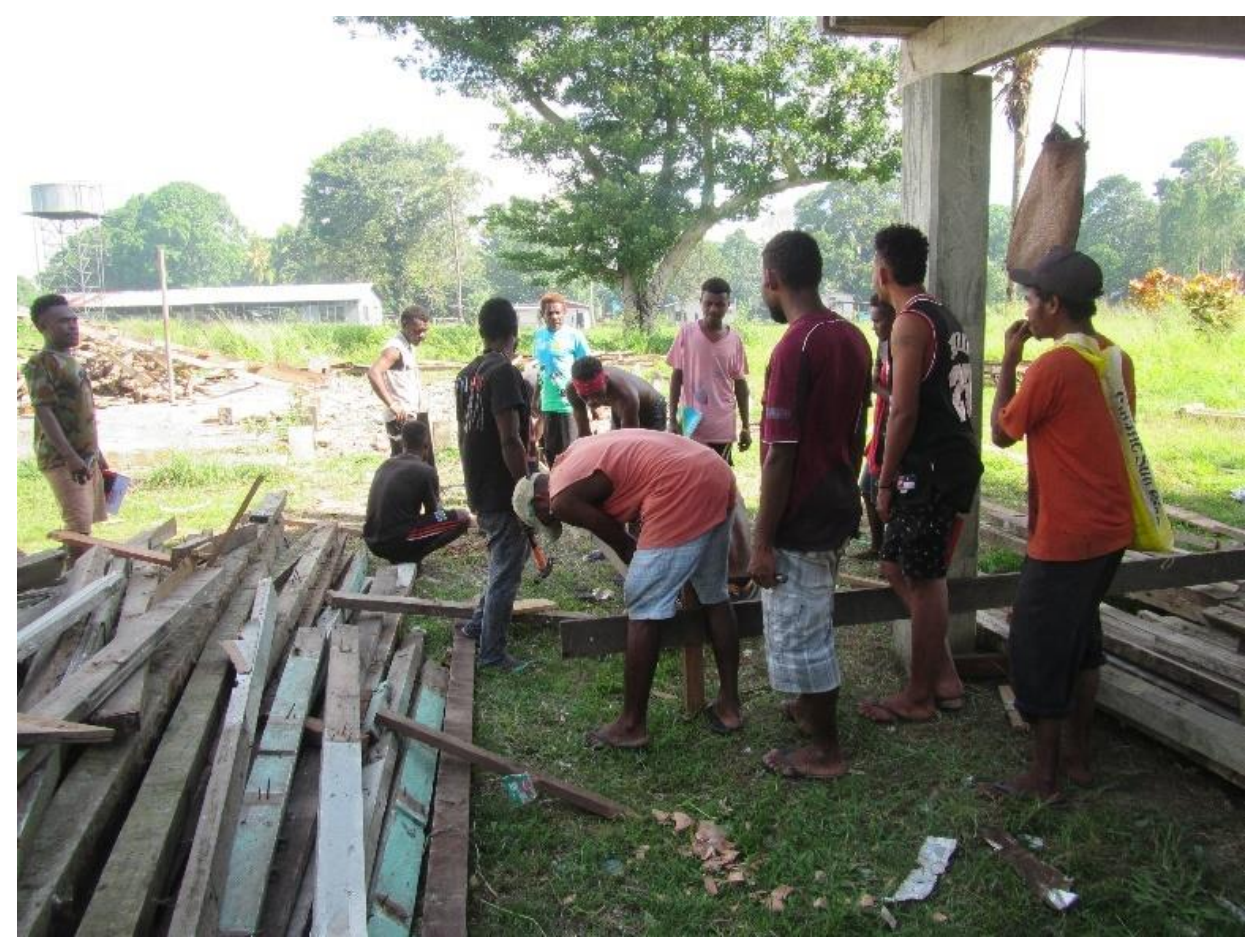

Figure 8. Students set up profiling for a new boy's dormitory at Kaotave RTC (Photo credit: Finn Egan).

them flexible to the various community needs that may arise in their own contexts. Students therefore received a much more holistic, if less in-depth, education that served them more effectively in their own settings. At Kaotave and Tabaka, students selected a primary course to focus on whilst also learning other core skills, such as gardening and financial planning at Kaotave, that could benefit local livelihoods. Students across all RTCs found the mixture of courses useful, although some noted challenges in keeping up with their expected workload.

\section{Youth development}

Alongside livelihoods, the RTC model develops the young people's attitudes to live and work effectively in urban and community settings. As noted previously, students play a key role in RTC operations, acting as the primary labour force for gardening, agriculture, construction, school maintenance and cooking (Figure 8). A student at Kaotave RTC notes, "the work is very tough maintenance, and sometimes we even do the sweeping ... but we don't say anything, just patient" (Interview, 9/5/19, Kaotave). From an outsider perspective this workload on top of studies compensates for limited RTC resources. Although this is partially true, it fails to capture the expectations placed on people in a community setting in the Solomon Islands. Consistent physical labour often makes up much of daily living, including many of the same duties that are expected of students at RTCs. Consistent work is therefore key to forming positive 'attitudes' or 'work ethic'. A community mind-set is also practiced in 
the classroom: "Our teachers and us students we work together in a workshop. When we [are] having class we share things together, so I thought that it was great and good for us" (Interview, 9/5/19, Kaotave). Students are therefore taught to be effective and reliable members of a community that is wider than would be considered in 'western' discourses of personal development. The community supports them but also relies on them to function effectively.

Another component of youth development at the RTCs is pastoral and emotional care. Many students interviewed, both male and female, came to RTCs with a history of drugs, crime, pregnancy and other situations that have been exacerbated by, or contributed to, their early departure from formal education. As noted by a staff member from St Dominic's, staff "are working with young men who were neglected by the society ... where the [education] system doesn't accept them anymore" (Interview, 28/5/19, St Dominic's). Rather than ignore this, I found that RTCs often tried to encourage students to work through these challenges in their lives. The main avenue for pastoral and emotional care within the RTC structure was the church, with all having a denominational leader on their staff. These leaders were the main referral avenue for student 'issues' that arose and included ordained clergymen and lay community leaders and staff.

\section{Labour force}

Along with community-level livelihoods, this research identified the formal workforce as a growing focus for many at the RTCs visited. The nature of wider economic discourses means that communities and individuals, both urban and rural, see themselves as increasingly more reliant on formal employment for certain things, which is no different in the Solomon Islands. When asked about the opportunities in their local communities, many students saw very few in the short-term, instead feeling a push into main centres for employment. This mentality was more prevalent in mechanic, electrical and tourism courses, with agriculture, life skills and carpentry courses having more variance in responses.

Although students identified the formal workforce as a purpose for the RTCs, administrators, tutors and officials' responses varied across different sites. Vatu and St Dominic's had a direct focus on the community level, while staff at Kaotave and Tabaka acknowledged that there was a need to provide formal employment skills. Table 6, below, shows difference in practical placement at the RTCS, which informed these underlying priorities and understandings. Provision of formal employment experience was evident in the six-month practical placement of students by Kaotave and Tabaka into contextually-relevant formal 
employment. At Tabaka there was a clear focus on tourism and fisheries in their placements, which was relevant considering these were the primary industries in surrounding local areas. At Kaotave the focus was on agriculture, particularly oil palm, and course-relevant industries in the large employment market of Honiara. Although St Dominic's staff noted a trend of students going into formal employment, their practical and coursework focussed on the community level. Changing purposes in semi-urban spaces, from informal to formal is important to note because it signals a change in priority for some from the original community livelihoods focus of RTCs.

\section{Table 6. Description of Practical placement locations at the RTCs visited}

\begin{tabular}{|c|c|}
\hline Location & Main Practical Placement locations \\
\hline Kaotave & $\begin{array}{l}\text { - Local agriculture industry (GPPOL oil palm, Taiwanese Technical } \\
\text { Mission) } \\
\text { - Honiara-based industry (Ports Authority, Hatanga Construction } \\
\text { Ltd., Frangipani Ice, Supreme Casino) } \\
\text { - Honiara-based South Sea Evangelical Church (SSEC) schools } \\
\text { (Florence Young Christian School) }\end{array}$ \\
\hline Vatu & $\begin{array}{l}\text { - Practical work integrated into coursework and needs of the RTC } \\
\text { - No extended external placement of students (short-term work in } \\
\text { local communities, as needs arise) }\end{array}$ \\
\hline St Dominic's & $\begin{array}{l}\text { - Practical work integrated into coursework and needs of the RTC } \\
\text { - One-off local construction and timber work (KPL Logging } \\
\text { company, surrounding communities) }\end{array}$ \\
\hline Tabaka & $\begin{array}{l}\text { - Munda-based industry (Agnes Gateway Hotel, other guest } \\
\text { houses) } \\
\text { - } \quad \text { Noro-based industry (SolTuna, National Fisheries Development } \\
\text { Ltd., local shops) } \\
\text { - } \quad \text { Local construction work (Tabaka primary school) }\end{array}$ \\
\hline
\end{tabular}

\section{'Rural' lifestyle}

Another key component of RTC community purpose was providing a preferred lifestyle for some participants away from urban settings. Whilst previous purposes were primarily student-focussed, this aspect related particularly to RTC administrators and instructors. For many, part of the decision to teach in a rural setting was that "it's much cheaper out in the rural" (Interview, 9/5/19, Kaotave). Inherent costs of living in and around main centres, particularly away from customary land, meant that doing so would impact on quality of life for many, and living rurally supported RTC staff to provide for their families. This need also extended to a preference for rural living for many staff interviewed. Participants spoke of their appreciation for the communal mentality when living within RTC communities, which differed from living in urban settings. This illustrates the mutually beneficial nature of the 
RTC model of practice, which staff are able to also benefit from in ways that do not fall into simplistic economic discussions.

\section{Re-entry into the formal education sector}

A final theme present across all RTCs was as an avenue for students to re-enter formal education systems. Students at all sites saw potential to go into further study of some kind. The practical skills developed at RTCs, coupled with earning a formal certificate, acted as a foundational bridging course that could compensate for leaving school early. This academic opportunity was a focus at Tabaka, with one student saying,

“Mi just garem chance for come work long Tabaka for continue study ... First time Tabaka em RTC nomoa olsem, hem no upgraded. Then taim, I think it last year putim Tabaka Institute ... olgeta upgradim moa so soon mi harim bai mi olsem like for go study long Tabaka now" (Interview, 31/5/19, Tabaka).

"I got a chance to go work at Tabaka to continue my studies... Before, Tabaka was only an RTC, it wasn't upgraded. Then last year they made it Tabaka Institute ... they upgraded it so when I heard that I wanted to study at Tabaka" (approximate translation, Finn Egan).

This excerpt highlights the importance of discourse and language in underlying assumptions of 'development', with a 'training centre' being seen as a lesser option in comparison to an 'institute'. Institutions mentioned for future study were the Solomon Islands National University (SINU) and Don Bosco Technical Institute, but some students also expressed a hope to pursue overseas study if possible. The main barriers to this were financial, with few students having the means to pay for their own education, and academic, primarily due to English writing and literacy skills required in Solomon Islands tertiary education. Students that did not have the means to afford their studies looked to regional and national scholarships, and extended family, as options for pursuing this goal.

This student focus on further education was highly dependent on age, previous education and, in some locations, gender. Younger students, aged 15-25, were more likely to view further education as a next step to 'development' for themselves and their families, while older students, aged 26-34, were more likely to return to their community with the skills they had learnt. This distinction between ages was notable in a student discussion at Vatu, where one of the older students commented on young ones having less to go back to than him. 
'Late' school leavers, Forms 3-6, were also more likely to see further study as a purpose of their education, while 'early' leavers often had an immediate practical purpose for their studies. A student at Kaotave, for example, was learning electrical skills because nobody else in his village had that knowledge, showing the holistic nature of community development in some settings. Finally, gender as a distinction was most notable at Vatu where female students all wanted to return 'home' immediately while there were mixed responses from males. As in 2015, students had long-term intentions to return to their communities, even when moving away for employment in the interim. This emphasises that although the means was in an urban setting, the end point for participants was still firmly grounded in their localities.

Along with students, some RTC tutors and administrators saw their involvement in RTCs as an avenue for their own studies. Some staff at all RTCs had received professional development training through either 'development' programming, such as START and S4EG, or other school and Church scholarships. Others who had not received training but were interested in it saw their roles as RTC staff as beneficial to this, improving their own knowledge and position and, often as a result, providing higher quality education to their students. Higher education was a factor in the government payment structure, giving staff the means to further provide for their families within the RTC system. Like with lifestyles, this reinforces the interdependence of different groups within the RTCs.

\section{Solomon Island RTCs as a 'social enterprise' model}

Given the diverse education, income generation and purposes visible within the RTCs, the focus returns to the model being practiced. Returning to Ridley Duff and Bull's model of social enterprise, it is possible to see some relevance to the conceptualisation of the RTCs as community development hubs. As noted previously most RTCs had clear income-generating operations that took place within the RTC structure. Where successful and sustainable, these maintained and supported education. Funds were used for the sole purpose of sustaining practical and personal skills development, often for people with few other avenues to support themselves and their communities. The RTC model is also inclusive and codependent, involving various groups within the 'community' to function effectively. This gives the foundations of a sustainable RTC organisational model, with many aspects suggesting the relevance of a social enterprise classification. The question from this discourse is therefore where to classify, rather than whether to do so. 
A quick analysis based on organisational structures and roles shows that Solomon Islands RTCs should not be classified as either Socially Responsible Businesses (SRBs) or Cooperative and Mutual Enterprises (CMEs). The main reason for this is grounded in their foundation as education institutions. As noted by an official from a Solomon Islands Education Authority, "originally, all rural training centres were run by churches ... providing both education and training, and the Government did not realise the importance of rural training centres until more recently" (Interview, 17/5/19, Honiara). These sentiments concerning the original organisational purpose were shared by all those interviewed across the RTCs. This educational grounding rules out SRBs due to the primary focus on financial goals in this classification. For CMEs there is some focus on financial sustainability in partnership with social goals, but these are undertaken separately. Of the four RTCs visited, none had a successful income-generating method that was separate from teaching and none could therefore be considered CMEs. The question is therefore whether there is scope to classify Solomon Islands RTCS as social enterprises that undertake Charitable Trading Activities (CTAs).

On the surface, the CTA classification has a lot of relevance for the way in which Solomon Islands RTCs operate. The people and processes have a community-focussed organisational mindset that prioritises social good through education for those who would otherwise struggle to access this. Income generation, where observed, is integrated with education and used only as a supplement to support the running of the RTC. This would therefore suggest that a classification of Solomon Islands RTCS as CTA 'social enterprise' would be appropriate.

\section{'Social enterprise' as discourse}

Despite the relevance of the model, the potential benefit of classifying RTCs as social enterprise is outweighed by how doing so would be both inaccurate and detrimental to the RTC network. RTCs are not enterprises that seek to make a profit, even for student benefit, and barely do so at the best of times. Staff at RTCS earn just enough to support themselves and their families, with most having to supplement their income with subsistence gardening. As noted by a staff member at Kaotave, "we find we survive the school year, going through some very careful budget management ... Some sacrifices ... I'm used to walking so it's no problem. It's my life" (Interview, 8/5/19. Kaotave). From an organisational perspective, levels of infrastructure and teaching resources vary across different RTCs, with many unable to find the means to go beyond maintaining what is already in place. The purpose of RTC income 
generation is therefore not about business, as would be the case in a social enterprise, but for the institutions' survival.

Classifying RTCs as social enterprises merely places them in a discourse of 'development' and 'modernity' that serves those outside, rather than within the community model. The way RTC communities operate collectively and interdependently in the Solomon Islands is something that is less visible in a 'western' discourse, where having social goal outside of business implies something more; a 'social enterprise'. However, the flaw in this discourse is the assumption of business as a core component of being connected to 'modernity'. To see communities working together, as in RTCs, in a way that is often disconnected from the formal sector, yet still managing to function, challenges the need to be connected. RTCs have

operated in and for the informal sector and this separation from formal economies is still present and necessary in providing education for those external to them. Whilst they may therefore be viewed as enterprising and diverse, RTCs should not be classified into a discourse which connects them to the formal economy but instead one that takes their needs more into account.

\section{A loose model of Rural Training Centre 'community' practice}

In proposing a model of the RTC organisational 'community' there are two keys points to acknowledge. This model is not intended as a discourse to homogenise RTCs into one form of organisational structure with one form of practice and purpose. While there are patterns of thought and process that have been detailed above, RTCs operate in geographically and contextually diverse places which can require equally diverse modes of operation. This model is intended to show external RTC stakeholders the diversity of purpose for which they operate that extends beyond an economic focus. This breaks down external perceptions of the RTCs as solely for livelihoods development, when in reality they are much more.

From the evidence presented, it is possible to see how the RTC 'community' model promotes diverse conceptions of 'development'. While suggesting that formal economic structures are not a part of this would be incorrect, it is important to challenge the notion that this is the main goal of RTC education (Gibson-Graham, 2005). Those within RTCs, whether students or otherwise, are there for many interconnected reasons, including economic, social, environmental and cultural. Whilst economic functions take place in most RTCs, these are often informal in nature and not done for financial profit. The intention is to sustain practice in a way that does not detract from students as the priority. This paints a picture of institutions that sustain themselves for different forms of 'development', rather than 
conforming to one unified purpose (Escobar, 2001). While education is commonly seen as the means of 'development' in the RTC model, many discourses of purpose form its ends.

The RTC model is also inclusive and co-dependent, involving various groups within the 'community' to function effectively, while also mutually benefitting them in different ways. These functions extend beyond the assumptions inherent in a traditional organisational analysis, where business forms the driving component of existence in education provision (Ridley-Duff \& Bull, 2018). Instead, culture and spirituality are as deeply ingrained as livelihoods into processes of education in the RTC model. This promotes holistic understandings of what 'development' means to different actors at local levels, including but not limited to lifestyle, family and community. Personal benefit from education, remuneration or otherwise is therefore hard to distinguish from the collective benefit at the organisational level given the interdependence of different groups in the RTC education model. It is therefore possible to distinguish these processes of interconnected operation within RTCs as 'communities of place' (Green \& Haines, 2015).

A view of RTCs as 'communities of place' suggests that RTCs might be viewed as communities in of themselves. These RTC 'communities' are linked but distinct from the surrounding communities with and for whom they operate as hubs of 'development'. The RTC 'community' has similar relationship structures to other social settings, but this is distinct from the interactions of staff and students with others outside the RTC itself. This is easily seen where students and staff come from separate geographic locations across the Solomon Islands, but also in how interactions with the 'surrounding community' were described as separate from every day RTC activities by interview participants. This shows people from other communities coming together to form their own communities that serve as hubs of 'development' (Esteva \& Prakash, 2014). Put forward together, these factors give a loose model of interdependent Solomon Islands RTC 'communities', each with diverse conceptions of 'development' and 'modernity' (Escobar, 2004) that do not conform to 'western' understandings of these terms.

\section{Conclusion}

This analysis of the RTC model of practice shows the diversity of people and purpose that underpins understandings and processes of community development in the RTCs. Where RTCs were previously shown to be perceived as key to community livelihoods development in rural areas, this chapter has shown how this takes place. Whilst Ridley-Duff and Bull's model of social enterprise is useful in showing how RTCs balance education and business, 
classifying them in this way has limitations for more holistic understandings of 'development' and 'modernity'. A post-development analysis, informed by the participant inputs, shows that these understandings extend beyond a solely economic lens to include other social, cultural and communal goals in the RTC model. This allows us to better understand the ways in which the RTC 'community' model is able to act as an interdependent hub of diverse 'development' for those within it. Presenting this local model of practice challenges uniform understandings of experience, opening up many discourses of what it means to 'develop'. The next chapter builds on this conception of local practice, seeking to understand the individual and community-level impacts of RTC education over the last five years, as well as how and where external 'knowledge' has contributed to this. 


\section{CHAPTER 6}

\section{Impact of community development hubs: Individual and community development and change in Solomon Islands rural training centres.}

\section{Introduction}

Having conceived of a rural training centre (RTC) 'community' as a local model of practice in the previous chapter, this chapter discusses the impact, change and outcomes of supporting such a model in local contexts. The purpose is to understand how RTC knowledge and learning support individual and community conceptions of 'development', and how external programming can contribute to this. The chapter begins with an academic overview of 'development impact' and 'knowledge', including a post-development critique of how these terms are conceived within 'western' discourses. Evidence is then presented to show how the RTC 'community' model has adapted and contributed to the purposes set out in the previous chapter, using external knowledge to create localised impact in this regard. Although Caritas' START programme features heavily in this chapter, it is only one component of wider processes of 'knowledge conversion' at the local level over the last five years. People are shown as the primary drivers of their 'development' processes within local models, with external support merely being a tool which they have agency to use as they see fit. Finally, I discuss ongoing challenges faced by different groups engaging within the 'development' model, suggesting how a more inclusive approach within the RTC 'community' might better support internal impact. Whilst external knowledge might have relevance to actors in local settings this is only as part of those internal processes of understanding and change, meaning this should be measured based on local indicators of impact rather on external ones.

\section{Impact in 'development'}

The measurement of impact is viewed as a central and logical component of 'development' practice. At its core, the purpose of measuring impact to help identify "the positive and negative, primary and secondary long-term effects produced by a development intervention, directly or indirectly, intended or unintended" (Leeuw \& Vaessen, 2009, p. 5). There are therefore two purposes to assessing impact: understanding the relevance of 'development' project outputs for those targeted under the process and, in theory, learning from this for future practice (Baker, 2000). Impacts are as diverse as the indicators by which they are measured, including but not limited to economic, sociocultural, institutional, environmental 
and technological factors depending on the context in which they are used (Leeuw \& Vaessen, 2009). Where accurate, relevant indicators are therefore considered by many as a key tool for effective learning and 'development'.

Despite the benefits of impact measurement, what is considered effective and relevant is something that is entirely dependent on the method, indicators and underlying purposes that inform measurement. Baker, for example, notes that "evaluating impact is particularly critical in developing countries where resources are scarce, and every dollar spent should aim to maximize its impact on poverty reduction" (2000, p. 4). This shows underlying assumptions of poverty reduction as the goal, with improved efficiency and growth as logical indicators of positive impact on this. However, these assumptions are made from an economic lens that is only reflective of certain priorities (Wilson, Mann, \& Otsuki, 2003). Other impacts of practice, both positive and negative, have therefore been excluded historically from assessments, ignoring anything that falls outside the predetermined economic 'development' agenda (Baster, 1972; Thomas, et al., 2000). In response to this, Zautra, Hall and Murray (2008) suggest creating more effective indicators that are relevant to specific communities when measuring impact; Though even this can ignore the iterative nature of community development priorities (Esteva \& Prakash, 2014). Predetermined indicators therefore act as a discourse in themselves, determining positive and negative impacts of a project based on what is initially thought to be important rather than what might occur in practice.

\section{Measuring impact in community development}

Inherent confusions in impact assessment are similar in many ways at the community level, although more holistic assessments of impact might improve this. Feeny, Hermes and Lensik note community development impacts are often measured based on how well community members adopt or use knowledge and resources provided to them (2006). Whilst this creates a clear cause and effect linkage that may be easily measured, the mentality is problematic in how it shifts blame on to communities rather than practitioners for not implementing 'new knowledge'. Although there is the potential to respond to local needs, diversity at the local level often makes this difficult to fully achieve, particulary when efforts are targeted at multiple local contexts with differing needs and priorities (Garikipati, Johnson, Guerin, \& Szafarz, 2016). Indicators also assume community buy-in to 'development' initiatives, suggesting a need to change or 'update' existing structures that may already be functioning effectively. However, this fails to consider that predetermined impact indicators might not 
be appropriate to ongoing processes of change. Impact measurement is therefore often used to shift blame for 'development' failures onto 'recipients', exempting inaccurate underlying assumptions, structures and practitioners from this in the process (Escobar, 2001).

The potential for exclusion and co-option in assessing impact means practicioners must ensure that it is done constructively, prioritising holistic and iterative community 'development' indicators (Powell \& Geoghegan, 2005). Powell and Geoghegan note that identifying these indicators can be challenging, given that political and cultural conditions often support "a homogenised, mono-cultural society" $(2005$, p. 96) rather than accounting for the various hidden interests that can exist at the community level. Indicators must therefore be multi-dimensional in focus, catering to this diversity of experience (Hák, Janoušková, \& Moldan, 2016). Grunkemeyer and Moss noted that "an integration of social, environmental and economic goals resolved conflicts and increased [community] mutual awareness of and collaboration among competing local interests" $(2011$, p. 29). The impact of this is better 'development' outcomes that are holistic in nature and more inclusive of diverse community-level experiences. The purposes of the RTC 'community' model identified in the previous chapter are therefore key to assessments of impact.

\section{Knowledge in 'development'}

Given the high priority placed on education in the RTC context, an area of interest is in assessing the impact and transfer of 'knowledge' over the last five years. Like 'education', what is meant by 'knowledge' is complex, given that all understandings of this term are based on various assumptions that are grounded in different places and values (van Dijk, 2014). This is equally true in 'development', where priorities and ideas of best practice regularly change and adapt to changing circumstances (Jing, Mendez, \& Zheng, 2019). The focus on 'knowledge' in practice is in how it is shared from the 'developed' to the 'developing', passing what was viewed as key 'knowledge' for success to those that lag behind (Arensberg \& Niehoff, 1971). However, many criticise this for how it overlooks 'knowledge' that already exists at the community level (Apffel-Marglin \& Marglin, 1996). Sillitoe et al., for example, note that "indigenous peoples have their own effective 'science' and resource use practices, and that to help them it is necessary to understand something about their knowledge" (2002, p. 2). As a consequence, different 'knowledges' must be considered as part of 'development' practice.

Despite attempts to engage with this 'indigenous knowledge' within practice, there remain issues with the underlying assumptions and discourses that continue to drive processes of 
'knowledge' transfer in 'development' (Apffel-Marglin \& Marglin, 1996; Briggs, 2005). Sillitoe et al. note that even referring to community-level knowledge as 'indigenous' frames it as outdated and external to mainstream conceptions of 'modernity' (2002). Though understanding different perspectives is important, the underlying assumption is that this is only to help transfer external practitioner 'knowledge' to communities more effectively, ultimately replacing 'indigenous' knowledge in the process (Apffel-Marglin \& Marglin, 1996). Another aspect of this discourse on 'indigenous' knowledge is that it homogenises knowledge at the community level into one collective understanding of the world. This "ignores the unevenness, and often fragmentary and mediated nature of indigenous knowledge, and how such knowledge can become quite differentiated across a community" (Briggs, 2005, p. 105). Although it might be easier for 'development' practitioners to work from this understanding, it does not reflect community-level diversity. The impacts of 'knowledge transfer' are therefore likely to be uneven and, at times, irrelevant to those involved.

\section{Decolonising 'indigenous knowledge'}

In response to these challenges of engaging with different sources of 'knowledge' in practice, post-development theory suggests decolonising processes of 'development' and 'knowledge transfer'. This involves challenging assumptions of 'indigenous' knowledge as a stagnant entity at odds with 'modernity' (Apffel-Marglin \& Marglin, 1996). In reality, 'knowledge' and community-level processes change and adapt in similar ways to external bodies, and assuming otherwise merely fuels discourses of inequality (Escobar, 1995). Conceiving 'indigenous' knowledge as fluid and adaptable helps incorporate external understandings of the world into a community setting. This creates space for external partners to support in community models of practice, if and when it is asked of them. Ball and Pence, for example, note successes in their university's partnership with indigenous Tribal Councils on culturally relevant early childhood curricula in Canada (2006). Their approach involved "a significant departure from the established and familiar paths of training and education in North America ... stepping outside expected institutional relationships to identify a common ground of caring, respect and flexibility" (2006, p. ix). Engaging within and at the request of communitylevel structures is therefore possible where adaptation and change are a choice, rather than requirements of 'modernity'.

Due to their position as 'development' hubs at the community level, RTCs offer "an indigenous perspective on knowledge, in which knowledge involves expanding on and 
(re)constructing information and skills" (Gegeo \& Watson-Gegeo, 2002, p. 392). Rather than reinventing the system of 'knowledge' at the community level, RTCs can repurpose external knowledge to fit local contexts for local purposes (Gegeo, 1998). In the case of START programming, external 'formal' knowledge has been passed on to staff with the intent that this leads to more effective 'education' outcomes at the community level. The following sections therefore assess the extent to which this 'knowledge' has been received and, where used, impacted on local level practice over the last five years. This includes discussion of the incorporation of 'formal' knowledge to an 'informal' context, the extent to which knowledge dissemination and retention have taken place and the impacts of RTC 'development' under START for various community groups.

\section{Administrator impact, and change}

The last five years saw a lot of administrative change, and in most cases growth, at the RTCS visited as part of this research. Of the nine administrators interviewed across four RTCs, four had taken part in START trainings and one other had taken part in a separate training funded by the New Zealand Ministry of Foreign Affairs and Trade (MFAT). This low percentage of participation in external programming was indicative of staff turnover that took place at some of the RTCs visited, with only half having retained their core leadership from 2015. The following are key themes highlighted by participants related to administrator adaptation and change over the last five years.

\section{Responsibility and communication}

Administrators outlined changes to how they approached their RTC roles following START training. A key aspect of this was a willingness to build trust and delegate responsibility to other staff within the organisation, which they and others felt led to more effective RTC 'community' operations. As noted by a leader at Vatu,

"After our training I delegate responsibility more. Like the agriculture [instructors] have to record their own finances, and they keep the money and they only give [me] the records, the reports to check ... Before that, I dealt with everything, but this time teachers they have the say about their funds" (Interview, 21/5/19, Vatu).

As well as taking the strain off the Vatu leadership, delegating financial responsibility empowered other staff to set priorities for their own teaching and student development. Whilst leading to more effective and responsive teaching, what is less easy to quantify on paper is the positive mentality that these actions appear to have developed within the staff 
at Vatu. Instructors had a clear understanding of the budget available to them, more freedom than before to use and build on this and a drive to build the community for each other. This open approach, also observed at Kaotave, was leader-driven, with staff finding them easier to approach and responsive to feedback to improve their RTCs.

Another key component of effective leadership that START training appeared to contribute to was in encouraging leaders to lead by example. At Tabaka, an administrator who took part in training emphasised the importance of holding himself accountable to others. In his own words,

"My first time [in training], was very tough ... it really saved me ... You come in late to the meeting training venue, you're fired ... It reminds me, helps me to be there on time. You must discipline your time" (Interview, 2/6/19, Tabaka).

This focus on personal development was also touched on at Vatu:

"2014 when this START Programme came, that's when I started to develop my personality and public speaking ... I had [personality] before but not much confidence so that's why I feel that the START programme had helped us much, especially for me" (Interview, 21/5/19, Vatu).

This confidence to make decisions for the RTC and lead was important, but also balanced with clear communication in the build-up and execution of decision-making. At Vatu, one instructor noted that there were regular staff meetings in which RTC 'community' operations were discussed. This gave staff a say in the direction of the school and provided communal support if, for example, someone needed cover for class. At St Dominic's, in contrast, shifting the principal's accommodation into what had previously been the staff office meant there was not a similar space for this communication to take place. This impacted on the ability of the wider staff body to communicate with each other, which the leadership was aware of and trying to address (Interview, 28/5/19, St Dominic's). Delegation and open communication were therefore key learnings for RTC administrators from START and, where put into practice, appeared to have positive impacts.

\section{Organisational development}

Many participants also noted the importance of clear RTC organisational structures as another change over the last five years that was learnt through external programming. As noted previously, staff in RTCs often go above and beyond in their work for their RTCs and 


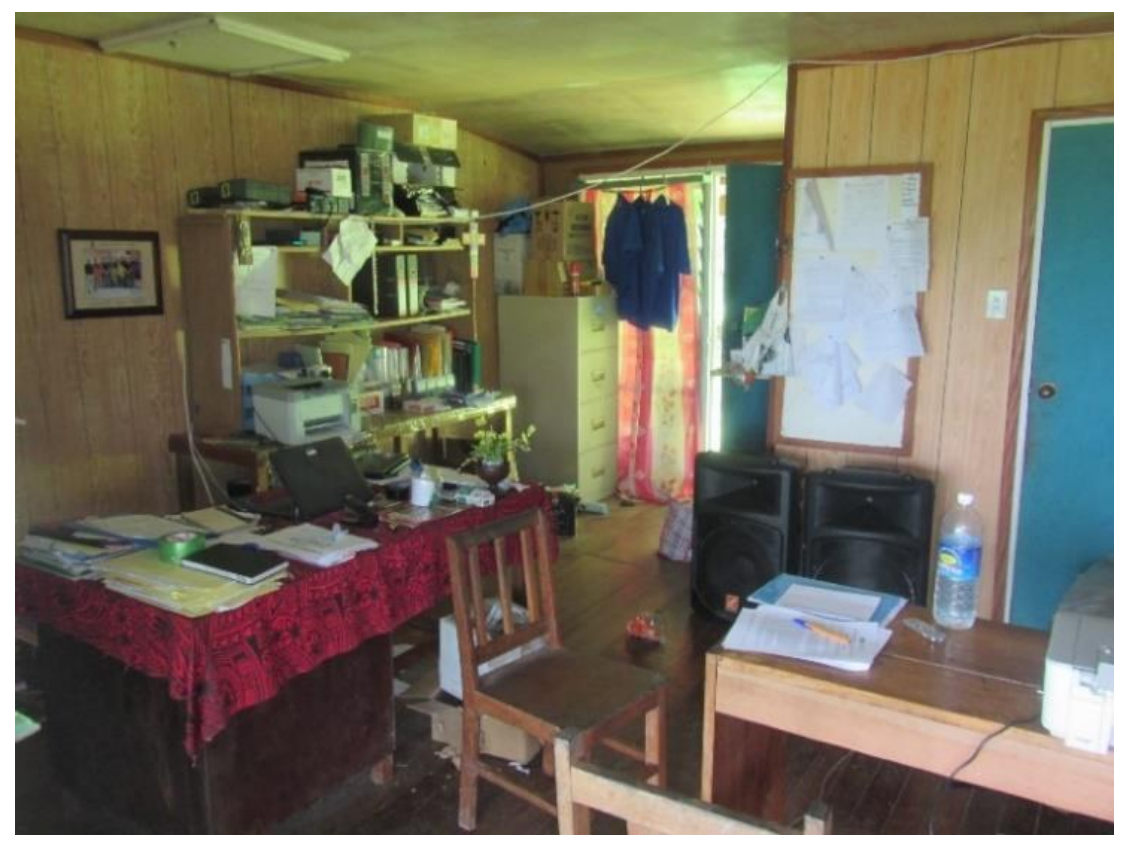

Figure 9. Administration offices at St Dominic's RTC (Photo credit: Finn Egan).

so some effort had gone into clarifying RTC staff responsibilities. As noted by one administrator,

"Me givim job descriptions long all staff here, sometimes verbally sometimes written ... this way how you [will] doim, this way how you [will] doim, you must report to who, this is the structure. No structure before [START training]" (Interview, 2/6/19, Tabaka).

"I now give job descriptions to all the staff, sometimes verbally sometimes written ... this is what to do here, this is what you will do there, who you report to, this is the structure. There was no structure before [START training]" (approximate translation, Finn Egan)

Although beneficial in giving staff clarity on their work expectations, I did notice that codification of responsibilities impacted on staff participation in the RTC 'community'. Some staff felt less obliged to facilitate extracurricular activities if it was not part of their job description, where they may have been happy to take part previously. This gave the impression that job descriptions had been written without consultation from staff, which may have impacted on their relevance to the community setting. A formalised role in an informal setting meant that instructors were confined to set expectations and less willing to be flexible to community needs. External understandings of roles and processes therefore conflicted with informal structures that contributed to the RTCs. This was also evident in 
other policies developed at the RTCs. Policies dealing with student discipline, for example, were not consistently followed for all students or overruled by leaders at times, which led to confusion around their implementation (Interview, 31/5/19, Tabaka).

A final change in some RTCs was in improving transparency, particularly regarding financial reporting. Along with curriculum development, accountability is one of the main reasons that RTCs have not received more substantial government funding in the past. As noted by an administrator at St Dominic's, for example,

"One thing I noticed this year ... when we spend I do not like to use cash, I like to use a cheque. That's proper record-keeping and I like that way, and I slowly started

it with the SIG grant; I never use cash I use a cheque" (Interview, 28/5/19, St Dominic's).

Having organisational accountability made it easier to keep track of spending and created more transparency in St Dominic's reporting than previously. This type of recording and accountability had improved at all the RTCs visited, with Tabaka now having a fulltime bursar, and Kaotave and Vatu maintaining much more comprehensive records than previously according to their external Education Authority offices (Interview, 17/5/19, Honiara). Having clear accountability structures benefitted external accountability, giving credibility to the RTC model, and also helped with internal transparency. There are therefore several changes that have taken place in the ways that administrators operate from external learnings over the last five years.

\section{Instructor impact and change}

As with administrators, there have also been changes for RTC instructors over the last five years. As part of this research, I tried to interview instructors who both had and had not taken part in external skills training to get a sense of the difference in experience between both. All RTCs visited had at least two instructors who were part of training, with regular staff turnover meaning that many trained staff had moved elsewhere. Another site visited had all but three of its instructors that had taken part in training, which highlighted some disparity in participation across different RTCs. Overall, interviews with participants showed that there have been both internal and external developments in the quality of teaching at RTCs over the last five years. Key learnings are highlighted below. 


\section{Teaching approach}

A major area of difference was in teaching approach, with most instructors gaining confidence since attending training (Figure 10). This was particularly true for younger instructors who, where they took part, took the opportunity to learn from their more experienced counterparts in other RTCs, as well as from New Zealand instructors (Interview, $6 / 5 / 19$, Tetere). For one instructor START training was the first opportunity she had ever received to practice teaching strategies and content. Having clear teaching strategies to apply with her students was therefore vital to improving her teaching quality (Interview, $7 / 5 / 19$, Tetere). As well as younger instructors, older instructors reported greater confidence in their teaching. As noted by a staff member, "I notice something different. Especially how [instructors] utilise the skills" (Interview, 21/5/19, Vatu). Many instructors reported learning to adopt a more practical approach. As noted by one,

“In the past I wasn't really good in engaging students for practical ... [after training] I'm involving students in practical work ... Even myself I feel it, students are really interested ... I think I'm doing different things from what I have learnt" (Interview, 28/5/19, St Dominic's).

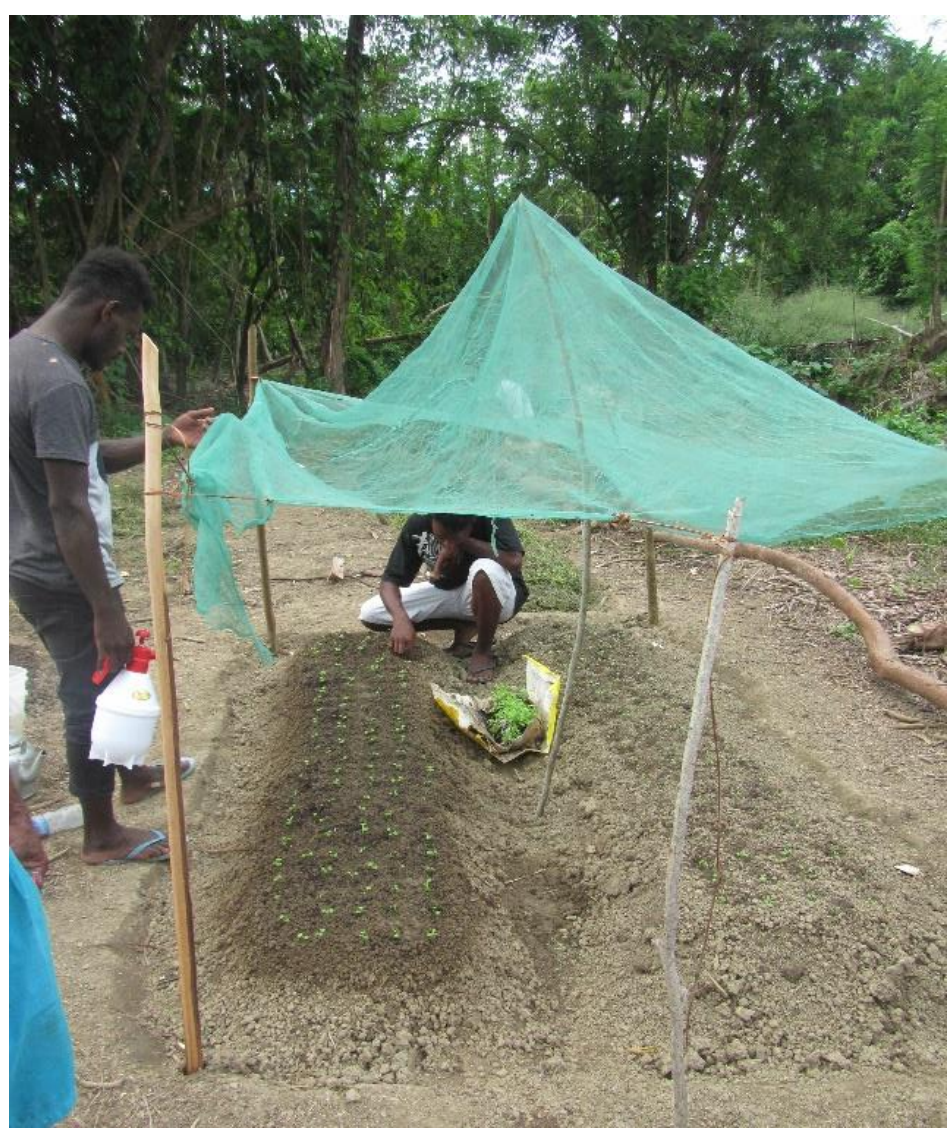

Figure 10. Practical learning in the plant nursery at Kaotave RTC (Photo credit: Finn Egan). 
Prior to training sessions, many focussed on theoretical aspects of learning, and external encouragement to balance this with practical work was viewed as a positive step for both teacher and student learning. Many teachers spoke of their prior ability to adapt to different types of learning, noting clear differences in strengths between early school leavers, who had better practical knowledge, and late school leavers, who had better theoretical skill (Interview, 9/5/19, Kaotave). Encouraging more practical work therefore gave students a more holistic grounding in course content. I noted an interesting difference in student interests between Tabaka and the other RTCs visited regarding these differences in learning strengths. Students at other RTCs generally reported that they were most interested in the practical aspects of learning because many struggled with the written nature of theory. However, this was different at Tabaka, with students mainly being interested in the theory component (Interviews, 31/5/19, Tabaka). The reason for this was that most students at Tabaka, as a Technical Institute, were late school leavers and aiming to go into further studies. In this environment, theoretical knowledge was a more important skill whilst most at the other institutions were looking to go into practical work. RTC instructors therefore had to respond to different interests across student intakes and localities.

\section{Teaching content}

As well as teaching approach, instructors across different RTCs adapted their teaching content in response to external training. Across all the different skills trainings, consistent learnings were the importance of health and safety and incorporating lesson plans into teaching. As noted by one instructor,

"I try my best to talk about safety to my students because it's very important to care for yourself and care for others ... When we use barbed wire ... we should store it in a proper place otherwise next day or next time when we're working there then we step on it, the barbed wire hurts us or nails our foot" (Interview, 8/5/19, Tetere).

Other examples of safety discussed by instructors in a Solomon Islands context were ensuring a two-metre distance between people when using machetes for gardening and, at Tabaka, the use of safety harnesses in construction. Instructors were therefore able to use external learnings in contextually relevant ways.

As well as safety, lesson planning was consistently highlighted by RTC instructors as a major external learning. Using their own knowledge alongside content resources from START, 
instructors found that structuring lessons was easy to do and helpful for their teaching. As noted by one instructor,

"When I teach I use a lesson plan. Just teach, follow the lesson plan ... It's different from Solomon Islands approaches, it's easier for us. Not as much writing ... when I observe this lesson plan [the instructor] gave us it's very short" (Interview, 6/5/19, Tetere).

As well as being easier to follow, other instructors noted that clear lesson plans helped them to focus more on teaching rather than trying to remember content. This helped their classes run smoother, creating a better learning environment for their students. Instructors were therefore able to incorporate external approaches into their own 'knowledgebase' to improve the quality of their teaching (Gegeo, 1998; Gegeo \& Watson-Gegeo, 2002).

\section{Relevance of external 'knowledge'}

Instructors discussed their use of external content, although their ability to do so varied from place to place. Table 7, below, sets out the feedback given by participants, including on the relevance of content and what they thought was missing. Carpentry and financial capability teaching resources were considered the most relevant, with tools and skills being easily transferable and incorporated into a Solomon Islands context. Examples of this included the use of basic hand tools for furniture instruction, which reinforced previous instructor knowledge, and the incorporation of budgeting and basic numeracy into teaching. This last point was also important for agriculture instructors, who incorporated this aspect of teaching into content related to the marketing of produce at community markets. As one noted,

"For the few years when I teach I don't have any activity, just straight in the practical, but now in the class before we continue the lesson sometimes we do little activities, games to relate the topic ... Some shortcuts, how to find out how many plants are in one hectare, that's what I learnt" (Interview, 6/5/19, Tetere).

Despite the benefits of content received, there were barriers for some in the use of START resources. A major barrier was in the distribution of resources through USBs, such as those distributed as part of agriculture trainings. Many instructors did not have access to a computer at their RTC or did not have the skills themselves to access those materials (Interviews, 6/5/19, Tetere). This meant that, although those with skills and access greatly benefitted from teaching resources, some had very little benefit from these external resources. Another barrier for some was language, with some participants finding difficulties 
using English as part of teaching (Interview, 31/5/19, Tabaka). The financial capability resources were the only ones translated into Pijin, which participants commented on as a benefit for their own knowledge and future use (Interview, 8/5/19, Kaotave). These examples help to highlight some of the barriers inherent in the communication of 'knowledge' cross-culturally, with not enough consideration being given to the needs of all stakeholders in community settings.

Table 7. Instructor learnings from START skills trainings, and their relevance to instructors for teaching in a Solomon Islands context

\begin{tabular}{|c|c|c|}
\hline $\begin{array}{l}\text { Relevance to } \\
\text { teaching } \\
\text { START Course }\end{array}$ & Relevant for SI teaching & $\begin{array}{l}\text { Less relevant for } \mathrm{SI} \\
\text { teaching/missing content }\end{array}$ \\
\hline Building/carpentry & $\begin{array}{ll}\text { - } & \text { Basic and electronic hand } \\
\text { tools } \\
\text { - }\end{array}$ & $\begin{array}{l}\text { Less relevant } \\
-\quad \text { High-grade industrial } \\
\text { equipment } \\
\text { Missing } \\
-\quad \text { Limited focus on teaching } \\
-\quad \text { Some did not travel to NZ }\end{array}$ \\
\hline Mechanics & $\begin{array}{ll}- & \text { Outboard motor content } \\
- & \text { Basic and electronic hand } \\
\text { - } & \text { tool resources } \\
\text { - } & \text { Lesson planning } \\
\text { - } & \text { Practical knowledge } \\
& \text { development }\end{array}$ & $\begin{array}{l}\text { Less relevant } \\
-\quad \text { Automotive vehicle content } \\
\text { Missing } \\
-\quad \text { Limited focus on electronic } \\
\quad \text { engines and equipment } \\
-\quad \text { Some did not travel to NZ }\end{array}$ \\
\hline Agriculture & $\begin{array}{ll}\text { - } & \text { Agrobusiness } \\
\text { - } & \text { Planting and composting } \\
\text { - } & \text { Pig and chicken resources } \\
\text { - } & \text { Fiji trip/agriculture systems } \\
\text { - } & \text { Agriculture-related literacy } \\
& \text { and numeracy activities } \\
\text { - } & \text { Lesson planning } \\
\text { - } & \text { Health and safety }\end{array}$ & $\begin{array}{l}\text { Less relevant } \\
\text { - NZ trip/agriculture } \\
\text { equipment and machinery } \\
\text { - Cattle and sheep-focused } \\
\text { content (raising, } \\
\text { insemination, milking) } \\
\text { Missing } \\
\text { - Cohort } 1 \text { did not travel to Fij } \\
\text { and wished they had }\end{array}$ \\
\hline $\begin{array}{l}\text { Financial } \\
\text { capability }\end{array}$ & $\begin{array}{ll}\text { - } & \text { Budgeting skills } \\
\text { - } & \text { Saving skills } \\
\text { - } & \text { Lesson planning }\end{array}$ & $\begin{array}{l}\text { Participants were happy with the } \\
\text { level and content of training, } \\
\text { some suggested a greater } \\
\text { incorporation of livelihoods into } \\
\text { the content. }\end{array}$ \\
\hline
\end{tabular}

In terms of the content itself, instructors found training useful in increasing their general knowledge of their subject, although in some cases this was more on a personal level than for teaching purposes. As noted in Table 7, there were aspects of almost all courses that some did not find useful, such as the scale and types of machinery used in New Zealand agriculture. However, participants noted that it was still important to understand these 
differences and make judgements of relevance to their own contexts for themselves. Some participants on the carpentry and mechanic courses did not travel to New Zealand, meaning they were unable to build a similar knowledge base to those that did. Agriculture participants from the first round of training also expressed disappointment at not travelling to Fiji, believing that this experience would have been more relevant to their own context than spending the whole time in New Zealand. As noted by one instructor,

"When I went over to New Zealand I saw a lot of livestock. Some of the things there, I think, maybe it's not relevant to us here in Solomon because they are almost doing things with a [power] plant ... Maybe the approach and big scale, because of the big scale ... we should start in a small scale" (Interview, 22/5/19, Vatu).

An important lesson from this is the relevance of content to participants. Although New Zealand-based mechanic and carpentry industries were relevant to the Solomon Islands context, the same was not true for agriculture. Adapting to this, as START did, by sending agriculture participants to Fiji instead, is a good example of iterative practice that responds to changing local needs. The location of Solomon Islands trainings was also important, with one participant noting that START improved this over time:

"Example, the previous agriculture training ... first phase ... they did everything in Gizo ... St Peter's. No plantation coconut long there, no plantation cocoa there, yeah? So taim olgeta go doim training there what na lukim what na?... [At] Tetere, different activities in agriculture" (Interview, 21/5/19, Vatu).

"As an example, the previous agriculture training in the first cohort did everything in St Peter's RTC in Gizo. There's no coconut plantations there, no cocoa plantations there, right? So, when they go do training there what are they going to see?" (approximate translation of excerpt, Finn Egan).

Having trainings in relevant locations for the content led to more personal development for participants and better learning outcomes overall.

\section{Knowledge 'conversion'}

There were mixed results in terms of instructors converting knowledge obtained from trainings into their own contexts. In some cases, such as at Tabaka, instructors from most courses were able to apply their learnt knowledge with students. Key to this, as noted by interview participants, was having the infrastructure and practical teaching resources to do so. The construction of a mechanic workshop at Tabaka under START's infrastructure 
component, for example, contributed greatly to students' learning experiences. One student noted that having more time focused on practical aspects of learning meant they learnt more relevant things for their own futures (Interview, 31/5/19, Tabaka). Although infrastructure created a more positive learning environment, this was complemented at Tabaka by having relatively greater access to teaching equipment. Tabaka's mechanic course had the most outboard motors, physical textbooks and other resources of any institution visited, which meant that students had more opportunity to participate in classwork. Whilst their smaller land area compared to other institutions meant that finding space for practical agricultural training was often difficult, they were therefore able to leverage other strengths to benefit the RTC community.

This contrast in resourcing across different courses was visible at the other RTCs visited as well. With the large amount of land available at all but Tabaka, agriculture courses were generally the best resourced. A large land area meant that agriculture departments could put learnings into practice. At Vatu, for example, instructors had the use of crop plantations and gardens, meaning that students were never short of work. Having this resource in place also allowed them to try other external learnings, including using ground septic tanks to collect pig manure for organic fertiliser (Interview, 22/5/19, Vatu). A key aspect of this was that, unlike some other courses at Vatu, the agriculture department had consistent income generation, which gave them the ability to resource themselves as needed. The Vatu building, mechanic and electric departments, in contrast, did not have any consistent income generation. The effect of this was that despite constructing a workshop using external funds, they were reliant on their administration for tools and parts, which it was not always in a position to provide.

\section{Knowledge sharing}

Along with knowledge conversion, there were variances in how, if at all, external knowledge was shared within the RTCs. At the extreme, there were cases in which those who took part in external trainings did not discuss their learnings with other staff in their departments at all, or only did so when it was not related to their own work. An example of this was in an agricultural department, where some information on livestock was passed on to another instructor to support in their lesson planning. However, the instructor who had taken part in training would not share the source of that information, meaning that they were later unable to find further information to support their teaching (Interview, 27/5/19, St Dominic's). This showed hidden agendas at play in the community setting, with external 'knowledge' being 
used for purposes of power at the community level (Escobar, 1995), creating resentment between those who had been part of trainings and those who had not. Learnings, as a result, were not so widespread across some RTC communities.

Knowledge was passed on more willingly in institutions and departments where communication between staff was more open and consistent. Staff who did not participate in trainings from Vatu, for example, were noticeably less resentful of their peers, and a big part of this was that they still shared in the learnings of others. As noted by one instructor,

"Friend bilong me na hemsa story for me wanem hemi go experience ... So when hem come back hemsa story for me then ... wanem hem doim, olgeta buildim disfela leaf hut long compost here bilong pikpik ... Staka things hem story for me" (interview, 20/5/19, Vatu).

"My friend told me about what they experienced [on training] ... When they came back they told me ... what they did, about building this leaf hut for pig composting ... She told me lots of things" (Approximate translation, Finn Egan).

Although this instructor wished there had been opportunities for her to do similar training for her own course, she did not see it as unfair that others had had that opportunity. There were also cases where instructors took external learnings back to their own departments with very positive results. This was visible in the St Dominic's mechanic department with instructors having regular discussions of their learnings, even doing peer observations of each other and trying to incorporate videos and other electronic resources into their teaching (Interview, 27/5/19, St Dominic's). Ongoing supporting of each other allowed them to identify areas for improvement in each other's teaching, such as body language, helping them to improve over time and ensure that learnings stayed within the RTC. There were therefore many examples of positive impact in terms of 'knowledge' transfer to RTC instructors.

\section{Youth impact and change}

Finally, there have been changes in student experience at the RTCs visited, although the overall mentality of students about their future prospects remains similar to in 2015 . As noted previously, there were challenges in assessing the impact of student education on home communities due to the logistical challenges of visiting all areas of the Solomon Islands. However, impact on the student experience is something many staff touched on, and 
anecdotes from students also demonstrate the benefits RTC education has had for their communities. The following sections highlight some of these learnings.

\section{Personal development tools}

Interviews with instructors and students show that RTC education quality has improved over the last five years (Figure 11). As with instructors, students were also conscious of the quality of teaching, equipment and infrastructure at their RTCs, and open in their praise and, in some cases, criticism of this. Students at Kaotave, for example, were happy with the visible developments targeted at their education, including work improving the male dormitory, and the construction of new classrooms (Interview, 9/5/19, Kaotave). They also valued the skills learnt through their own contributions to the RTC 'community', one commenting that he would use profiling skills he was learning in the construction process to help build his own home when he returned to his village (Interview, 10/5/19, Kaotave). Students across the RTCs found the content interesting and thought it was useful for their futures, although this depended on the opportunities they had to practice their skills within class time. As noted by one student,

"Mi findim electrical hem good ... Mifela lilebit no garem good equipment too, yeah? So mifella rely nomoa long school, olsem if school providim the equipment

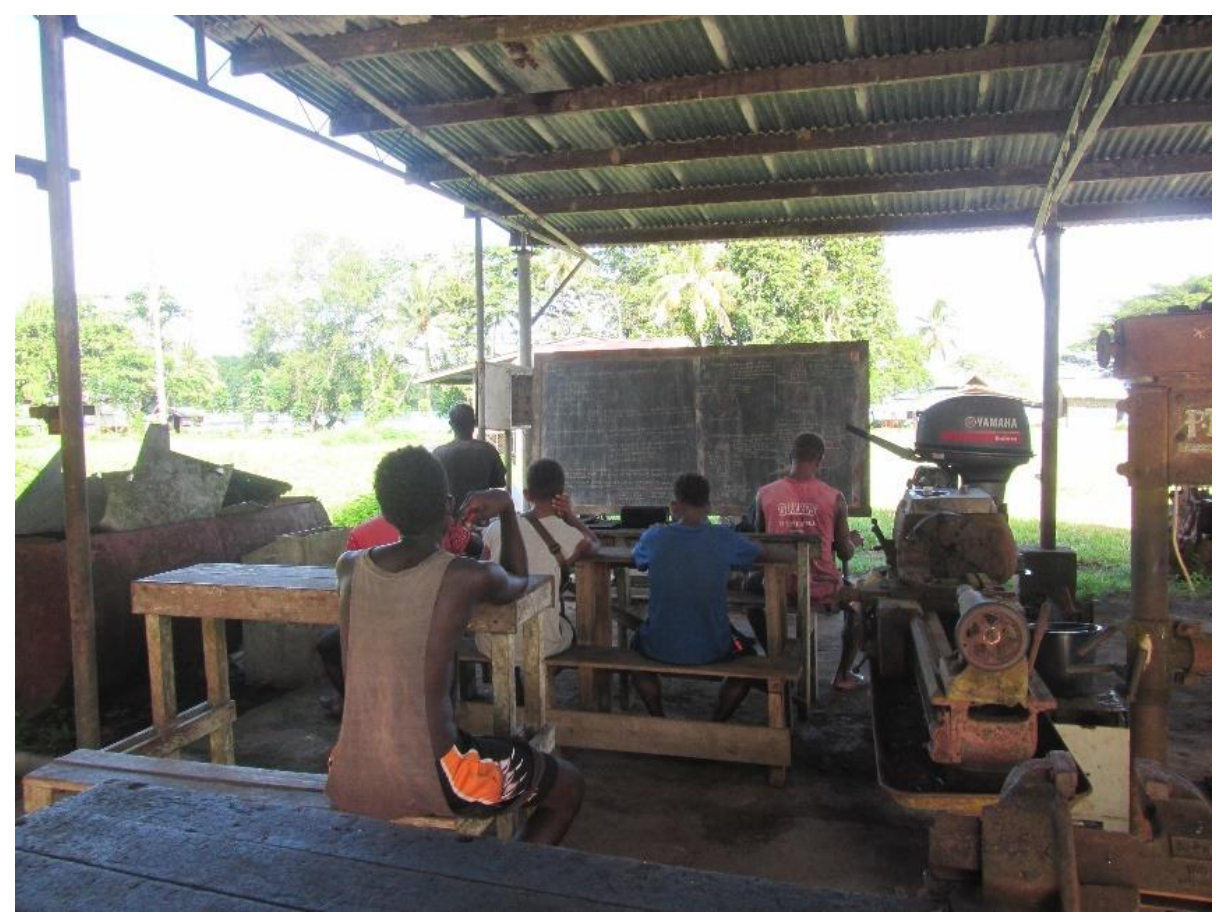

Figure 11. Students take notes in a mechanic teaching area at St Dominic's RTC (Photo credit: Finn Egan). 
for mifela usim bai mifela doim practical nomoa bai stay theory nomoa ... Mifela have to share" (Interview, 31/5/19, Tabaka).

"I enjoy electrical ... we don't have too much equipment. We rely on the school, so if the school provided the equipment for us to use we would just do practical and leave theory ... [Instead] we have to share with others" (approximate translation, Finn Egan).

This sentiment around learning practical skills was shared by students across all the RTCs, and something which they were actively trying to address. Though the building-carpentry department at Vatu, for example, had recently been fully equipped with a range of basic hand tools, the mechanic and electrical courses had very little to work with. Tools and other resources had been purchased for the electrical department, but these had yet to arrive, while the mechanic department was working with administrators to do the same. Administrators and instructors were therefore trying to respond to student needs. Whilst this limited current student learning, given that tools were only arriving halfway through the school year, it spoke well to future student learning. Vatu staff noted that funding their own equipment was much easier than five years ago as a direct consequence of improved incomegeneration.

As well as improving RTC education, there is further evidence that the RTC model supports diverse livelihood opportunities. Anecdotally, participants across all the RTCs spoke of connections they had, such as family, friends and former students, who were now either supporting their communities locally or in formal employment (Interview, 7/5/19, Tetere). Formal employment included in trades, construction, plantations and hotels, whilst informal employment included marketing, transport and community-based activities. I met RTC graduates during my time in the Solomon Islands, including a St Dominic's graduate who was working on a construction site in Gizo. Stories from RTC staff and students, as well as my own encounters in urban centres, show that there are tangible outcomes for RTC graduates, with their education supporting them into future formal and informal livelihood opportunities.

\section{Work ethic and accountability}

As well as the practical skills taught to students, another key tool identified by students was the development of their 'work ethic'. This emphasis on character shaping, which Sanga (2019) sees as a key component of Melanesian education, was rated highly as a purpose by RTC staff and students. Both groups saw tangible personal changes from contributing to the 
RTC community. Students at multiple RTCs said that they struggled with the workload and expectations of the RTC community when they started, but accepted it as part of their education and learnt from those expectations (Group interview, 21/5/19, Vatu; Interview, 9/5/19, Kaotave). The RTC community environment also benefitted students upon returning to their communities. A second-year student at St Dominic's talked about continuing his routine of morning gardening when he returned for the holiday period, and the sense of pride this gave him in supporting his family (Group interview, 27/5/19, St Dominic's). RTC education's impact was therefore both external, in the practical skills learnt, and internal, in the personal growth of students.

Alongside the development of work ethic, some RTCs worked to hold students accountable for their actions as part of holistic personal development. At Vatu, entire year groups had been sent home for bad behaviour in the most extreme cases (Interview, 21/5/19, Vatu). Although it was my initial impression that these kinds of consequences were too strict on students, those I talked to that had been suspended for a year spoke of this experience positively. One noted, for example, that the experience helped him to confront personal issues with alcohol because of the time it gave him to take stock of his life (Group interview, 27/5/19, St Dominic's). What may, in New Zealand, have been considered a significant loss of time, had less significance to RTC students. However, administrators at RTCs emphasised that these kinds of suspensions were only in extreme cases. One noted that there was a risk of 'spoiling' students by allowing them to return home, instead of helping them address their actions (Interview, 28/5/19, St Dominic's). All RTCs visited had rules and expectations that students said were clearly explained as part of their orientation, which contributed positively to student accountability overall.

Finally, an internal change identified for many students interviewed was in their faith and outlook on life. Students at Kaotave highlighted how their own engagement in the Church through their RTC gave them a more positive outlook on their own circumstances. One student spoke of their role in the RTC's liturgy group, which had changed and made them happier overall (Interview, 9/5/19, Kaotave). A reason for this was that the environment and culture within the RTC community encouraged less 'trouble'. At St Dominic's, students valued their weekly personal development course with the Marist Brothers, which gave them a lot to think about for their own growth (Group interview, 26/5/19, St Dominic's). Some RTC communities, therefore, gave students the space to grow in ways beyond a simple economic lens. The SSEC system at Kaotave encouraged an equal role in religious proceedings, whilst students at St Dominic's spoke highly of their personal development leader. In contrast, this 
positive relationship was not present in the same way at Tabaka, meaning that students were less responsive to RTC community systems and structure. The most impactful aspect in this regard was positive internal relationships.

\section{Becoming 'someone' (for community impact)}

The RTCs' pastoral role, and the development of practical skills, were not only key to addressing the stigma that many students felt from having left school early, but also in addressing the sense of burden many felt they created for their communities. In particular, male students and staff at St Dominic's and Tabaka spoke of wanting to 'be someone', an expression of a wish to be a contributing and esteemed member of their respective communities (Group Interview, 20/5/19, Vatu). This idea is quite reflective of the 'big man' system that is central to Melanesian culture, where worth (for men in particular) is derived from an ability to create and redistribute 'wealth' across yours and others' communities (Lindstrom, 1981). The skills developed at RTCs were seen as a pathway for many students to employment, either formally in industry or informally at the community level, giving them the means to then contribute to their own families and communities. This sense of purpose was noted in interviews with female students, although more targeted at being able to provide at the family level. As noted by an RTC graduate, female students were more interested in agriculture or life skills courses because if they chose building then other housework, such as gardening and cooking, would still take precedence over this (Interview, $7 / 5 / 19$, Tetere). This speaks to either the historical importance of women working for their families in Melanesian culture or as an ongoing challenge for Solomon Islands women, and is a key point of consideration for how and why RTCs operate across genders. Melanesian gender roles and norms are not the focus of this thesis, nor do I believe it my place to comment on which of these two perspectives is closer to the reality. However, it is relevant to understanding student course choices at the rural community level. Female students at Tabaka, where most came from urban settings, were more likely to take other courses. Regardless of gender, RTCs were seen as the main, and sometimes only, avenue of opportunity for young people to work towards a higher standing in their local communities.

Anecdotally, there is evidence to suggest that students do make tangible contributions to their communities in various ways using skills developed at the RTCs. Many second-year students spoke of passing on knowledge to others in their communities after their first year of study, working in gardens and building houses with their families using the skills they had learnt (Group interview, 21/5/19, Vatu; 26/5/19, St Dominic's). Interviews with RTC staff 
showed that student contributions and outcomes also extended into other areas, such as education. Many RTC instructors at the sites visited were graduates themselves and had gone into teaching on the suggestion of their own teachers. Almost all the instructors interviewed at Vatu, for example, had gone into RTCs after leaving the formal education system early. At Tabaka, one student I spoke to was going through this process:

"I decide to become a teacher because ... maybe I'm too getting old now for these heavy jobs. Maybe it's better if I finish from [Tabaka], complete this study, graduate and go to the SINU for further studies ... let's say, a diploma in teaching ... It is always our culture to have this idea of one good thing deserves another ... Some of these teachers even encourage me, 'oh yes, if you want to become a teacher, and then you can't come and help here, then we have other RTCs around here that belong to this United Church" (Interview, 31/5/19, Tabaka).

Encouraging RTC graduates into teaching ensured that the RTC community model was able to sustain itself through encouraging a future pool of instructors to pass knowledge on. The impact of this was not only employment opportunities for graduates in a communallyrespected field, but also facilitation of long-term community development across the Solomon Islands; RTC graduates therefore had various means to 'become someone' in their own contexts.

\section{Ongoing RTC community challenges}

Although the RTC community model has many positive impacts, this is not felt equally by all actors across different community contexts. Participants cited various ongoing challenges, both external and internal, to the effective operation of the RTC community model, where little change had occurred over the last five years. Key challenges for the various participants groups are highlighted below.

\section{Ongoing administrator challenges}

Despite positive impacts of external programming and internal 'development', some ongoing challenges appear to still impact on administrators. One of these is a fine line between effective and restrictive financial recording and accountability. Where St Dominic's and Tabaka had some freedom in their spending, Vatu and Kaotave administrators were highly restricted in accessing school funds. Both RTCs had Church Education Authority (CEA) officials as signatories to their Solomon Islands government (SIG) grant, meaning administrators 
required external sign-off on all operational spending (Figure 12). This created several issues, as highlighted in the following words of a Kaotave administrator:

"The Authority is in control of our finance ... I only collect the school fees and then I give them for recording and banking ... I have to go and ask for the balance and if we need anything we go and receipt ... and then they will release the payments. So if we go, it's very annoying sometimes, if we go and those responsible in signing of the cheque they are not there, we have to wait for the whole day and even, sometimes, we have to come back and go the next day before we receive the payment" (Interview, 8/5/19, Kaotave).

The administrator's words help to show how too much oversight impacts on the ability of the RTC model to run effectively. In the case of Vatu, a similar accountability system for the SIG grant through the CEA meant it was not financially viable for them to travel and claim it, meaning that they did not bother accessing it at all.

As well as accountability systems, another ongoing challenge is in creating holistic consultation systems within the RTC communities. Although there have been clear, and at times formal, changes in communication between staff at some institutions, this had yet to extend to include students. There were leadership positions for students in religious and extracurricular activities, but student leaders were regularly left out of most operational

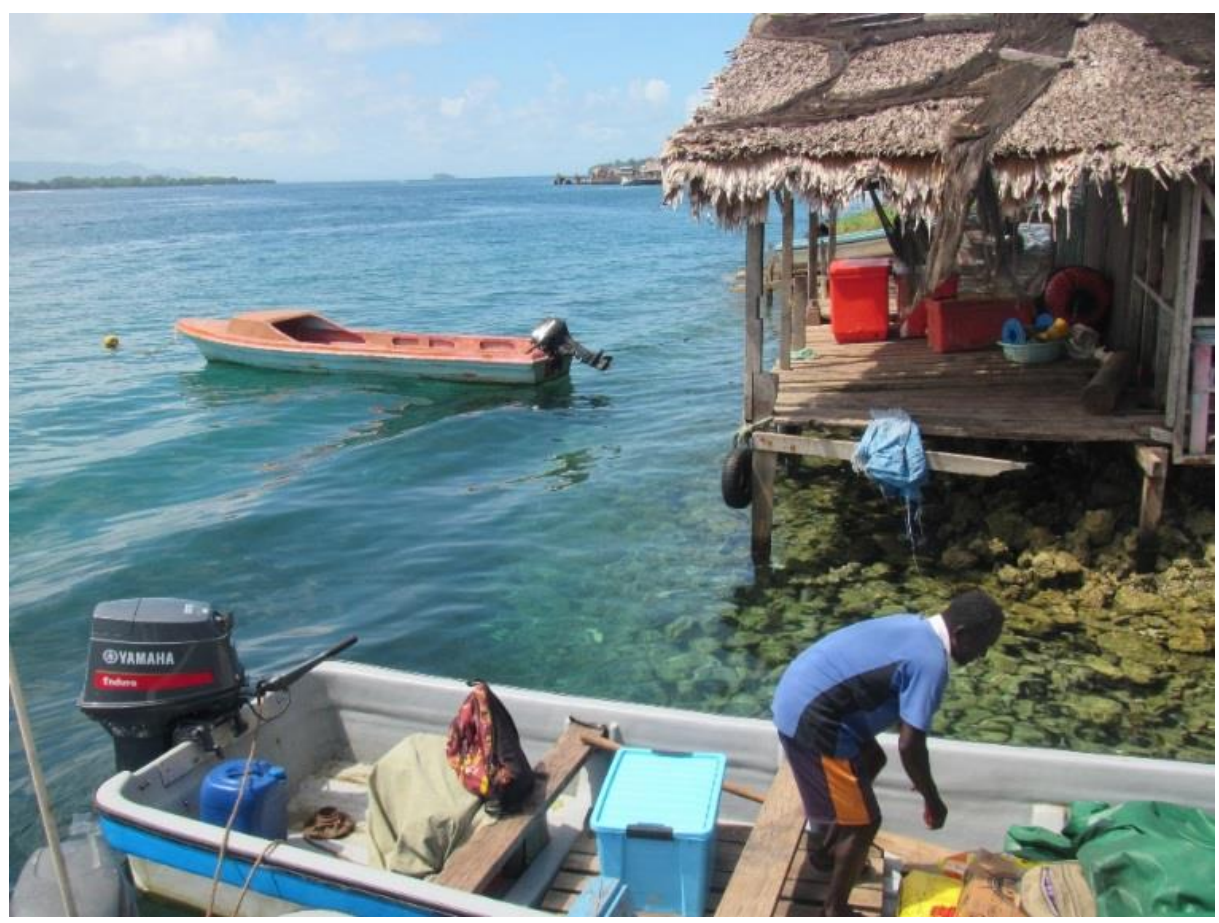

Figure 12. St Dominic's RTC staff travel at least 50 minutes by boat to Gizo for any shopping and administration needs (Photo Credit: Finn Egan). 
discussions. Administrators viewed student issues and interests being primarily around discipline, when it was food, accommodation and teaching that most students prioritised (Interviews across all RTCs). This meant there was an important perspective that students had to offer to the RTC communities that was being overlooked. St Dominic's staff expressed plans to set up regular student-administration meetings, but this had yet to take place when I visited (Interview, 28/5/19, St Dominic's). Although there were many positive changes and developments visible for RTC administrators over the last five years, there are also areas that remain for consideration.

\section{Ongoing instructor challenges}

Along with the positive changes that have taken place for RTC instructors, there remain some challenges for them in their work. Firstly, there are few opportunities for instructor professional development outside of external trainings like START and Skills for Economic Growth (S4EG). Some instructors noted that there were scholarship opportunities available to them through their Education Authorities. However, these were only awarded annually to one instructor per region across the relevant denominations' RTCs, primary and secondary schools (Interview, 17/5/19, Honiara). External 'development' trainings were therefore the only form of professional development some instructors had received over the past five years, with many wishing there were other opportunities for this. Further education was important for pay increases to support families, but also to improve personal knowledge and teaching ability for students.

Internally, Tabaka was the only institution with a formal training system and roster in place for its staff. As noted by one of the administrators, "I had organised in-house trainings for staff using tutors. Those who have skill in some areas, I had asked them to facilitate..." (Interview, 30/5/19, Tabaka). Trainings covered various topics, ranging from understanding the new curriculum being developed under the S4EG programme to general knowledge on the use of computers, and were held weekly. This ongoing training was particularly important for instructors at Tabaka given the institution's transition to a 'Technical Institute', and the new expectations this created. Staff were able to upskill and share knowledge amongst themselves to improve the institution as a whole. Although some professional development took place in the other RTCs visited, it was informal and outside of working hours.

As well as internal networks, the focus of external development programmes, namely START and S4EG, overlooked some key courses offered at the RTCs. The most notable of these courses was life skills, which is significant given the course specifically targeted female 
students. Caritas staff acknowledged this as a major oversight in the design phase that was a consequence of wider New Zealand 'development' priorities at the time. Electrical was the other notable course not targeted as part of external programming. It was my understanding that it was not commonly offered in 2015 , which was the main reason for it being overlooked at the time. Although many life skills instructors were included as participants in START financial capability training, this did not target their own specific needs. Life skills courses, instructors and students have therefore benefitted much less from external learnings overall, both in terms of education and teaching resources. Although there have been clear benefits for instructors across the RTCs visited, there are still gaps in instructor support.

\section{Ongoing student challenges}

Although the changes that have taken place at some RTCs over the last five years have clearly benefitted students, there are ongoing challenges that could be addressed. One of the primary areas that could be improved, as discussed previously, is a greater focus on student welfare. Whilst students were happy to contribute to RTC community operations they also expected to be taken care of as part of this mutually beneficial relationship. At St Dominic's, there was some student resentment in group interviews about expectations placed on students (Group interview, 27/5/19, St Dominic's). Unlike at Vatu or Kaotave, infrastructure priorities were targeting staff housing, which many students believed was already in a better condition than the dormitories, kitchen facilities or classrooms. Students at multiple RTCs also noted teacher absenteeism as an issue at times, which gave the impression their own work was being taken for granted (Group interview, 24/5/19, St Dominic's). Staff's focus on student welfare was also more directly targeted at those with problems external to the RTC, such as those from "broken homes" or "complicated pasts" (Interview, 6/5/19, Tetere; $28 / 5 / 19$, St Dominic's). The effect of this was that the day-to-day lived experience of students at the RTCs was often not considered, leading to underlying and unspoken conflicts that could have been avoided if discussed.

\section{Community 'knowledge': change and impact?}

Having examined the changes and ongoing challenges from the last five years, I now propose to turn attention to the impact that external programming has had on local 'knowledge', RTCs and their role as facilitators of community development. There have been many significant improvements made to the quality of education and management at the RTCs. Administrators and instructors at all the RTCs visited identified how they were able to incorporate external 'knowledge' into their local processes, supporting more effective 
teaching and administration in the RTC model. Student experiences also supported this, with many highlighting the benefits of increased practical teaching that external development programmes had both encouraged through training and facilitated through improved infrastructure and resources. These experiences help to highlight ways in which external programming can feed into community development models without co-opting the process (Escobar, 2001). Key to this success was giving agency to RTC training participants to decide the relevance of 'knowledge' to their own contexts, allowing them to adapt in contextuallyrelevant ways (Gegeo \& Watson-Gegeo, Whose knowledge? Epistemological collisions in Solomon Islands community development, 2002). Areas of most success were where external ideas were incorporated in to current practice, rather than usurping previous 'knowledge'. As a result, there have been many cases over the last five years in which RTC 'development' has led to improved outcomes for various members of the RTC model, as well as for others across the Solomon Islands.

Despite these clear successes, the level of positive impact has varied across and within different institutional contexts. Where many staff adopted the tools presented to grow their own institutions, others have not done so for various reasons either within or beyond their own control. There was, for example, a clear distinction between RTCs with open organisational cultures, which promoted communication and knowledge-sharing between staff, and those where 'knowledge' was retained by a select few. This helps to reinforce the complexity of internal community processes, challenging notions of uniform experience and interest at the community level (Escobar, 1995). The danger in highlighting this point is that $I$ run the risk of shifting blame to the community for failures in 'development' practice (Apffel-Marglin \& Marglin, 1996). Variances in experience across and within different communities suggest that there is scope for organisational culture to play some part in these impacts, but another way to frame these failures of 'development' are as successful examples of local agency (Esteva \& Prakash, 2014). Participants interviewed were often clear on what was and was not useful to them in their own settings, suggesting it is simply a consequence of the 'knowledge' incorporation process that not everything will be used (Apffel-Marglin \& Marglin, 1996). The role of 'development' in this process is therefore as an exposure tool, with the challenge being to ensure that a uniform discourse is not forced on local actors. This helps to highlight complexities at the community level that should not be overlooked in 'development' practice.

Along with internal factors, it is also important to consider how 'development' programming itself contributes to any challenges in discussions of 'knowledge'. Overarching discourses 
have been shown to negatively impact on processes of 'development' at times, and there are some key learnings that can be drawn from the RTC case. Firstly, there is a clear need to engage RTC staff with content that is not only relevant to their local contexts, but also accessible to them in their own community settings. Whilst content and training venue relevance improved over time in response to local needs, there remained evidence of assumed 'knowledge' on the part of some external programmers regarding language, computer literacy and accessibility. This is indicative of challenges in 'knowledge' transfer identified previously, which are often so ingrained in 'development' discourse that they can be hard to overcome (Wilson, Mann, \& Otsuki, 2003). Even when 'development actors are willing to adapt their programming, as with the prior examples, there are still sometimes constraints on how far this can go. As well as this, the disparity of support across courses under external development was visible, with a clear oversight of START being the differing needs and roles of women in Solomon Islands community settings. The challenge in this regard is in identifying and prioritising needs for all at the community level, whilst also being constrained by external 'development' forces (Jing, Mendez, \& Zheng, 2019). External decisions like this have the potential to sustain discourses of homogenisation that overlook the experience and needs of some community-level groups (Powell \& Geoghegan, 2005). There is therefore a need to learn from and improve 'knowledge' transfer systems to ensure that a wider group of people at community levels can benefit.

\section{Conclusion}

Processes of 'knowledge' and 'development' in RTCs are therefore ongoing and contested, with impact and change varying across different groups and communities. While external programming can play a key part in these processes, its role is as a facilitator of local models of practice rather than as the main driver of community 'development'. Though external knowledge is therefore only relevant in local settings as a component of understanding and integration, this does not mean it does not have the potential to shape RTC processes on a national scale. The following chapter therefore explores RTCs within wider processes of 'development' at the national level, including their sustainability and the extent to which external programming shapes and drives this. 


\section{CHAPTER 7}

\section{Assessing 'sustainable development' practice and impact: Outcomes for Solomon Islands rural training centres in the wider 'development' space.}

\section{Introduction}

The previous chapters have sought to show how rural training centre (RTC) models of practice might be conceived and impact on community 'development' goals in the Solomon Islands. As a result, these chapters have concentrated on local levels of influence, impact and operation. However, this fails to acknowledge wider spheres of influence that, like it or not, inform the direction of communities of practice. This chapter therefore discusses the position of RTCs in wider discourses of 'sustainable development' in the Solomon Islands, including wider outcomes and implications of this position on their 'sustainability', and for community education. This shows to what extent 'development' stakeholders and their education priorities have contributed to positive outcomes for the future outlook of RTCS and their students. The chapter therefore begins with a review of 'sustainable development' literature, including a post-development critique on the co-option of this agenda into mainstream economic discourses. Student experiences of community livelihoods are then examined, showing a continued divide between national priorities and local realities, before moving on to the successes and challenges of 'development' programming and 'sustainability' for RTC communities. Particular attention is given to relationships between different 'development' actors in the RTC sector, and how this has affected 'development' practice in the Technical and Vocational Education Training (TVET) sector. In assessing the impact of these factors on the RTC model of practice, a case is made to conceive of sustainable outcomes in a more holistic way, acknowledging history and community-level intent over external economic 'development' pressures.

As with the previous chapters, this focus on the wider context and processes of 'development' in the Solomon Islands, of which START is a part, aims to inform better practice. This section is critical by nature of wider patterns of 'development' in the Solomon Islands but is not intended as an attack on any organisation or institution. Highlighting ongoing challenges that impact on RTC 'development' challenges assumed perspectives that may overlook diverse experiences in the context of wider discourses. 


\section{The 'sustainable development' agenda}

The 'sustainable development' agenda is a practical manifestation of 'sustainability' principles in the context of 'development' (Olawumi \& Chan, 2018), which are grounded in historical concerns about environmental, political and social consequences of the current world system (Meadows, Meadows, Randers, \& Behrens III, 1972). Challenges to the endurance of the aid regime's economic growth agenda within these wider concerns prompted the rise of 'sustainable development' as a component of 'development' discourse. The Brundtland report in 1987 is widely synonymous with this, citing the following as goals for global 'development':

"Sustainable development is development that meets the needs of the present without compromising the ability of future generations to meet their own needs. It contains within it two key concepts:

- the concept of 'needs', in particular the essential needs of the world's poor, to which overriding priority should be given; and

- the idea of limitations imposed by the state of technology and social organization on the environment's ability to meet present and future needs" (WCED, 1987, p. 43).

The three pillars of 'sustainable development' practice are therefore economic, social and environmental, with the goal being to 'harmonise' all three in achieving 'development' (Desai \& Potter, 2014). Carley and Christie (2000) note this 'development' approach reflects a more holistic form of action, responding to the needs of all whilst avoiding what Daly refers to as assumptions of "the macroeconomy... as the Whole" (2007, p. 157). 'Sustainable development' therefore "calls for a world in which economic progress is widespread; extreme poverty is eliminated; social trust is encouraged through policies that strengthen the community; and the environment is protected from human-induced degradation" (Sachs J. D., 2015, p. 3).

In the context of 'development', the Sustainable Development Goals (SDGs), adopted at a United Nations (UN) Summit in 2015, represent a collective political voice responding to these holistic 'sustainable development' expectations (Le Blanc, 2015). The framework consists of 17 overarching goals and 169 targets, which were created through consultation with multiple national stakeholders across the UN system (Hák, Janoušková, \& Moldan, 2016). The SDGs acknowledge interconnected areas of 'development' that different member states can work towards within their own national priorities. This gives flexibility to the 
contextual needs of different countries, engaging and holding both 'developing' and 'developed' countries accountable for processes of 'sustainable development' (Le Blanc, 2015). The goals cover areas, such as education, health and responsible consumption, that reflect the core pillars of 'sustainable development', and are highly relevant to contextual factors in the Solomon Islands.

\section{'Sustainable development' agenda as discourse}

Despite claims of 'sustainable development' principles being incorporated into 'mainstream' agendas, many challenge the extent to which this has occurred. Carant (2016) notes that global collective approaches that have defined the push towards 'sustainable development', such as the SDGs and its predecessor Millennium Development Goals (MDGs), are used by those in power to overshadow and dictate processes according to their own agendas. The MDGs, for example, were reflective of this in their prescriptive nature, with the voices of 'developed' countries and UN agencies overshadowing the 'developing' within the consultation process (Carant, 2016). Whilst the SDGs' more inclusive process tried to address this, Cummings et al suggest this was "instrumental in excluding more transformational discourses and maintaining the status quo (2018, p. 728). The inclusion of voices from 'developing' states, who were traditionally excluded from 'development' discussions and now wanted their share, and corporate sector voices, who had a vested interest in economic outputs, only reinforced an economic discourse (Sachs W. , 2017). Therefore, although the 'sustainable development' vision, strategy and language reflect 'sustainable development' principles, "the implementation and goals and targets appear to represent business as usual" (Cummings, Regeer, de Haan, Zweekhorst, \& Bunders, 2018, p. 739).

\section{Hierarchies and a paradox in 'sustainable development'}

Along with these operational critiques of 'sustainable development', a post-development analysis of the approach suggests a hierarchy of priorities regarding its three pillars. Patterns in the literature suggest that 'development' funding is assessed based primarily on economic indicators of 'sustainability'. A recurring theme in the literature is the changing nature of aid priorities driving hybridisation, such as 'social enterprise', for many community organisations. Maclean and Brass (2015) examined processes of organisational hybridisation in Kenya and Uganda to sustain renewable energy provision initiatives for local communities. They highlight "decreasing donor funding to more traditional programming [and] an ideological shift ... among donors ... toward funding profit-oriented or financially sustainable organisations" as drivers of this hybridisation (MacLean \& Brass, 2015, p. 75). This suggests 
'sustainability' principles have been co-opted in the 'development' discourse to be synonymous with a primarily economic focus, rather than including environmental and social factors alongside this (Sachs W. , 2017). Devine (2003) notes that a focus on solely economic 'sustainable development' at the national level creates a 'development' paradox for communities. Either communities conform to national systems that support the 'development' of their models of practice, thereby losing relevance to their own settings, or they resist these systems and are left with limited external means to support their own processes of 'development'. As will be discussed in this chapter, needing to be 'sustainable' long-term (read: economically self-sufficient) is a pressure increasingly placed on RTCs at the national level, unlike formal education institutions, making this highly relevant to current 'development' processes in the Solomon Islands.

\section{Supporting local understandings of 'sustainability'}

Given 'sustainability's' co-option at the national level, expanding the 'development' discourse by highlighting community-level experience of this co-option is key. Hák et al (2016) suggest that indicators of 'success' must change and adapt, rather than remain fixed across contexts, to be relevant in diverse settings. However, the current approach remains inflexible at the community level, with external expectations of 'success' being placed on community's processes of 'development' (Escobar, 1995). Smith (2016) shows that these external expectations of 'sustainability' often do not conform to local priorities, which leads to frustration and resistance from all sides. Instead, priorities must respond to local conceptions of 'sustainable development' in practice, given that opposing priorities in programming can lead to failures to create tangible benefits for communities (Curry, 2003). Though local actors, as shown previously, do have agency to resist external priorities, this becomes increasingly challenging in wider scales of influence. This following section therefore begins an examination of how external forces, have impacted on community livelihoods and RTC education's 'sustainability' over the last five years.

\section{Community livelihoods development}

Despite the clear impacts of 'development' on the quality of RTC operations and education, there has been little change in young people's community-level livelihoods opportunities in the wider Solomon Islands context. As noted previously, the vast majority of RTC students interviewed see few opportunities to support themselves and their families in a rural community setting (Group interview, 20/5/19, Vatu). Although not an original focus of the START programme, the addition of 'Grow Youth Business' as a component was targeted at 
offering more opportunities for graduates at the community level. This did not have the desired effect of promoting local livelihoods for young people because it was not viewed as viable long-term employment option by them (Interview, 8/5/19, Kaotave). The impact of this on a wider scaler is an influx of young people into urban centres for employment across the Solomon Islands. This further exacerbates current challenges faced by the majority of the population and puts pressure on urban centres to cater for more than their capacity allows.

\section{Youth livelihoods support networks}

Despite the limited opportunities for 'traditional' employment in the provinces, there have been efforts to promote youth business and social enterprise over the last five years. A student I interviewed at Kaotave described 'Youth at Work' courses he attended that encouraged entrepreneurship through training and internships; a stepping stone to him gaining employment after leaving school (Interview, 9/5/19, Kaotave). Observations and conversations with young people and 'development' workers in Honiara also showed there is infrastructure work on youth spaces to cater for these needs. Examples of this include lumi Waka, a youth business and enterprise space that facilitates mentoring and workshops, and the MFAT-funded youth recreation and social support centre that is under construction (MFAT, 2019b). Although these types of initiatives aim to help address the needs of young people and promote 'enterprise' in the Solomon Islands, almost all these services are provided in urban centres. Although understandable given the high costs involved in service provision across the Solomon Islands, this urban bias in 'development' only encourages more youth into urban centres.

\section{Ongoing rural livelihoods challenges}

In contrast to changes for youth in urban areas, rural communities have been relatively overlooked in the provision of similar support networks. Interviews with officials pointed to some ongoing projects through Church networks targeting the holistic 'development' of communities, but these only impact young people indirectly (Interview, 17/5/19, Honiara). The only financial support at the time of writing is through Solomon Islands Association of Vocational Rural Training Centres' (SIAVRTC) Bamford Scholarship system. As explained by a SIAVRTC staff member, this is a small grant scheme encouraging RTC graduates to promote community-level enterprise (Interview, 6/5/19, Honiara). These grants are used in various ways, including for tools to support various community level enterprises, such as farming and furniture-making. According to a SIAVRTC staff member, "I just had one [person] making cane baskets ... and the chairs and he went over to Auckland last week for an expo [in] New 
Zealand" (Interview, 6/5/19, Honiara). Having these kinds of funding mechanisms in place gives students the opportunity to support themselves in their own setting, with less pressure to move away.

Despite the benefits of this scheme in encouraging young people into rural livelihoods at a larger scale, no students interviewed at the RTCs were aware that this option was available to them. This suggests that SIAVRTC's promotion of this type of funding is either not effective or not done across all the RTCs, meaning many young people miss out on applying for it. There were also limitations to this funding, with only ten graduates being selected each year, leaving the majority of students with limited external support for community work. Along with awareness of the support available to them, another consideration is the difficulty for some in accessing services due to the remoteness of communities and associated costs of doing so. The overall impact of these factors is that, like five years ago, there are still limited forms of livelihoods support available to students at the community level following graduation.

\section{RTC Organisational development and change}

\section{Organisational development and spread through SIAVRTC}

Outside of 'development' programme-funded RTCs, there has been little change to infrastructure and staff development in existing RTCs over the last five years. START programming has been the only platform for cross-RTC engagement and learning, which many administrators and instructors saw as a major benefit of the trainings (Interviews, 7/5/19, Tetere; $2 / 6 / 19$, Tabaka). While there were notable successes in RTCs targeted by 'development' programming, many interviewees noted that the same was not necessarily true for organisations who did not receive support under the infrastructure and 'Grow Youth Business' components of START. As noted previously, a challenge for many RTCs is accessing teaching resources and equipment, with many missing even basic tools for courses (Figure 13). Conversations at Tabaka and with Skills for Economic Growth (S4EG) programmers suggest that a large component of the S4EG student grant was retained by SIAVRTC to distribute through grants across the RTC network (Interview, 30/5/19, Tabaka). However, discussions with staff from SIAVRTC and various RTCs show that knowledge of this is not widespread throughout the network. This suggests that SIAVRTC staff are not communicating available funding opportunities to the RTCs, and many are still struggling to resource themselves as a result. 


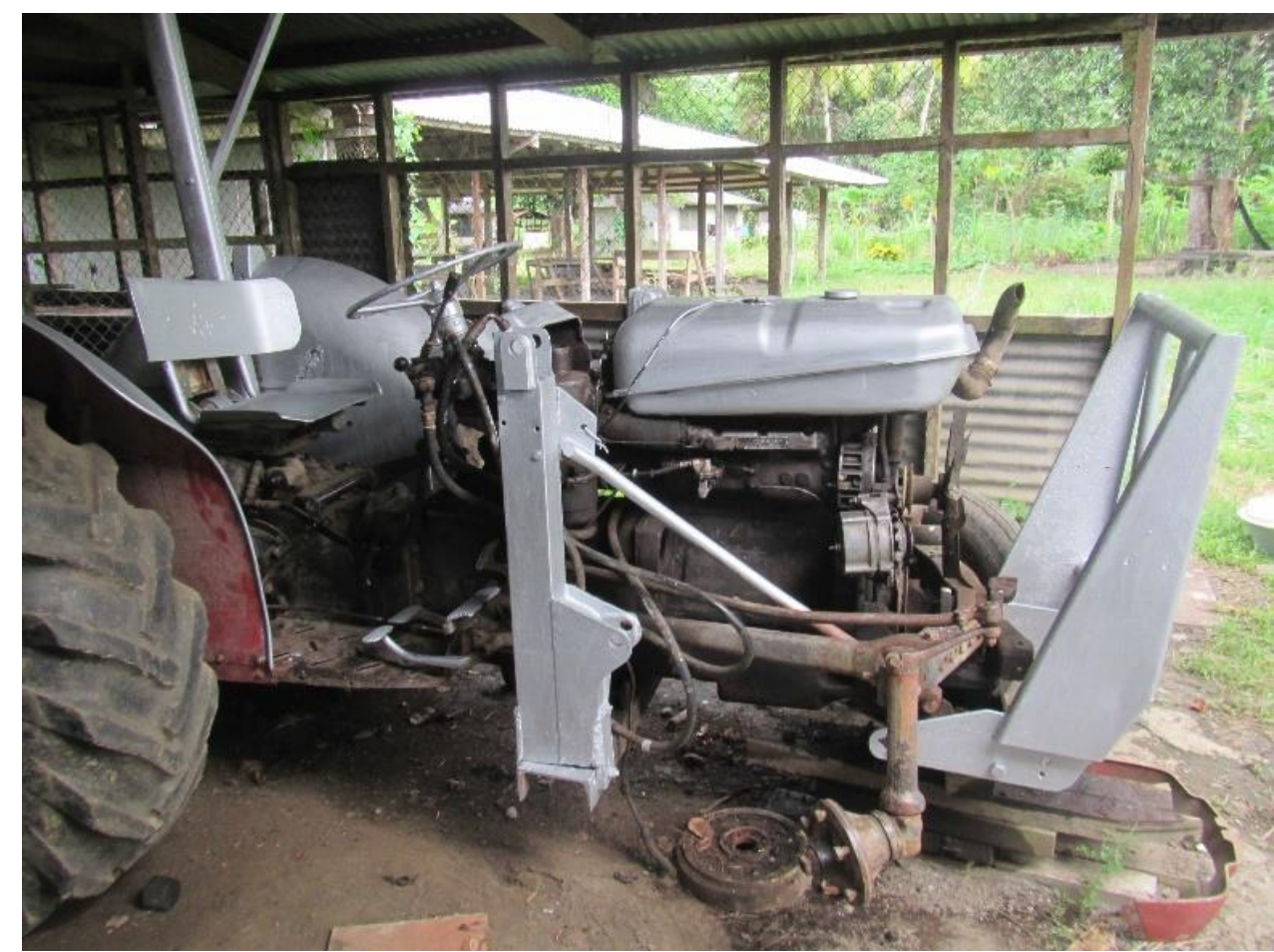

Figure 13. A newly painted, yet non-functioning tractor in the mechanic area at Kaotave RTC (Photo credit: Finn Egan).

Another aspect of the RTC network's development is that SIAVRTC's priority has been in expanding to new institutions, rather than developing those that already exist. According to SIAVRTC staff, the total number of RTCs across the Solomon Islands has expanded from 45 to 60 in the last five years (Interview, 6/5/19, Honiara). Although this shows the continued need and demand for rural livelihoods training, this focus on expansion has allowed the gap in infrastructure and educational support across different RTCs to expand. SIAVRTC have been able to support expansion of livelihoods training, with 'tilapia' fish farming courses being piloted in Malaita in partnership with the Waikato Institute of Technology International Development Services (WINTEC, 2017). Interviews with leaders that attended START Leadership training suggest this work has been successful and is an interesting development in Solomon Islands vocational training. However, SIAVRTC leadership were hoping to expand the network further at the time of writing, suggesting a similar trend in support to RTCs is likely to continue.

External to SIAVRTC, there are also noticeable differences in the capacity of various Church Education Authorities (CEAs) to support the RTC 'development'. Whilst some RTCs visited, such as Vatu, have ongoing contact and support from their CEAs on governance and development, others only receive an annual visit. Limited external support did not mean that an organisation was not functioning, but it did create a space where threats to an organisation's effectiveness were not dealt with properly. At St Dominic's, for example, staff 
spoke of mismanagement that had been overlooked in the past due to an inactive relationship with their CEA (Interview, 28/5/19, St Dominic's). Although it would be easy to blame this lack of oversight on CEAs, this overlooks the expectations placed on them and the context in which they operate. In some cases, one person is responsible for the oversight of all primary, secondary and vocational institutions in their jurisdiction, with many of these being in remote locations or in institutions that they have had little experience managing. One CEA I interviewed had a lot of experience in primary school systems, but very little in other education institutions. As a result, most of their time was spent supporting the primary schools in their jurisdiction because that was where they felt most comfortable. This CEA expressed an interest in supporting the RTCs but was uncomfortable in that environment and had nobody else to support them in this. There is therefore an ongoing need for support to the CEAs in providing RTC oversight.

\section{The rise of the 'Technical Institute'}

An interesting development that has taken place in the Solomon Islands TVET sector has been in qualification standard development under the S4EG programme. This work has been done in partnership with the Solomon Islands Government (SIG) and is designed to create a standardised curriculum across the sector, providing clear steps for RTCs to receive more government support. As noted by a S4EG worker, the standards set out expectations of infrastructure, teaching quality, resources and content that an institution must meet to qualify under new government funding (Interview, 6/6/19, Honiara). Different institutions will be expected to specialise in different subjects, based on local context and expertise. At Tabaka, for example, the course and curriculum being piloted is in Hospitality and Tourism due to sector growth taking place in nearby Munda (Figure 14). The goal is to develop a small number of regional 'Technical Institutes' that respond to varying needs in the labour force, including tourism, construction and agriculture across the Solomon Islands. The lack of a clear curriculum and standard development path for the RTCs has been a major barrier to greater SIG support for the model, meaning that this work has potential to bring increased support to TVET.

As well as responding to the Solomon Islands' economic needs and providing a clear path for RTC 'development', there are other benefits of the 'Technical Institute' model. Incorporating vocational training into the wider Solomon Islands education system gives many early school leavers a clear path back into the formal education sector through standardised certification levels. Under the current structure, students taking the Hospitality and Tourism course can 

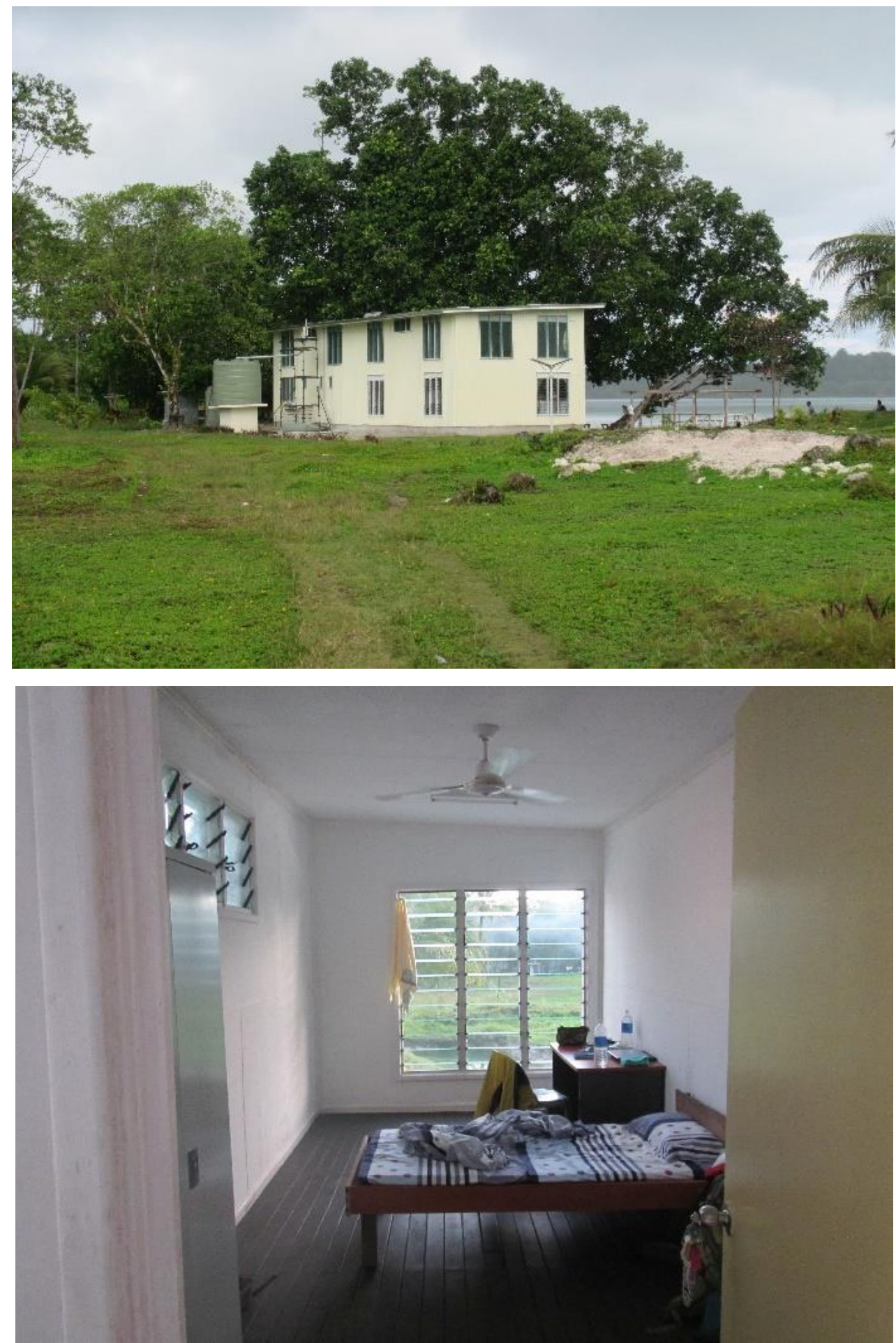

Figure 14. Above, the Hospitality and Tourism building constructed under S4EG funding at Tabaka RTC. Below, a model guest house in the Hospitality and Tourism building (Photo credit: Finn Egan).

progress through certificate 1 and 2 at DIVIT RTC, before moving to Tabaka for certificate 3 , and then on to a higher qualification at Solomon Islands National University (SINU) or into employment. This creates a more 'qualified' labour force that can support economic 'development' (Interview, 6/6/19, Honiara). Alongside this, there is support amongst the Churches to have a tiered system of education within the TVET sector. Staff at the South Sea 
Evangelical Church (SSEC) Education Authority, for example, see benefits in transitioning Kaotave into a Technical Institute, supporting re-entry into the formal education system while retaining other RTCs to support community-level needs (Interview, 17/5/19, Honiara). This could benefit various groups in the RTC network, increasing education and livelihood opportunities for early school leavers, as well as prestige for the Churches and SIG in the 'development' of TVET as a whole.

\section{Challenges in TVET 'development'}

Despite the perceived benefits of the 'Technical Institute' model, there are challenges that remain unanswered at present. Firstly, there has been limited consultation and collaboration across the various stakeholders in the TVET sector, which has created a lack of clarity around the process and overall goals of the qualification standards. The regional approach to Technical Institute 'development' does not, for example, consider the diverse religious background of TVET institutions. Regional placement has meant that some Churches, such as SSEC, have been overlooked in the pilot phase of this transition, and S4EG staff informed me that the current institutions will ultimately become the only SIG-funded Technical Institutes (Interview, 6/6/19, Honiara). This means that, contrary to many stakeholders' assumptions, the Technical Institute model will not be accessible to other institutions in the future, which is likely to cause tension amongst TVET's traditional stakeholders. Another important consideration is SIG's goal of developing a small number of institutions to a high standard, which conflicts with SIAVRTC's focus on expanding the overall number of RTCs. There are therefore some notable ways in which stakeholder interests are not currently aligned.

As well as this, limited clarity on the intentions of the new structure and curriculum has created confusion in the operations of some of the pilot institutions that are currently in the 'transition period'. At Tabaka, for example, 'Life Skills' and 'Hospitality and Tourism' courses are being taught simultaneously by different staff members. The only major difference between the courses is that Life Skills targets rural livelihoods, while Hospitality and Tourism's content is industry-focussed. Hospitality and Tourism staff and students also had access to a S4EG-funded kitchen, bathroom and model guest house (Figure 13), which Life Skills staff and students were excluded from using (Interview, 31/5/19, Tabaka). This not only creates confusion and frustration over access to teaching resources, but also highlights a lack of understanding from 'development' workers of the holistic impact of their programming on Tabaka and its stakeholders (Interview, 31/5/19, Tabaka). The process of transition 


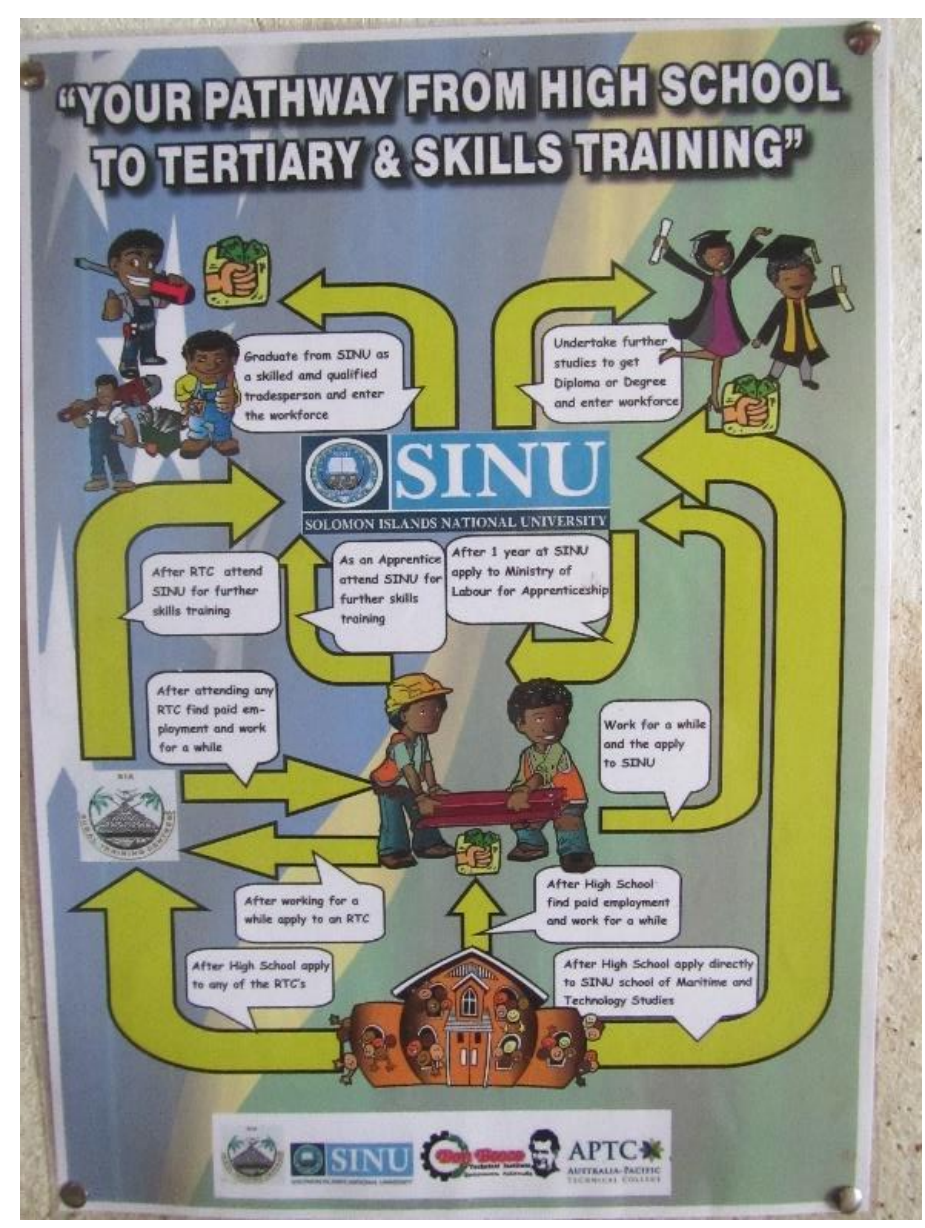

Figure 15. A poster promoting RTC education as a pathway to re-entry into formal education and industry (Photo credit: Finn Egan).

facilitated by S4EG has therefore not considered the experience of those external to the pilot scheme, effectively treating itself as an isolated process and ignoring anything external to its own work.

There are major implications for START programming that arise from current TVET changes. Firstly, qualifications standards development has in some ways superseded the programme's original goal of providing for community livelihoods due to the infrastructure and teaching capacity expectations placed on S4EG pilot institutions. None of the RTCs have the infrastructure, staffing or resources to meet these expectations of the standards, but those institutions selected as pilots were closest to being able to do so (Interview 6/6/19, Honiara). However, many of the institutions selected are closest because they have received funding under START, meaning that efforts put into promoting avenues for community livelihoods will instead feed into 'development' of the formal education system. Although there are still clear benefits for school leavers from Form 3 and up who have the intention of re-entering into this system, the focus of TVET 'development' is being shifted away from early Standard 6 leavers who were the original focus of the RTC model. 


\section{Implications for student engagement}

A primary barrier to effective student engagement in this changing TVET model is in literacy and numeracy. This particularly impacts early school leavers, who instructors across all the institutions visited said struggled most with the theory component of teaching (Interview, 20/5/19, Vatu; 8/5/19, Kaotave; 26/5/19, St Dominic's; $1 / 6 / 19$, Tabaka). Staff at Tabaka who had experience with the previous style of teaching said that the content of the new curriculum is much more theory-driven due to those being the primary needs for re-entry into formal education (Interview, 31/5/19, Tabaka) (Figure 15). This means that early school leavers may be excluded from even the TVET sector, unless consideration is given in the current standards and curriculum to bridge this barrier between 'formal' and 'informal'. At the time of writing S4EG staff had explored the idea of a bridging course, but this was yet to be developed.

On a more operational level, a factor that has not been considered in transitioning from RTC to Technical Institute is the changing expectations of students for the new institutions (Figure 16). Interviews with students at Tabaka showed much greater expectations of infrastructure and personal freedom in a Technical institute, and not responding to this caused frustration amongst the student body. The following points were noted by students:

"Learning environment long school hem no mas good tumas long mifela due to the leadership inside long school hem, some of our teachers or staff, olsem olgeta no much good tumas olgeta, olsem uh olgeta kain makim mefela olsem slave tumas ... Hem na waka every day nomoa ... Mifela stay but olsem mifela no feel long same long tertiary. Mi feels like in primary or secondary" (Interview, 31/5/19, Tabaka).

"The learning environment at the school is not great for us due to the school leadership. Some of the teachers or staff aren't good because they make us feel like slaves ... We have to work every day ... We're still here but we don't feel like it should be like this at a tertiary level. We feel like we're in primary or secondary school" (approximate translation, Finn Egan).

"We have the basic tools for carpentry only ... If we go further in construction sites, in the industrial sites, nowadays ... you don't even see them using a [measuring] tape. They use digital ones, like using lasers, so when we come into [a Technical] Institute then we expect an upgraded standard of learning too" (Interview, 31/5/19, Tabaka). 

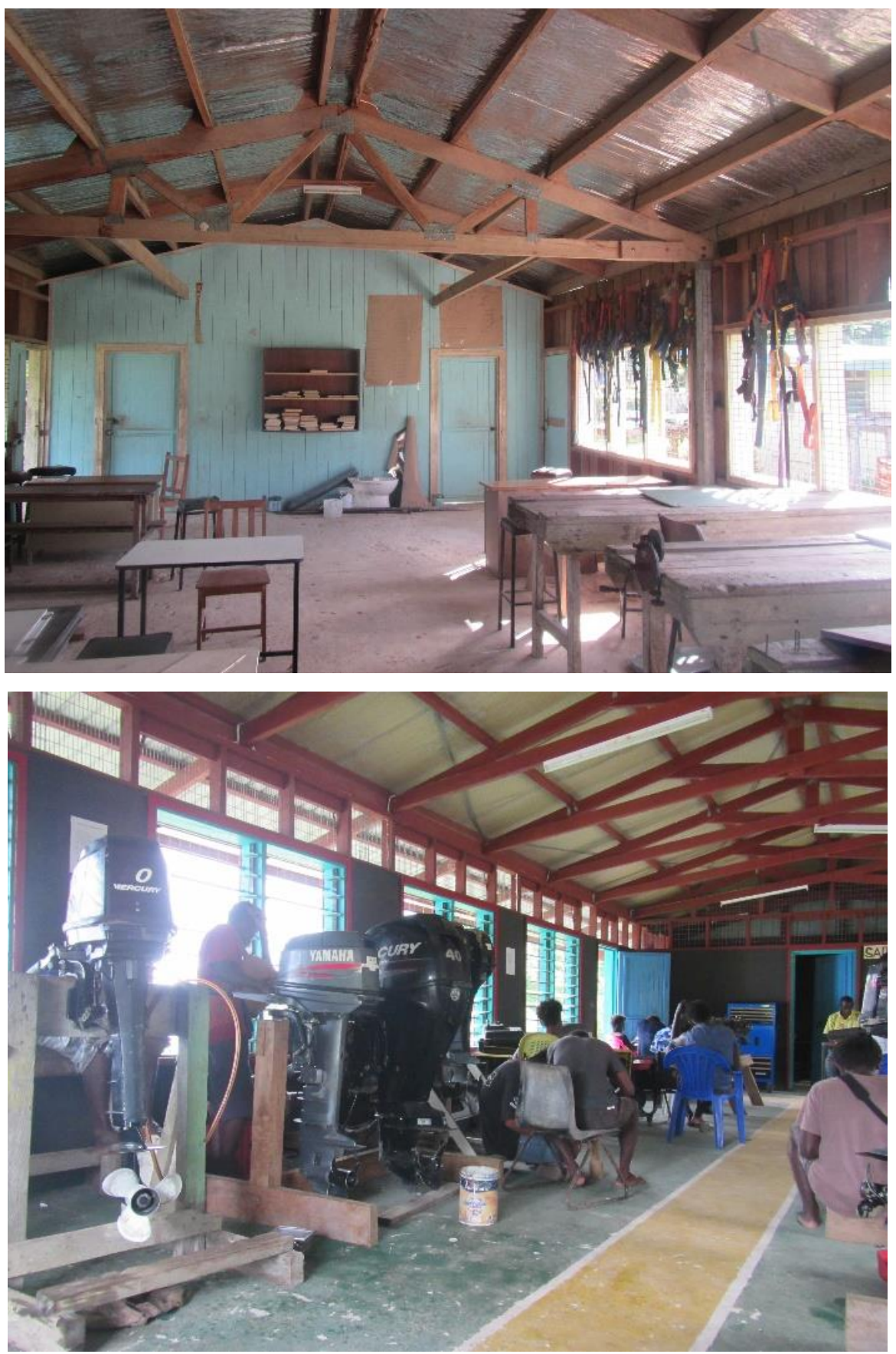

Figure 16. Above, textbooks and safety equipment supplied to the Tabaka carpentry teachers under S4EG. Below, a mechanic class being taken in a START-funded workshop at Tabaka (Photo credit: Finn Egan).

A key aspect of this was that students now view Tabaka as a 'formal' tertiary-level institution. This is a different style of education to the 'informal' RTC model, and also comes with new expectations from members of the 'community'. These differing expectations have serious implications for the RTC 'community' model discussed in chapter 5 because students play a key role in the ongoing operation of this model, which requires their buy-in to function. Further 'development' of TVET institutions therefore not only comes with greater student expectation around education quality, but also freedom within their own education 
experience. The current RTC model does not provide this freedom, instead requiring constant student engagement in structured work and study. RTCs will therefore have to keep engaging students in their role within the current 'community' model or adapt to not having the student body as a key component in supporting their operational needs.

\section{'Development' Priorities in RTC Programming}

When the priorities of traditional and new donors align, such as with START and the Churches' focus on community livelihoods, 'development' programming relationships are easy for RTCs to balance. RTCs not only have a clear vision, but also the financial backing to 'develop' as organisations to provide a high quality of education to young people. However, with the Churches unable to fully fund RTC 'development' they have looked to other external funding to further support them. By doing so, RTCs support their 'development'; but this comes with challenges.

\section{Balancing donor relationships}

Despite the inherent benefits of having multiple sources of 'development' funding, there were challenges for the RTC network in balancing old and new relationships over the last five years. Firstly, different 'development' actors have taken different approaches to engaging with RTC stakeholders. Where Caritas have worked through the Church EAs as the traditional drivers of RTC 'development', S4EG contractors have engaged with SIG and industry. For Caritas, the route through the Churches has given them easy access to the RTCS and a mandate for their programming that has created buy-in at the local level. However, not working through SIG on long-term RTC challenges meant that there is limited change to SIG support from five years ago. Whilst this kind of change was never the purpose of START, it is a key factor in promoting positive outcomes for the RTC network as a whole.

On the other hand, S4EG programming has engaged almost solely with government and industry, focussing on providing 'legitimacy' to the RTC model through formalisation (Interview, 6/6/19, Honiara). While this has resulted in a government body, Solomon Islands Tertiary Education and Skills Authority (SITESA), focusing on the RTCS, their work has overlooked the informal Church roots from which the RTCs emerged. This is relevant in a Pacific context, given Sanga's (2009) point that people are expected to serve Church interests alongside those of government and family. Implementation of the qualification standards has therefore been challenged due to a perceived snub to the Churches in RTC decisionmaking. As noted by one staff member at Tabaka, a staff member being trained under S4EG 
may have been purposefully moved to another RTC due to frustrations around Church perspectives in programming being ignored (Interview, 30/5/19, Tabaka). This means that START has had fewer positive effects at the national level whilst S4EG has had fewer positive effects at the community level, due to both programmes not fully engaging all relevant stakeholders in their approaches.

\section{Cross-programme collaboration}

Another challenge has been balancing different agencies' priorities for RTCs, given that their intended outcomes do not fully align with each other. Where START's focus has been on the promotion of better outcomes for people at the community level, S4EG's work targets outcomes for people through the formal workforce and industry. Although both are focusing on livelihoods for young people, this distinction between 'informal' and 'formal' appears to have caused S4EG contractors to resist engaging with their START counterparts. Conversations with staff working on both projects gave the impression that Caritas had regularly tried to engage and find ways to avoid overlaps in programming, with very little response from S4EG workers. When interviewed, one contractor said there was very little crossover between the two projects, except that START leadership and financial capability trainings might contribute to administrators' capacities to manage funding provided under S4EG (Interview, 6/6/19, Honiara). While the projects had different outcomes they still operated in similar contexts and communities, meaning they did affect each other. There therefore appears to have been some missed opportunities over the last five years in working together more effectively.

The limited amount of collaboration between 'development' workers across START and S4EG over the last five years has even, at times, been detrimental to the effectiveness of practice in some RTCs. Part of this has been in overlapping programming, with both projects targeting some of the same RTCs and staff in their work. As an example, a RTC staff member noted that the curriculum developed for them under S4EG was more theory-focused compared to what they had been taught as part of START, and to their previous approach (Interview, $7 / 5 / 19$, Tetere). The focus on practical learning in START skills trainings was therefore undermined by a curriculum that emphasised other aspects of learning, leading to less effective and sustainable outcomes.

At an organisational level, having both projects operating in the same institutions created noticeable funding disparities and blurred the mission of some targeted RTCs. Where some RTCs, such as Tabaka, received funding under START and S4EG infrastructure, others received 
no infrastructural support at all. One RTC staff member noted that the way funding was allocated in the first cohort of START gave the impression that Catholic institutions were prioritised over others, though this was rectified in the makeup of the second cohort (Interview, 9/5/19, Kaotave). In START-funded RTCs, where S4EG also funded infrastructure, the difference between 'haves' and 'have nots' was further exacerbated, with institutions like Tabaka receiving significantly more external resources compared to, for example, St Dominic's RTC. More effective communication between START and S4EG programmers may have allowed them to spread funding across RTCs in a more effective, equal and, ultimately, sustainable manner.

Finally, RTCs targeted under external funding in both START and S4EG were those that were already comparatively 'developed' within the wider RTC network, and more easily accessible for 'development' programming. This gave the impression that external funding over the last five years may have further exacerbated the disparity between some RTCs. Although there were exceptions to this pattern, notably Vatu, the focus on easily accessible RTCs was quite noticeable in the first cohort under START. It is my impression that START workers tried to compensate for this in the second cohort of START programming, selecting more geographically remote and financially underfunded RTCs. However, fully addressing this was

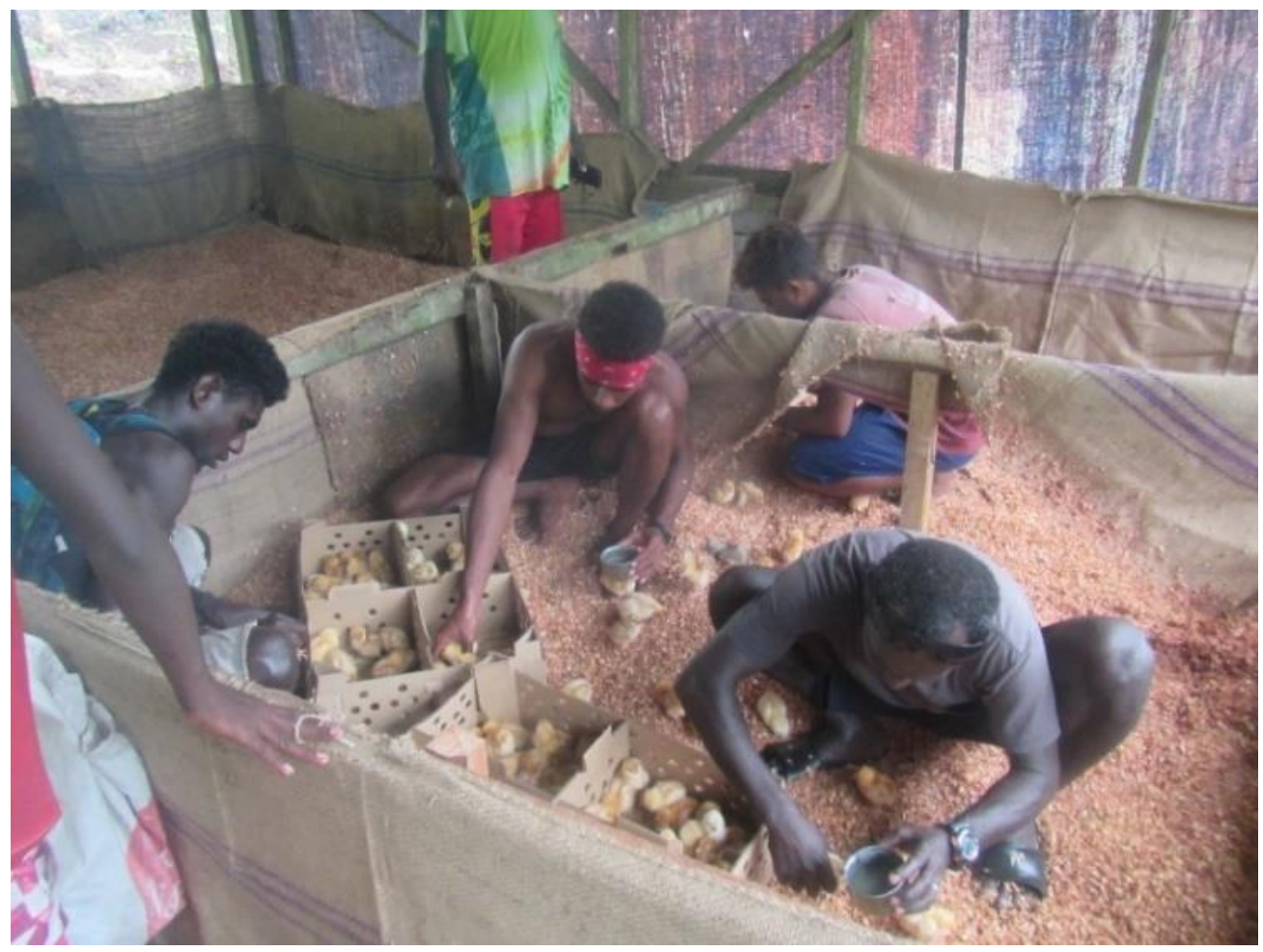

Figure 17. Students and their instructor give water to new-born chicks at St Dominic's RTC (Photo credit: Finn Egan). 
difficult due to the added cost and budget constraints that were already in place as part of the programme.

\section{RTC 'Sustainability'}

The extent to which the RTC model and network are now more 'sustainable' requires putting 'development' processes into perspective because current programming has only just touched the service and breadth of the RTC network. Where there have been noticeable benefits for targeted RTCs, the majority have had little external support since 2015 and are in a similar position to where they were. As noted by a SIAVRTC staff member, "if we were only depending on the government then there is no improvement by now" (Interview, $6 / 5 / 19$, Honiara). The infrastructure and skills promotion that have occurred in targeted RTCs have created tangible improvements in teaching quality and operational management that would not have occurred otherwise (Figure 17). The discussion in Chapter 5 shows that there have been attempts in RTCs to create more consistent and sustainable forms of income generation. In these ways, START skills trainings have been beneficial in promoting better 'sustainable' outcomes for targeted RTCs at both an operational and educational level.

Despite these improvements, it is important to realise that operational 'sustainability', meeting the operating and development costs of an RTC, is still an ongoing goal at most RTCs. Although START leadership trainings have encouraged and supported administrators and instructor capacity to work towards more 'sustainable' operational models, most RTCs are not in this position of economic 'sustainability' as of yet. Many instructors still find challenges in meeting their students' practical learning needs, and there are cases over the last five years where administrators have had to end school terms early due to operational costs (Interview, 28/5/19, St Dominic's). However, there are also cases where changes have occurred, such as Vatu purchasing its own resources and tools for the electrical department and St Dominic's being able to remain open the entire school year over the last two years. The full benefits of improved operational 'sustainability' are therefore varied and ongoing.

\section{Dangers in the (economic) RTC 'sustainability' push}

However, giving responsibility to RTCs to meet their own operating costs ignores SIG's responsibility to provide effective support in the provision of core education services. Although there may be clear benefits to 'development' actors encouraging RTC 'sustainable development', this process puts pressure on RTCs to have primary responsibility over their own survival. RTCs are encouraged to adopt self-sustaining business components alongside 
their education delivery as part of a process of 'hybridisation'. This is reflective of wider patterns across the world, as noted previously, but Harris (2010) notes concerns about this process of hybridisation, in particular how hybridisation impacts on the social goals of community initiative, given the pressure to engage with business interests (Harris, 2010). This pressure to be self-sufficient is similar to external pressures on the RTC network.

As noted in chapter 5 , one of the main concerns arising from this process of hybridisation is the extent to which social goals become overshadowed by business interests over time. Homi Kharas and Rogerson's work on changing trends in development aid (2012) shows that this business focus in 'development' is increasing over time. Although not a new concern, it is one which carries significant implications for organisations, such as RTCs, that currently struggle to balance the priorities of their donors. On one side are the needs of students from diverse contexts, increasingly both rural and urban, that they prioritise in their work. However, these priorities do not always align with the business-centric agenda of 'sustainable development', which is challenging given RTCs do not always have the means to support their ongoing 'development' in this regard. RTCs therefore see themselves as needing to engage external donor or government funding to support this.

\section{The paradox of the RTC 'sustainability' push}

Although external funding is a viable short-term solution to RTC 'development' this comes with conditions that prioritise wider economic outcomes over individual realities. While START tried to prioritise community livelihoods in its programming, there still appears to have been a push towards operational sustainability through independent income generation. MacLean and Brass (2015) note that directly adopting a business-oriented model could reduce downward accountability to community members, undermining the original social mission of an organisation. RTCs would likely be economically sustainable in the way that was appealing to external funders but may also effectively become profit-driven businesses that do not prioritise student education.

On the other hand, some models, "with [a] for-profit spin-off" (MacLean \& Brass, 2015, p. 73), are more likely to maintain links to their overall social mission whilst generating some supportive income. These are closer to the RTC models being operated at present that are, as noted previously, inconsistent in generating income. RTCS that operate a traditional system, like Kaotave, do not have enough output consistency to sustain a business due to the broader focus of their coursework. However, students develop a more complete understanding of community-relevant skills in this system. In a cycle system, like St 
Dominic's, it is easier to maintain consistent income-generating activities, due to staff being focused on one activity, but students only take part in a small component of the whole process. As an example, students that were not part of the St Dominic's chicken-raising cycle when I visited missed out on the practical experience of caring for new-born chicks. The challenge is therefore that focussing more on income generation means less priority is given to student education. However, not focusing on income generation means that RTCs are less 'sustainable' in the eyes of external donors, meaning they have less opportunity to improve the quality of education for their students.

\section{Challenging economic conceptions of RTC 'sustainability'}

While seen as important by donors and leaders, a narrow focus on organisational efficiency and economic outcomes is, ironically, unsustainable (Barkemeyer, Holt, Preuss, \& Tsang, 2014). Firstly, placing the full responsibility of economic sustainability on RTCs does not prioritise the immediate learning needs of students, who are the main priority of these institutions. RTC instructors almost always become the drivers of income generation due to their local expertise and there being no other staff willing to do so, and this impacts on their ability to attend to student needs. The focus on 'sustainable development' instead supports patterns of economic growth for donors and others who benefit from this wider economic system (Barkemeyer, Holt, Preuss, \& Tsang, 2014). In the case of the RTCs the purpose that the new qualification standard encourages is labour force development, which does more to support the national economy than it does to support most Solomon Islanders. Developing the labour force benefits industry through access to more qualified employees but ignores the large bubble of youth unemployment that industry cannot support at present (UNDP, 2018). In contrast, START's focus on community livelihoods, current models of operation and individual needs of rural youth is arguably closer to the principles of 'sustainability'.

Along with overlooking the needs of the 'poor', an economic focus in RTC 'sustainable development' is unsustainable in its encouragement of further growth in a planet that cannot support it. Current trends suggest that the focus in 'development' remains on an economic agenda that supports private sector growth and runs counter to these environmental limitations (Mawdsley, 2015; Murray \& Overton, 2016). The use of New Zealand organisations in the delivery of START skills trainings to support targeted RTCs also promotes New Zealand growth. Whilst the work of these trainers has effectively presented external 'knowledge' to RTC staff over the last five years, there has been no facilitation of local trainers or mentors to deliver similar trainings going forward. Solomon Islands RTCS 
therefore remain dependent on people external to their own environment for training. This not only creates barriers to further RTC 'development' but it also overlooks how 'development' programming contributes to long-term outcomes. There is therefore a need to ensure that 'development' programming adopts a more holistic lens to understandings of 'sustainable' outcomes.

\section{Vatu: A case for holistic 'sustainability'}

Vatu offers a compelling case for how 'sustainable development' may be conceptualised in a more holistic manner. Conversations with RTC staff show a collective mentality that is targeted, where possible, at local solutions for local challenges. This approach is evident in all aspects of Vatu's operations, with a priority on internal staff growth, resources and even infrastructure. Most staff at the institution are graduates of Vatu that were retained as instructors following their studies, helping sustain Vatu's internal culture. As noted by Fleming (2015), Vatu staff have built the institution from the ground up, using local knowledge and materials to facilitate teaching, and construct housing and classrooms. At the same time, Vatu staff have accessed, and learnt from, external knowledge in the last five years in ways that support local practice (Figure 18). Where these learnings have been relevant to them, such as in organic farming and more effective education techniques, Vatu staff have incorporated external 'knowledge' into their own context in a way that supports local practice. 'Development' programming has effectively supported these local priorities

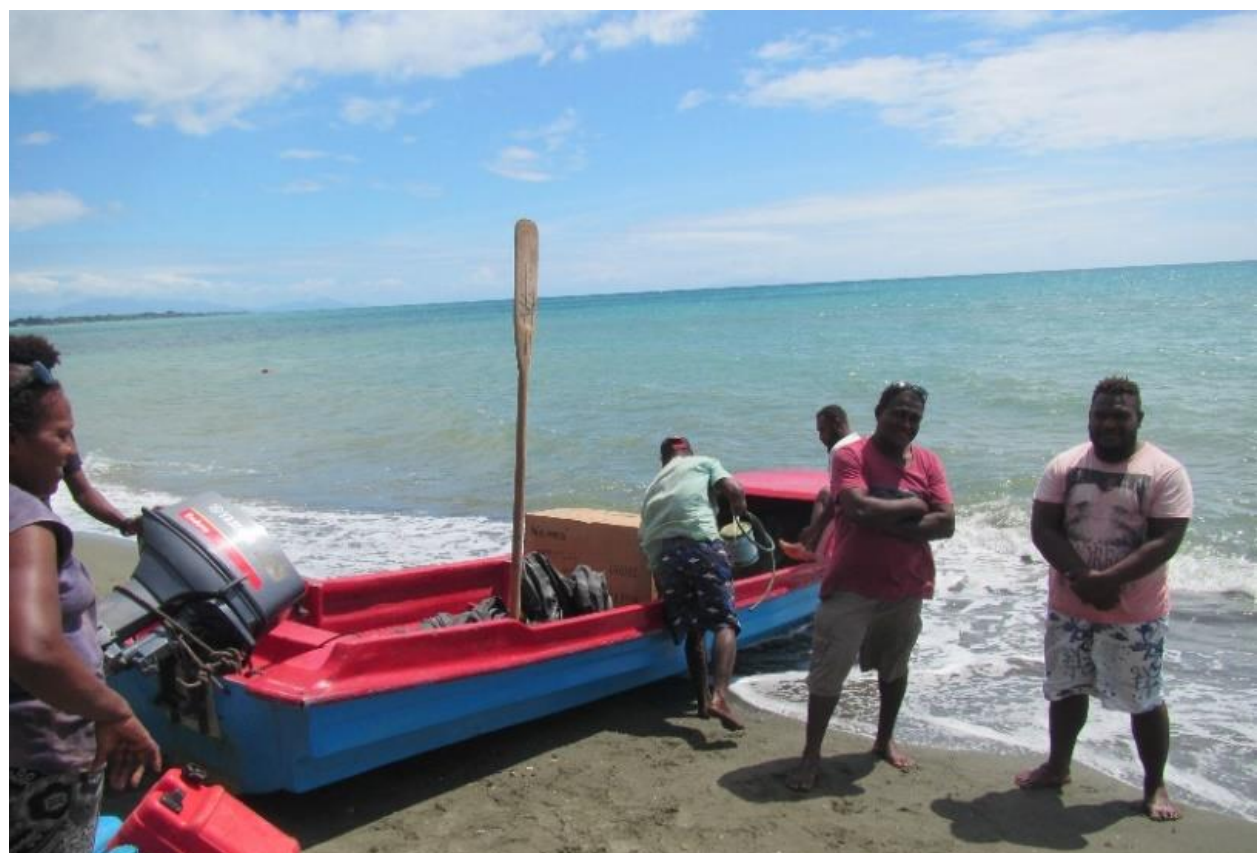

Figure 18. Goods and people bound for Vatu and its surrounding community are transported on a START-funded boat (Photo credit: Finn Egan). 
by giving agency to Vatu staff in how funds were used, as well as presenting 'knowledge' in an unbiased way.

Alongside the 'development' of physical and social capacity at Vatu, the RTC's institutional mentality is flexible to local needs and limits. One staff member noted, for example, that the annual student intake often changes, ranging from as few as two students to as high as twenty (Interview, 21/5/19, Vatu). This depends on the needs of surrounding communities, but also on the capacity of the RTC to provide an acceptable level of education and service to its students. Vatu staff therefore ensure that they do not go beyond theirs and the RTC's means in the provision of education to the surrounding community. Compared to other institutions who work to increase their student intake and develop through the resulting funding, Vatu seeks to find ways to develop itself at a slower rate before expanding its intake. Core to this mentality is the concept of 'enough' in Vatu's 'development', rather growing simply for the sake of it. Vatu therefore embodies multiple pillars of 'sustainable development', making it a sustainable promoter of community 'modernity'.

Despite, arguably, a more holistic form of 'sustainable development', Vatu staff face external pressure for how they operate. Although Vatu operates a sustainable model, it is not 'sustainable' in the way that external parties expect of it. Vatu's size and student intake, for example, are considered an issue by many external parties, including the Education Authorities, who see its potential to respond to wider needs across the Solomon Islands (Interview, 17/5/19, Honiara). Interviews with Vatu's administrators show they are willing to expand to address these needs but are also careful to do so in a way that does not impact on their overall education delivery (21/5/19, Vatu). Another pressure placed on Vatu is the content of their courses, which remains primarily concentrated on community livelihoods. Vatu's remoteness means that it is ill-placed to service urban needs, but there has been some pressure from external actors to service future industry that may arise from increasing 'development' in Eastern Guadalcanal. Vatu's leadership therefore face large pressure from external forces to change their practice which, if it were to happen, may impact on an already 'sustainable' community model of practice.

\section{Development, programming and sustainability}

The wider context in which RTCs continue to operate therefore poses various challenges, both to them and their graduates. Finding livelihoods opportunities at the community level remains a challenge for young people, with current options not seen as viable to support their families. While infrastructure and knowledge 'development' have taken place at many 
RTCs over the last five years, this has at times exacerbated the gap in funding between institutions. Alongside this, a changing TVET sector agenda means that many Solomon Islands RTCs now have to balance conflicting priorities that will impact their visions and purposes. This means that though many RTCs continue to operate in what would be considered a financially 'unsustainable' way, they are equally constrained by conflicting priorities in their ability to change this. These 'development' funding trends show the challenges and constraints RTCS face in balancing and adapting to what is currently a changing 'development' environment in the Solomon Islands.

However, it is key to remember, as noted previously, that RTCS are not a form of social enterprise. RTCs are, and have always been, education institutions that provide a core service that targets the majority of Solomon Islanders who are forced to leave school early. As a core service, their primary focus should be on delivering that service at a high level to ensure that young people have the best opportunity to support themselves and their communities. RTCS are only forced into economic self-sufficiency because they remain overlooked by national stakeholders for not conforming to the formal education sector's industry-focused priorities. Although promoting education as a pathway to 'development' has benefits, prioritising formal education institutions ignores the majority of Solomon Islanders (Fito'o, 2012). The reality is that there is not the demand in industry at present for those who graduate from formal institutions in the Solomon Islands, while there is a demand for relevant community skills. Although RTC economic 'sustainability' may be vital for RTCs in the short-term to ensure that staff have the resources to continue to produce positive outcomes for young people, this should not free central government from its responsibility to support these institutions in a way that is reflective of the lived experience of most people.

\section{Conclusion}

The extent to which local models of practice are supported by external 'sustainable development' agendas therefore depends very much on the alignment of their priorities. Whilst external actors can contribute to positive outcomes in supporting local models it is equally easy for their priorities to overshadow and co-opt the direction of these models; even working against local priorities at times. In the context of 'sustainable development', a primarily economic focus creates an unsustainable situation for RTCs in trying to support the needs of diverse communities across the Solomon Islands. External actors must therefore adopt more holistic conceptions of 'sustainable development', acknowledging the limits but 
also understanding that these limits promote a more truly 'sustainable' agenda to work towards. 


\section{CHAPTER 8}

\section{Conclusion}

This thesis explored how rural training centres (RTCs) function as local hubs of 'development' for people and their communities across the Solomon Islands. In doing so, it considered the nature and purpose of RTCs, presenting a holistic and internally co-dependent community model of education practice that external programming could and, at times, has supported over the last five years. Rather than portray a uniform 'community' perspective, it highlighted the many conceptions of 'modernity' that exist at the local level and the potential, and challenges, in external 'development' to support tangible impacts that address these 'development' goals. Questions of RTC function, impact and 'sustainability' can subsequently be discussed from this new perspective.

Exploring and supporting the RTC model has given credibility to the agency and ability of communities to dictate and drive their own processes of 'development' and 'modernity'. Revealing local stakeholder perspectives shows 'western' conceptions of education and 'development' practice are incomplete in their assessment of impact and 'sustainable development', and overlook many areas of community significance. Assumptions of stagnant 'rural knowledge' are also shown to be false, with RTCs effectively incorporating 'external knowledge' from programming into areas of local practice where they deemed it appropriate and useful. Whilst this creates impactful and sustainable outcomes for local communities when local agency is reinforced, external actor priorities often risk overshadowing this. 'Development' actors might therefore respond more effectively to power imbalances in the future, using holistic and iterative interpretations of practice that place diverse community interests first.

This final chapter therefore outlines the key findings of the research from an expanded understanding of localised practice, knowledge and wider considerations of 'development'. The contribution this research has made to future practice, and future areas for exploration, are also discussed. Finally, I conclude with a return to the post-development lens in the assessment of RTCs as hubs of 'development'.

\section{Expanding discourses of localised practice}

Using a social enterprise framework to analyse the RTC model of practice was insufficient in providing a holistic understanding of 'development' and 'modernity' in the Solomon Islands context. While core components of income and education were present, a further post- 
development analysis, informed by the input of participants, showed understandings that extended beyond a solely economic lens. Localised practice, including the people, processes and purposes, were equally driven by social, cultural and communal goals in the RTC 'community' and beyond.

We are therefore able to better understand how 'community' models can act as their own interdependent hubs of diverse 'development' (Green \& Haines, 2015). This shows that communities are well-placed and capable of setting their own priorities for 'development', within cultural and social structures that are already firmly established at the local level (Esteva \& Prakash, 2014). Rather than risk silencing this through destructive discourses, the emphasis in practice should be to work with and from what is already in place. This is significant given the fears that many in other contexts have expressed in having to balance the economic and social paradoxes of 'development' expectations (MacLean \& Brass, 2015). In the RTC context, directly adopting a business-oriented model in an educational context had the potential to reduce downward accountability to the 'community' and undermine their original social missions. Whilst other organisational models might maintain links to an overall social mission, identifying which models is most appropriate can only be done on a case-by-case basis. These consequences are important to consider for TVET in the Solomon Islands context and beyond and can inform the ways in which education institutions engage with these processes over time.

\section{Expanding discourses of localised 'knowledge'}

Further exploration of the RTC 'community' model showed mixed impact and change over the last five years across different groups and communities. This included assessing 'knowledge' transfer through 'development' programming, and how this impacted on 'indigenous knowledge' at the community level. Evidence from participants showed multiple ways in which new concepts and approaches were incorporated into RTC education and operations, but also the varied impact of this across communities. Staff that took part in trainings, and those that did not, adapted and incorporated new learnings into their own understandings and contexts, rather than simply replacing one set of 'knowledge' with another.

There are two key lessons from this regarding interpretations of 'knowledge' and impact in 'development' practice. Firstly, this research has challenged the idea of 'indigenous' knowledge as something that is stagnant, separate or a pre-cursor to 'western' knowledge (Apffel-Marglin \& Marglin, 1996). Rather, the distinction is better understood as stemming 
from what Agrawal describes as "multiple domains and types of knowledges, with differing logics and epistemologies" (1995, p. 433). Where some RTC staff noted benefits from external programming, others thought that some information was already known prior to training and, at times, not relevant to their context. 'Indigenous' knowledge might therefore be better conceived as contextually-relevant understanding, which has the capacity to adapt and change over time based on local processes, goals and needs (Gegeo \& Watson-Gegeo, Whose knowledge? Epistemological collisions in Solomon Islands community development, 2002). Though external knowledge can support in this regard, it is important it does not detract from what is already in place through some sort of false 'knowledge superiority'. Secondly, external programming can play a key part in creating positive impact through 'knowledge' transfer. However, the role of 'development' in this process is as a supplier to local models of practice rather than as the conductor of community 'development' (Ball \& Pence, 2006). The agency of local actors, both within the Solomon Islands and beyond, extends past setting the agenda to also include what learnings are taken onboard. External knowledge is therefore only relevant to local settings as a component of understanding and knowledge integration.

Though local actors have agency in the creation of localised knowledge, there are some limitations to this. Whilst promoting local perspectives and processes of knowledge, this thesis does not seek to idealise everything that takes place in local communities. Equally important in this assessment of impact was emphasising that the benefits of 'development', whether due to direct or indirect reasons, were not felt equally by all (Sachs W. , 2013). Those at the local level in the Solomon Islands are not exempt from their own discourses of power and this was felt particularly by women, in their relative exclusion from 'development' outputs, and young people, in processes of decision-making (Escobar, 1995). For wider practice, the challenge is to explore these imbalances and understand how, within the confines of local structures, support can reach a broader group of people (Escobar, 2001). Changes on the part of Caritas workers, including expanding outputs to include financial capability for women, are good examples of how external programming can adapt to diverse sets of localised 'knowledge'.

\section{Expanding discourses of 'development'}

Finally, it is important to highlight the national and global processes of 'development' that can, and have had, great influence on successes and challenges for local models of practice. An exploration of the ways in which RTCs and their graduates navigate these processes 
showed various ongoing and evolving challenges to local livelihoods and practice. Historical, political and economic imbalances still negatively impact on rural areas, with young people often forced into urban centres in pursuit of employment. Decisions on RTC nature, purpose and 'sustainable development' are also regularly made outside of communities this impacts. The push for RTC sustainability through new governance structures that promote global economic discourses of 'development' has been aided and, at times, driven by external 'development' actors (Escobar, 1995). Processes of RTC formalisation, through the 'Technical Institute' model, have the potential to support mainstream discourses at the expense of the most marginalised. As a consequence, RTCs are effectively caught in a sustainability paradox (Devine, 2003) between conforming to external perceptions to support their 'development' or maintaining their relevance in informal settings with few options for growth. Though there are notable examples of RTCs challenging and overcoming these external pressures, sustaining localised models of 'development is not an easy process.

Given the power of external 'development' discourses to influence in these ways, there are some key lessons for practice. Firstly, 'development' practice in general would benefit from an approach that places its work in context and considers the wider implications of its outputs (Gallopin, 2003). Doing so reduces the risk of projects and workers becoming too insular in their approaches to 'development' (Gibson-Graham, 2005). The lack of collaboration and alignment of goals across the two major 'development' programmes targeting the Solomon Islands TVET sector over the last five years has at times negatively impacted on the success of both initiatives. Key to this was the failure of 'development' workers to acknowledge areas of overlap, despite operating in the same sector. This illustrates the dangers of insular approaches to 'development', which fail to understand and respond to the interconnectedness of systems and processes (Escobar, 1995).

Secondly, effective and accurate governance and 'development' structures that are able to connect with and serve local interests are key to supporting local models of practice (Barkemeyer, Holt, Preuss, \& Tsang, 2014). Variations in the ability of RTC governance structures to support local practice creates challenges to the trajectory of the RTCs network, and this is primarily due to differing 'development' priorities. Engaging with more holistic conceptions of 'development' opens the door for new perspectives and values that are more representative of diverse understandings (Ziai, 2015).

Following on from this, we must expand global 'development' discourses to include and cater to diverse understandings of 'modernity' (Escobar, 1995). The economic development 
agenda that was prevalent in donor funding five years ago remains the primary means and measurement in 'development' (Murray \& Overton, 2016), and this is incomplete in its assessment of RTC outcomes. If flexible aid approaches are not adopted in the case of RTCS we threaten to overlook and undermine the work that started long before more mainstream and rigid strategies of aid and 'development' were involved (Sidaway, 2014).

\section{Contribution of this research}

This research focused on assessing the outputs of 'development' practice. It not only provided an example of how academia can work alongside practical 'development', but also showed how this can inform better practice and encourage meaningful research. It shows that this is possible in the confines of a master's thesis, encouraging future engagement and learning between sectors, for the mutual benefit of both.

The findings of this research have evaluated the work of Caritas Aotearoa New Zealand (Caritas), Solomon Islands Association of Vocational Rural Training Centres (SIAVRTC) and other stakeholders over the last five years. A shorter organisational report and findings summary were also prepared to distribute to the RTCs and other interested parties, as well as individual organisational feedback that was given at the request of the RTCs during visits. Feedback on my analysis and recommendations indicated that it was useful in showing tangible areas of improvement for RTC programming, as well as for the design of future programming in the RTC sector. A key strength in this regard was engaging students as stakeholders in the RTC community, giving voice to some notably distinct perspectives on the key themes discussed.

The research built on existing literature and processes to explore the forefront of current 'development' thinking. It considered the challenges and opportunities in balancing education, operational sustainability and 'development' (MacLean \& Brass, 2015) in the Solomon Islands context. These findings are grounded in place but have significant implications for how we approach 'development' practice. They contribute to multiple areas of the literature, including community development (Green \& Haines, 2015), sustainable enterprise (Ridley-Duff \& Bull, 2018), 'indigenous' knowledge and aid discourses (Cummings, Regeer, de Haan, Zweekhorst, \& Bunders, 2018) in the Solomon Islands, which are relevant to wider patterns at the global scale.

Finally, this research engaged with post-development critiques of 'development' (Escobar, 1995; Esteva \& Prakash, 2014; Sachs J. D., 2015) whilst also going beyond this in providing 
tangible solutions to programming challenges. In doing so, it has reinforced the relevance of post-development to practical settings as a constructive tool to realistically improve practice.

\section{Where to from here?}

The wide thematic scope of this research has opened several areas for future study. Though the selected sites have been studied in depth, future research might assess the disparities between RTCs across the Solomon Islands, particularly those not targeted under 'development' projects. The ongoing evolution of the Solomon Islands Tertiary Education and Skills Authority (SITESA), including changes to policy surrounding qualification standards and curriculum, are areas of uncertainty in the ultimate direction of the TVET sector. In particular, the future implications of the Technical institute model of education for different Church stakeholders is an area that remains unclear.

At the regional and global level, there are two areas that stand out for further research. The shift towards a programmatic approach to 'development' as part of the New Zealand government's Negotiated Partnerships mechanism encourages organisations in the sector to build shared learnings across place (MFAT, 2019a). The increasingly developed body of literature on RTCs in the Solomon Islands could be used as a starting point for wider understandings of localised education models throughout the Pacific. Similar to this, studies of organisational hybridisation and adaptation in the Pacific, such as education institutions adopting social enterprise models (MacLean \& Brass, 2015), have yet to be explored in any great depth. Work in this area could explore conceptions of 'sustainability' and their influence on national policymaking for core public services.

\section{Enterprising hubs of local practice}

This thesis has sought to expand conceptions of 'modernity' in a way that gives credibility and agency to local models of practice as hubs of 'development' in the Solomon Islands and beyond.

Underlying global assumptions have consistently portrayed a singular 'modernity' that creates ordered and uniform 'progress' for all (Gupta, 1995). However, the fruits of this apparent progress remain to be seen globally, and in many places the gap between economically 'rich' and 'poor' is only expanding. Therein lies the issue, with the assumption of 'modernity' being based on an economic discourse that is incomplete in its understanding of the world. For most young people in the Solomon Islands, the formal education that they are often not in a position to even receive rarely prepares them for the realities of life. For 
those that travel to urban centres, employment opportunities are in short supply, with 'development' rarely extending to remote areas of the country to support community livelihoods. As a result, people are boxed into an "under-developed subjectivity endowed with features such as powerlessness, passivity, poverty and ignorance" (Escobar, 1995, p. 8). However, in the midst of this comes the realisation that many of 'those people' do not see it that way. The worldview that we place on others fails to capture what 'we' do not understand about how others perceive 'modernity'. For some 'modernity' is also family and home; as much 'informal' as it is 'formal'. In this light, the RTCs are key to supporting local 'development' goals. They do so with education that is considered 'informal', yet it is very relevant for the young people they work with and for. The RTC model expands understandings of 'development' practice at local levels, with external actors as the followers, rather than drivers, of this process. This thesis does not reject 'development', but it does aspire to better approaches in practice, and START's work over the last five years with the RTCs has often been in the right direction in this regard. 


\section{References}

ADB. (2019). Asian Development Bank Member Fact Sheet: Solomon Islands. Honiara, Solomon Islands.

Agrawal, A. (1995). Dismantling the divide between indigenous and scientific knowledge. Development and Change, 26, 413-439.

Amir, A., Ghapar, A., Jamal, S., \& Ahmad, K. (2015). Sustainable tourism development: A study on community resilience for rural tourism in Malaysia. Procedia-Social and Behavioral Sciences, 168, 116-122.

Apffel-Marglin, F., \& Marglin, S. A. (1996). Decolonizing Knowledge: From Development to Dialogue. Oxford: Oxford University Press.

Arensberg, C. M., \& Niehoff, A. H. (1971). Introducing Social Change: A Manual for Community Development (2 ed.). London: Routledge.

Austin, J., \& H Stevenson, J. W.-S. (2006). Social and commercial entrepreneurship: same, different or both? Entrepreneurship Theory and Practice, 30(1), 1-22.

Baker, J. L. (2000). Evaluating the Impact of Development Projects on Poverty: A Handbook for Practitioners. New York: World Bank.

Ball, J., \& Pence, A. (2006). Supporting Indigenous Children's Development. Vancouver: UBC Press.

Barkemeyer, R., Holt, D., Preuss, L., \& Tsang, S. (2014). What happened to the 'development' in sustainable development? Business guidelines two decades after Brundtland. Sustainable Development, 22(1), 15-32.

Barrett, A. (2011). A millennium learning goal for education post-2015: a question of outcomes or processes. Comparative Education, 47(1), 119-133.

Baster, N. (1972). Measuring Development: The Role and Adequacy of Development Indicators. London: Frank Cass and Company Ltd.

Bennett, J. A. (2000). Pacific Forest: A History of Resource Control and Contest in Solomon Islands, c. 1800-1997. Cambridge: The White Horse Press.

Birchler, K., \& Michaelowa, K. (2016). Making aid work for education in developing countries: An analysis of aid effectiveness for primary education coverage and quality. International Journal of Educational Development, 48, 37-52.

Bray, M. (1991). Making Small Practical: The Organisation and Management of Ministries of Education in Small States. London: Commonwealth Secretariat.

Briggs, J. (2005). The use of indigenous knowledge in development: problems and challenges. Progress in Development Studies, 5(2), 99-114.

Bujra, J. (2006). Lost in translation? The use of interpreters in fieldwork. In V. Desai, \& R. B. Potter, Doing Development Research (pp. 173-179). London: SAGE Publications Ltd. 
Campbell, A., \& Groundwater-Smith, S. (2007). An Ethical Approach to Practitioner Research. New York: Routledge.

Carant, J. B. (2016). Unheard voices: a critical discourse analysis of the millennium development goals' evolution into the sustainable development goals. Thrid World Quarterly, 38(1), 16-41.

Carley, M., \& Christie, I. (2000). Managing Sustainable Development. London: Routledge.

Castro-Sitiriche, M. (2015). Transformations for sustainable development: promoting environmental sustainability in Asia and the Pacific. International Workshop on System Dynamics, Big Data and Cloud Computing. Mayaguez: University of Puerto Rico.

Cavaye, J. (2001). Rural community development- new challenge and enduring dilemmas. Journal of Regional Analysis and Policy, 31(2), 1-16.

CDP. (2018). Vulnerability Profile of Solomon Islands. Committee for Development Policy 20th Plenary Session. New York: United Nations.

Chambers, R. (1983). Rural Development: Putting the Last First. Harlow: Prentice Hall.

Chambers, R. (2007). From PRA to PLA and Pluralism: Practice and Theory. Brighton: Institute of Development Studies.

Connell, J. (2013). Islands at Risk? Environments, Economics and Contemporay Change. Cheltenham: Edward Elgar Publishing Ltd.

Cooke, B., \& Kothari, U. (2001). Participation: The New Tyranny? New York: Zed Books.

Cooperrider, D., \& Whitney, D. (2000). A positive revolution in change: appreciative inquiry. In D. Cooperrider, P. Sorensen, D. Whitney, \& T. Yaeger (Eds.), Appreciative Inquiry (pp. 4-24). Champaign, IL: Stipes.

Corbridge, S. (1998). 'Beneath the pavement only soil': the poverty of post-development. The Journal of Development Studies, 34(6), 138-148.

Corbridge, S. (2007). The (im)possibility of development studies. Economy and Society, 36, 179-211.

Cummings, S., Regeer, B., de Haan, L., Zweekhorst, M., \& Bunders, J. (2018). Critical discourse analysis of perspectives on knowledge and the knowledge society within the sustainable development goals. Development Policy Review, 36, 727-742.

Curry, G. (2003). Moving beyond postdevelopment: facilitating indigenous alternatives for "development". Economic Geography, 79(4), 405-423.

Daly, H. (2007). Sustainable development and OPEC. In H. Daly, Ecological Economics and Sustainable Development (pp. 156-166). Cheltenham: Edward Elgar.

De Ferranti, D., Perry, G. E., Ferreira, F. H., Walton, M., Coady, D., Cunningham, W., . . . Wodon, Q. (2003). Inequality in Latin America and the Caribbean: Breaking with History? Washington D.C.: The World Bank. 
Desai, V., \& Potter, R. B. (2006). Doing Development Research. London: SAGE Publications Ltd.

Desai, V., \& Potter, R. B. (2014). The Companion to Development Studies (3 ed.). New York: Routledge.

Devine, J. (2003). The paradox of sustainability: reflections on NGOs in Bangladesh. The American Academy of Political and Social Science, 590(1), 227-242.

Dinnen, S. (2010). Winners and losers: politics and disorder in the Solomon Islands 20002002. Journal of Pacific History, 37(3), 285-298.

Edwards, A. D., \& Jones, D. G. (1976). Community and Community Development. The Hague: Mouton \& Co.

Escobar, A. (1995). Encountering Development: the Making and Unmaking of the Third World. Princeton: Princeton University Press.

Escobar, A. (2001). Culture sits in places: reflections on globalism and subaltern strategies of localization. Political Geography, 20, 139-74.

Escobar, A. (2004). Beyond the third world: imperial globality, global coloniality and antiglobalization social movements. Third World Quarterly, 25(1), 207-230.

Esteva, G., \& Prakash, M. S. (2014). Grassroots Postmodernism: Remaking the Soil of Cultures. London: Zed Books Ltd.

Esteva, G., Babones, S., \& Babcicky, P. (2013). The Future of Development: A Radical Manifesto. Bristol: Policy Press.

Ezilon Maps. (2015). Solomon Islands Map - Politcal Map of Solomon Islands. Retrieved from Ezilon Maps: https://www.ezilon.com/maps/oceania/solomon-islandsmaps.html

Feeny, S., Hermes, N., \& Lensink, R. (2006). Controversies over the impact of development aid: it works, it doesn't; it can, but that depends... Journal of International Development, 18(7), 1031-1050.

Ferguson, J., \& Lohmann, L. (1994). The anti-politics machine: "development" and bureaucratic power in Lesotho. The Ecologist, 24(5), 176-181.

Fito'o, B. (2012). Rethinking citizenship in the Solomon Islands. In K. Sanga, \& J. Kidman, Harvesting Ideas: Niu Generation Perspectives (pp. 72-86). Suva: USP Press.

Fleming, K. (2015). Diverse Education for Diverse Economies: The Relevance of Rural Training Centres in the Solomon Islands. Wellington: Victoria University of Wellington.

Foucault, M. (1980). Power/Kowledge: Selected Interviews and Other Writings 1972-1977. New York: Pantheon Books.

Gallopin, G. (2003). A Systems Approach to Sustainability and Sustainable Development. Santiago: UNCEPAL. 
Garikipati, S., Johnson, S., Guerin, I., \& Szafarz, A. (2016). Microfinance and gender: issues, challenges and the road ahead. The Journal of Development Studies, 57(5), 641648.

Gegeo, D. (1998). Indigenous knowledge and empowerment: rural development from examined from within. Contemporary Pacific, 10(2), 289-315.

Gegeo, D., \& Watson-Gegeo, K. (2002). Whose knowledge? Epistemological collisions in Solomon Islands community development. The Contemporary Pacific, 14(2), 377409.

Gibson-Graham, J. (2005). Surplus possibilities: postdevelopment and community economies. Singapore Journal of Tropical Geography, 26(1), 4-26.

Gray, D. E. (2004). Doing Research in the Real World. London: SAGE Publications.

Gredler, M. (1997). Learning and Instruction: Theory into Practice (3 ed.). New Jersey: Prentice-Hall.

Green, G. P., \& Haines, A. (2015). Asset Building \& Community Development. London: SAGE Publications.

Gross, J., LeRoy, G., \& Janis-Aparicio, M. (2002). Community Benefits Agreements: Making Development Projects Accountable. Washington D.C.: Good Jobs First.

Grunkemeyer, W. T., \& Moss, M. L. (2011). The sustainable community model approach to the development and use of multi-dimensional quality of life indicators. In J. Sirgy, D. Rahtz, \& D.-J. Lee, Community Quality-of-Life Indicators (pp. 29-52). Dordrecht: Springer.

Gupta, A. (1995). Blurred boundaries: the discourse of corruption, the culture of politics, and the imagined state. American Ethnologist, 22(2), 375-402.

Hák, T., Janoušková, S., \& Moldan, B. (2016). Sustainable development goals: a need for relevant indicators. Ecological Indicators, 60, 565-573.

Hall, S. (2018). The west and the rest: discourse and power. In T. D. Gupta, C. E. James, C. Andersen, G.-E. Galabuzi, \& R. C. Maaka, Race and Racialization: Essential Readings (2 ed., pp. 85-93). Toronto: Canadian Scholars.

Hansen, J. A., \& Lehmann, M. (2006). Agents of change: universities as development hubs. Journal of Cleaner Production, 14(9-11), 820-829.

Harris, M. (2010). Third sector organisations in a contradictory policy environment. In D. (. Billis, Hybrid Organisations and the Third Sector: Challenges for Practice, Theory and Policy (pp. 25-45). New York: Macmillan International Higher Education.

Homi Kharas, H., \& Rogerson, A. (2012). Horizon 2025: Creative Destruction in the Aid Industry. London: Overseas Development Institute.

IMF. (2018). Solomon Islands 2017 Article IV Consultation. Washington D.C.: International Monetary Fund. 
Jing, Y., Mendez, A., \& Zheng, Y. (2019). New development assistance in the making: an introduction. In Y. Jing, A. Mendez, \& Y. Zheng, New Development Assistance. Governing China in the 21st Century (pp. 1-18). Singapore: Palgrave Macmillan.

Jones, M. (2018). Solomon Islands. In M. Lamport, Encyclopedia of Christianity in the Global South (pp. 733-737). Lanham: Rowman \& Littlefield.

Kabutaulaka, T. T. (2017). Deforestation and politics in Solomon Islands. In P. Larmour, Governance and Reform in the South Pacific (pp. 121-153). Canberra: National Centre for Development Studies, ANU.

Kim, B. (2001). Social constructivism: a review. Conference on Emerging Perspectives on Learning, Teaching and Technology. Atlanta: University of Georgia.

King, E., \& Hill, A. (1993). Women's Education in Developing Countries: Barriers, Benefits, and Policies. New York: World Bank.

Knutsson, B. (2012). Education, development and the imganiary global consensus: reframing educational planning dilemmas in the South. Third World Quarterly, 33(5), 807-824.

Korten, D. (1980). Community organization and rural development: a learning process approach. Public Administrative Review, 40(5), 480-511.

Laungi, A. J. (2019, July 21). No more grade 6 exams. Solomon Star.

Le Blanc, D. (2015). Towards integration at last? The sustainable development goals as a network of targets. Sustainable Development, 23(3), 176-187.

Leal, P. (2010). Participation: the ascendary of a buzzword in the neo-liberal era. Development in Practice, 17(4-5), 539-548.

Leeuw, F., \& Vaessen, J. (2009). Impact Evaluations and Development: NONIE Guidance on Impact Evaluation. Cairo: NONIE.

Lindstrom, L. (1981). 'Big man': a short terminological history. American Anthropologist, 83(4), 900-905. Retrieved from https://www.jstor.org/stable/676254?seq=1\#metadata_info_tab_contents

Longhurst, R. (2010). Semi-structured interviews and focus groups. In N. Clifford, \& G. Valentine, Key Methods in Geography (pp. 103-115). London: SAGE Publications.

Lyon, F., \& Jackson, T. (2015). Alternative enterprise and gross national happiness: an agenda for sustainable prosperity. International Conference on Gross National Happiness. Paro, Bhutan.

MacLean, M., \& Brass, J. (2015). Foreign aid, NGOs and the private sector: new forms of hybridity in renewable energy provision in Kenya and Uganda. Africa Today, 62(1), 57-82.

Matthews, S. (2004). Post-development theory and the question of alternatives: a view from Africa. Third World Quarterly, 25(2), 373-384.

Mawdsley, E. (2015). DFID, the private sector and the re-centring of an economic growth agenda in international development. Global Society, 29(3), 339-358. 
Maxwell, J. A. (2013). Qualitative Research Design: An Interactive Approach. New York: SAGE Publications.

Mayoux, L. (2006). Quantitative, qualitative or participatory? Which method, for what and when? In V. Desai, \& R. B. Potter, Doing Development Research (pp. 115-129). London: SAGE Publications Ltd.

McEwan, C. (2008). Postcolonialism and Development. London: Routledge.

McGregor, A. (2009). New possibilities? Shifts in post-development theory and practice. Geography Compass, 3(5), 1688-1702.

McMahon, M. (1997). Social constructivism and the world wide web - a paradigm for learning. ASCILITE conference. Perth.

Meadows, D. H., Meadows, D. L., Randers, J., \& Behrens III, W. W. (1972). The Limits to Growth. Washington DC: Potomac Associates.

Mercer, C. (2006). Working with partners: NGOs and CBOs. In V. Desai, \& R. B. Potter, Doing Development Research (pp. 94-103). London: SAGE Publications.

MFAT. (2019a, November 18). New Zealand Foreign Affairs and Trade. Retrieved December 13, 2019, from https://www.mfat.govt.nz/en/aid-and-development/working-withus/funding-opportunities/partnering-for-impact-2/partnering-for-impact-a-newapproach-to-partnering-with-new-zealand-ngos/

MFAT. (2019b, November 11). Our Development Cooperation in Solomon Islands. Retrieved from New Zealand Foreign Affairs \& Trade: https://www.mfat.govt.nz/en/countries-and-regions/pacific/solomon-islands/ourdevelopment-cooperation-in-solomon-islands/

Murray, W., \& Overton, J. (2016). Aid and the 'circle of security'. In J. Grugel, \& D. Hammett, The Palgrave Handbook of International Development (Vol. 16, pp. 433450). London: Macmillan Publishers Ltd.

Nyssens, M. (2007). Social Enterprise: At the Crossroads of Market, Public Priorities and Civil Society. London: Routledge Publishing.

Ohmer, M., Meadowcroft, P., Freed, K., \& Lewis, E. (2009). Community gardening and community development: individual, social and community benefits of a community conservation program. Journal of Community Practice, 17(4), 377-399.

Olawumi, T. O., \& Chan, D. W. (2018). A scientometric review of global research on sustainability and sustainable development. Journal of Cleaner Production, 183, 231-250.

Pearson, R. (2005). The rise of gender and development. In U. Kothari, A radical history of development studies: individuals, institutions and ideologies (pp. 157-179). London: Zed Books.

Petty, N. J., Thomson, O. P., \& Stew, G. (2012). Ready for a paradigm shift? Part 1: Introducing the philosophy of qualitative research. Manual Therapy, 17(4), 267274. 
Pieterse, J. (1998). My paradigm or yours? Alternative development, post-development, reflexive development. Development and Change, 29, 343-373.

Pieterse, J. N. (2010). Development Theory: Deconstructions/Reconstructions (2 ed.). Los Angeles: SAGE Publications.

Plan International Australia. (2019). Our Education, Our Future. Southbank: Plan International Australia.

Powell, F., \& Geoghegan, M. (2005). The Politics of Community Development. The Adult Learner, 95-98.

Psacharopoulod, G., \& Patrinos, H. A. (2004). Returns to education in developing countries. Education Economics, 12(2), 111-134.

Rahnema, M., \& Bawtree, V. (1997). The Postdevelopment Reader. London: Zed Books Ltd.

Ridley-Duff, R., \& Bull, M. (2016). Understanding Social Enterprise: Theory and Practice (2nd Ed.). London: Sage Publications.

Ridley-Duff, R., \& Bull, M. (2018). Towards and appreciation of ethics in social enterprise business models. Journal of Business Ethics, 159, 1-16.

Robson, C. (1993). Real World Research. Oxford: Blackwell.

Sachs, J. D. (2015). The Age of Sustainable Development. New York: Columbia University Press.

Sachs, W. (2013). Liberating the world from development. New Internationalist, 460, 22-27.

Sachs, W. (2017). The sustainable development goals and laudato si': varieties of postdevelopment? Third World Quarterly, 38(12), 2573-2587.

Said, E. (1985). 'Orientalism reconsidered': cultural critique. Race \& Class, 27(2), 1-15.

Sanga, K. (2009). The Pacific Public Servant: Serving Three Masters? Canada: Graduate School of Public Policy, University of Saskatchewan.

Sanga, K. (2019). Ethics curriculum in indigenous Pacific: a Solomon Islands study. AlterNative: An International Journal of Indigenous Peoples, 15(3), 243-252.

Sanga, K., \& Houma, S. (2004). Solomon Islands principalship: roles perceived, performed, preferred and expected. Directions: Journal of Educational Studies, 26(1), 55-69.

Sanga, K., \& Maneipuri, J. (2002). School changes and the Solomon Islands secondary principal. Directions: Journal of Educational Studies, 24(2), 40-59.

Santos, B. d. (2004). The world social forum: towards a counter-hegemonic globalisation (part 1). In J. Sen, A. Anad, A. Escobar, \& P. Waterman, The World Social Forum: challenging empires (pp. 235-245). New Delhi: The Viveka Foundation.

Scott, A., Gilbert, A., \& Gelan, A. (2007). The urban-rural divide: myth or reality? SERG Policy Brief Number 2. Macaulay Institute. 
Sebele, L. (2010). Community-based tourism ventures, benefits and challenges: Khama Rhino Sanctuary Trust, Central District, Botswana. Tourism Management, 31(1), 136-146.

Sen, A. (1999). Development as Freedom. New York: Random House Inc.

Shamin, F., \& Qureshi, R. (2013). Informed consent in educational research in the south: tensions and accommodations. Compare: A Journal of Comparative and International Education, 43, 464-482.

Sidaway, J. D. (2014). Post-development. In V. Desai, \& R. B. Potter, The Companion to Development Studies (3 ed., pp. 147-152). New York: Routledge.

SIG. (2015). Household Income and Expenditure Survey- Provincial Analytical Report. Honiara: Solomon Islands National Statistics Office.

SIG. (2017a). Ministry of Education and Human Resources Development- Annual Report 2017. Honiara: Solomon Islands Government.

SIG. (2017b). Youth empowerment for sustainable livelihoods- leave no one behind. National Youth Policy 2017-2030. Honiara, Solomon Islands: Ministry of Women, Youth, Children and Family Affairs.

SIG. (2018). Solomon Islands Budget 2018: Budget Strategy and Outlook. Honiara, Solomon Islands: Ministry of Finance, Solomon Islands Government.

Sillitoe, P., Bicker, A., \& Pottier, J. (2002). Participating in Development: Approaches to Indigenous Knowledge. London: Routledge.

Simon, D. (2007). Beyond antidevelopment: discourses, convergences, practices. Singapore Journal of Tropical Geography, 28(2), 205-218.

Smith, J. (2016). Contested understandings of sustainability and climate issues in southern Costa Rica. The Economics of Ecology, Exchange, and Adaptation: Anthropological Explorations Research in Economic Anthropology, 36, 33-56.

Sumner, A., \& Tribe, M. (2004). The nature of epistemology and methodology in development studies: what do we mean by 'rigour'? Exploring the frontiers in Development Studies epistemology and methodology. London: DSA Annual Conference.

Sumner, A., \& Tribe, M. (2008). International Development Studies: Theories and Methods in Research and Practice. London: SAGE Publications Ltd.

Swart, K., \& Bob, U. (2004). The seductive discourse of development: the Cape Town 2004 olympic bid. Third World Quarterly, 25(7), 1311-1324.

Thomas, V., Dailimi, M., Dhareshwar, A., Kaufmann, D., Kishor, N., Lopez, R., \& Wang, Y. (2000). The Quality of Growth. Berlin: Oxford University Press.

UNCTAD. (2019). The Least Developed Countries Report 2019. New York: United Nations Publications.

UNDP. (2018). Solomon Islands Youth Status Report 2018. New York: United Nations Development Programme. 
UNDP. (2018a). Human development indices and indicators: 2018 statistical updateSolomon Islands. New York.

UNESCO. (2019, March 25). Solomon Islands Participation in Education. Retrieved from UNESCO Institute of Statistics: http://uis.unesco.org/country/SB

UNICEF. (2011). UNICEF Annual Report 2010. New York: United Nations.

United Nations. (2019). Why it matters: quality education. Sustainable Development Goals resource.

Valentine, G. (2005). 'Tell me about... using interviews as a research methodology'. In R. Flowerdew, \& D. Martin, Methods in Human Geography: A Guide for Students Doing a Research Project (2 ed., pp. 110-127). Edinburgh Gate: Addison Wesley Longman.

van Dijk, T. A. (2014). Discourse and Knowledge: A Sociocognitive Approach. Cambridge: Cambridge University Press.

van Donge, J. K. (2006). Ethnography and participant observation. In V. Desai, \& R. B. Potter, Doing Development Research (pp. 180-188). London: SAGE Publications.

WCED. (1987). Our Common Future: The World Commission on Environment and Development. Oxford: Oxford University Press.

Wilson, J. S., Mann, C. L., \& Otsuki, T. (2003). Trade Facilitation and Economic Development: Measuring the Impact. Washington DC: The World Bank Development Research Group.

WINTEC. (2017). WINTEC Annual Report 2017. Hamilton.

Wodak, R., \& Meyer, M. (2016). Methods of Critical Discourse Studies. London: SAGE Publications.

Zautra, A., Hall, J., \& Murray, K. (2008). Community development and community resilience: an integrative approach. Journal of the Community Development Society, 39(3), 1-18.

Ziai, A. (2015). Post-development: premature burials and haunting ghosts. Development and Change, 46(4), 833-854. 
Appendices

Appendix 1: VUW Human Ethics Approval

TE Whare wãnANGa o TE Ó POKo O TE IKa a MãUI

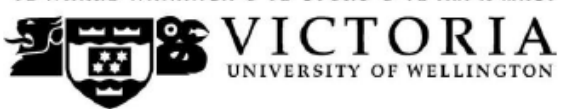

MEMORANDUM

Phone 0-4-463 6028

Email judith.loveridge@vuw.ac.nz

\begin{tabular}{l|l}
\hline TO & Finn Egan \\
\hline FROM & Dr Judith Loveridge, Convenor, Human Ethics Committee \\
\hline
\end{tabular}

\begin{tabular}{l|l}
\hline DATE & 18 April 2019 \\
\hline PAGES & 1 \\
\hline
\end{tabular}

\begin{tabular}{l|l}
\hline SUBJECT & Ethics Approval
\end{tabular}

Number: 27385

Title: Enterprising Enterprises: Sustainable rural training

centre models in the Solomon Islands

Thank you for your application for ethical approval, which has now been considered by the Human Ethics Committee.

Your application has been approved from the above date and this approval is valid for three years. If your data collection is not completed by this date you should apply to the Human Ethics Committee for an extension to this approval.

Best wishes with the research.

Kind regards,

\section{A. homeidge}

Judith Loveridge

Convenor, Victoria University of Wellington Human Ethics Committee 


\section{Appendix 2: Solomon Islands Research Permit}

Solomon Islands Government

Ministry of Education and Human Resources Development $\quad \mathrm{Ph}$ :(677) 24664

POBox G 28

Fax: (677) 22042

Honiara, Solomon Islands

Our Ref: $13 / 19$

Date: $13 / 05 / 2019$

In Accordance to the Research Act 1982 (No. 9 of 1982) RESEARCH PERMIT:

Permission is hereby given to:

1. Name (s): Finn Egan

2. Country: New Zealand

3. Research subject areas: The study will be on Enterprising Enterprises: Sustainable rural training centre models in Solomon Islands.

4. Ward (s): Vatu, Visale and Tetere, Kolobangara and Noro

5. Provinces: Guadalcanal and Western Province

6. Conditions:

a. To undertake research only in subject areas specified in 3 above.

b. To undertake research only in the ward (s) and Province (s) specified in 4 and 5 above.

c. To observe with respect at all times local customs and the way of life of people in the area in which the research is carried out.

d. Not to take part at any time in any political or missionary activities or local disputes.

e. To leave four (4) copies of your final research report in English with the Solomon islands Government Ministry responsible for research at your own expense.

f. A research fee of SBD500.00 must be paid in full or the Research Permit will be cancelled. (See sec. 3 subject 7 of the Research Act).

g. This permit is valid until $\mathbf{8}^{\text {th }}$ June, $\mathbf{2 0 1 9}$ provided all conditions are adhered to.

h. No live species of plants and animals to be taken out of the country without approval from relevant authorities.

i. A failure to observe the above conditions will result in automatic cancellation of this permit and the forfeit of your deposit.

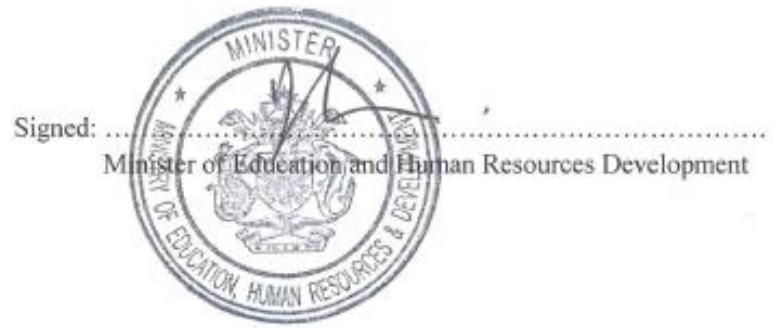

Date:

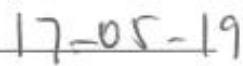




\title{
Appendix 3: Participant information sheet and consent form
}

\section{TE WHARE WĀNANGA O TE ŨPOKO O TE IKA A MĀUI

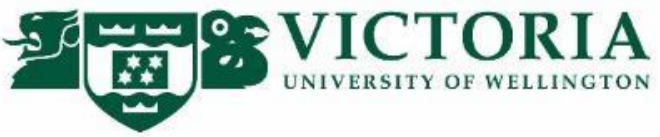 \\ Enterprising Enterprises: Sustainable rural training centre models in the Solomon Islands}

\author{
INFORMATION SHEET FOR INTERVIEW PARTICIPANTS
}

You are invited to take part in this research. Please read this information before deciding whether or not to take part. If you decide to participate, thank you. If you decide not to participate, thank you for considering this request.

Who am I?

My name is Finn Egan and I am a Masters student in Development Studies at Victoria University of Wellington. This research project is work towards my thesis.

What is the aim of the project?

This project project looks at the different businesses that are used by Solomon Islands rural training centres and the ways in which different community groups interact with them. Your participation will support this research by showing us how rural training centres have changed over the past 5 years. This research has been approved by the Victoria University of Wellington Human Ethics Committee (\#0000027385).

How can you help?

You have been invited to participate because you are a local community leader, member, student, administrator or teacher with a connection to your local rural training centre. If you agree to take part, I will interview you in a location that we are both comfortable with. I will ask you questions about the business of your local rural training centre and the opportunities it gives to you and the community. The interview will take about 30 minutes to an hour. I will audio record the interview with your permission and take notes to help with my memory to write up later. You can choose to not answer any question, ask to turn off the recorder or stop the interview at any time, without giving a reason. You can withdraw from the study by contacting me at any time by email, phone, or through SIARTC before $1^{\text {st }}$ June, 2019. If you withdraw, the information you provided will be destroyed or returned to you.

What will happen to the information you give?

This research is confidential*. This means that the researchers named below will be aware of your identity but the research data will be combined and your identity will not be revealed in any reports, presentations, or public documentation. However, you should

\footnotetext{
* Confidentiality will be preserved except where you disclose something that causes me to be concerned about a risk of harm to yourself and/or others.
} 
be aware that in small projects your identity might be obvious to others in your community.

Only my supervisors, a translator, a transcriber (who will both be required to sign a confidentiality agreement) and I will read the notes or transcript of the interview. The interview transcripts, summaries and any recordings will be kept securely and destroyed on March 3, 2020.

\section{What will the project produce?}

The information from my research will be used in my Masters thesis and a report to Caritas Aotearoa (a New Zealand development organisation) and the Solomon Islands Association of Rural Training Centres (SIARTC), who are working together on a project to support rural training centres. A summary page of the key findings, in Pijin, will also be distributed to your rural training centre, and verbal summaries of the work will also be passed on. The findings will be used to evaluate the work that is currently being done in your community by Caritas and SIARTC and may support projects to strengthen rural training centres using other New Zealand government funds in the future. It may also be used for other academic publications and conferences.

\section{If you accept this invitation, what are your rights as a research participant?}

You do not have to accept this invitation if you don't want to. If you do decide to participate, you have the right to:

- $\quad$ choose not to answer any question or withdraw from the interview;

- $\quad$ ask for the recorder to be turned off at any time during the interview;

- $\quad$ withdraw from the study before June $1^{\text {st }}, 2019$;

- $\quad$ ask any questions about the study at any time;

- $\quad$ read over and comment on a written summary of your interview;

- be able to read any reports of this research by emailing the researcher, CANZ or SIARTC to request a copy.

If you have any questions or problems, who can you contact?

If you have any questions, either now or in the future, please feel free to contact either:

This content is unavailable. 


\section{Enterprising Enterprises: Sustainable rural training centre models in the Solomon Islands TOKSAVE LONG 'INTERVIEW'}

Mi laek invaitim yu helpim mi long disfela research. Ridim disfela toksave before yu helpim mi olsem. Suppose yu laek helpim mi, ten kyu tumas. Suppose yu no laek helpim mi, ten kyu tumas olsem.

\section{Husat?}

Nem bilong mi Finn Egan. Mi from Wellington long New Zealand, na mi studyim Masters billong 'Development' long Victoria University. Mi bai usim disfela research long 'thesis' bilong $\mathrm{mi}$.

\section{'Aim' bilong disfela wok}

Mi kam long Solomon Islands na doim sumfela 'research' long business bilong olgeta 'rural training centre' 'and' olgeta 'community' bilong em. Mi laek save olgeta changes bilong 'rural training centres' ast fifela yia na long disfela community. Government bilong Solomon Islands na Victoria University givim mi 'permission' long doim disfela wok (Approval $\# 0000027385)$.

\section{How yu bai helpim mi}

Mi laek tok wantaim olgeta 'community members', manmeri, rural training centre students, staff husat laek tok wantaim mi long disfela 'research'. Suppose yumi tok pastem, 'you can suggest a place to meet that you are comfortable with'. Mifela bai toktok long 'business' bilong 'rural training centre' long disfela 'community' na olgeta wok long disfela 'community'. Suppose yu garem taim, mi laek tok wantaim yufela wanfela hour. Suppose yumi tok, mi bai askim yu 'to give me consent on a tape recorder or by signing a form'. Mi bai writim sumfela 'notes' but mi laek recordim disfela 'conversation' long 'tape recorder' so mi no lusim tingting long answers bilong yufela. Em orait suppose yu no laek tok long sumfela question na suppose yu laek mi no usim sumfela 'tape recorder'. Suppose yu amamas long mi usim 'answers' bilong mi long disfela 'research', yu must tok long Finn Egan or SIARTC 'before' June 1, 2019, na Finn bai 'destroyim' em.

\section{How mi usim answers bilong yu?}

Olgeta 'answers' bilong yu em 'secret'. Mi na 'supervisor' bilong mi, na wanfela 'transcriber' na 'translator' bai readim em nomoa. Taim mi writim em 'report' bai mi no usim nem bilong yu, 'except' suppose yu laek mi usim em.

Mi bai destroyim em olgeta 'answers' long disfela toktok bilong yumi (transcript, summary, recording) long March 3, 2020.

Taim mi pinis disfela wok 
Mi bai usim disfela research long Masters bilong mi na wanfela 'report' long Caritas Aotearoa na Solomon Islands Association of Rural Training Centres (SIARTC). Em bai usim disfela research long 'evaluation' bilong START Programme na em bai trai makim sumfela moa 'project' long 'improvim' olgeta 'rural training centre'. Mi bai givim wanfela copy long 'Report' mi writim long SIARTC suppose yu laek ridim em. Mi bai givim wanfela tokesave long olgeta rural training centre. Mi usim em 'answers' long sumfela toksave/'conference' long Victoria University. Suppose yu laek askim sumfela question yu ken emailim mi na 'supervisor' bilong mi.

\section{Suppose yumi tok, yu ken:}

- No givim sumfela 'answer' long 'questions' bilong mi or stopim disfela 'interview'

- $\quad$ Askim na mi no usim sumfela 'tape recorder'

- $\quad$ Askim mi no usim em 'answer' bilong yu before 1 June, 2019 (mi ken destroyim em 'answer')

- $\quad$ Askim olgeta 'question' long research bilong mi

- $\quad$ Ridim na givim mi sumfela 'comment' long toksave bilong disfela 'interview'

- Ridim olgeta 'report' bilong disfela 'resesarch'. Yu ken emailim mi, Caritas or SIARTC na askim long givim yu disfela 'report'

\section{Suppose yu garem sumfela question bilong disfela research}

This content is unavailable. 


\section{Enterprising Enterprises: Sustainable rural training centre models in the Solomon Islands}

\section{CONSENT TO INTERVIEW}

This consent form will be held for 5 years.

Researcher: Finn Egan, School of Geography, Environment and Earth Sciences, Victoria University of Wellington, New Zealand.

- I have read or been read the Information Sheet and the project has been explained to me. My questions have been answered to my satisfaction. I understand that I can ask further questions at any time.

- I agree to take part in an audio recorded interview.

- I I understand that I can give recorded oral consent if I choose to do so instead of written consent without question, including my answers to all the questions below.

I understand that:

- I may withdraw from this study at any point before June 1, 2019, and any information that I have provided will be returned to me or destroyed.

- The identifiable information I have provided will be destroyed on March 3, 2020.

- $\quad$ Any information I provide will be kept confidential to the researcher, the supervisor, the translator and the transcriber.

- I understand that the results will be used for a Masters thesis, a report to SIARTC and Caritas NZ, and/or academic publications and/or presented to conferences.

- I wish to remain unidentified in any reports on this research: Yes

- I would like a summary of my interview:

- I would like to receive a copy of the final report and have added my

Signature of participant:

Name of participant:

Date:

Contact details: 


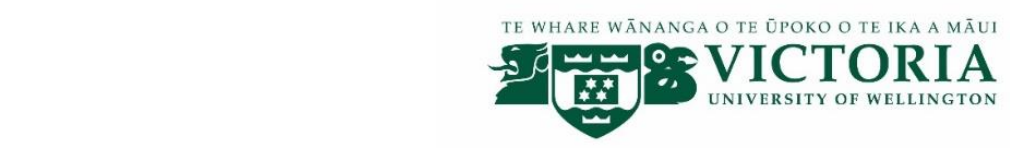

\section{Enterprising Enterprises: Sustainable rural training centre models in the Solomon Islands}

'CONSENT TO INTERVIEW' (?)

Finn bai keepim disfela 'consent form' long fifela yia.

Researcher: Finn Egan, Skul bilong Geography, Environment and Earth Sciences, Victoria University of Wellington, New Zealand.

- Mi na ridim disfela 'Information sheet' na mi save disfela wok bilong Finn Egan. Em tok long olgeta question bilong mi. Suppose mi garem sumfela moa question, mi can askim em olsem.

- Mi amamas suppose yumi toktok na yu usim sumfela 'recording device'

- Suppose mi no laek writim em, em orait na mi givim 'consent' long olgeta question long disfela 'information sheet'.

Mi save:

- Suppose mi no amamas na yu usim 'answers' bilong mi long disfela 'research', mi must tok long Finn Egan 'before' June 1, 2019, na em bai 'destroyim' (rausim?) 'answers' bilong mi.

- Finn Egan bai 'destroyim' olgeta 'recording answers' long March 3, 2020.

- 'Answers' bilong mi em 'confidential'. Finn, 'supervisor' bilong em, na wanfela 'translator' and 'transcriber' bai riddim nomoa.

- Mi save Finn bai usim olgeta 'answers' long 'research' bilong em. Caritas na SIARTC bai usim em 'answers' long sumfela 'report' na toksave/'conference' (meetings?)

- Mi laek suppose nem bilong mi em secret:

- Mi laek sumfela liklik toksave long 'interview' bilong mi: Yes No

- Mi laek kisim (have?) wanfela 'copy' long disfela 'research', na mi putim Yes No sumfela email bilong mi 'below'.

Signature:

Nem:

Date:

Email: 


\section{Appendix 4: Interview Schedule}

\section{Interview Schedule}

The following themes/topics will be used as a guide for potential discussion areas. These evolved over time in the field and were designed to start discussion.

\section{Pre-interview checklist:}

Put some time in so they have seen you about and are relaxed

Confirm location where to sit etc...

Introduce myself and explain purpose of research and topics to be covered in interview

Go through formal ethics protocol and give information sheet.

Check in with them, are they nervous about anything, do they have any questions?

Confirm willingness to participate and ask to record interview.

Start recording, if willing, and confirm consent.

\section{Participants:}

- RTC Administrators

- RTC Tutors

- RTC Students (adult)

- Community members (leaders, women, men, etc.)

\section{Topics of Discussion:}

\section{Background}

Administrators - Initial history of this RTC, reasons for its emergence and 'development' over the last 5 years. Maybe brief discussion of courses that are offered and why. (Flowing into what business/other work are run to support the RTC operating costs)

Tutors- Description of their role at the RTC, including what role they play in the running of it. Brief history of the person (are they from the area? Why did they start working at the RTC?) (Flowing into what business/other work is run to support the RTC operating costs)

Students - Discussion of their history (with the RTC/where they're from), reasons for joining, what kind of work and education they are doing at the moment/in the past. (Flowing into what business/other work they are aware of that are run to support the RTC)

Community members - Discussion of personal history/connection to the RTC. What knowledge they have of the RTC and what it does/how it supports itself. (Flowing into what business/other work they are aware of that are run to support the RTC) 


\section{Nature of RTC Business model}

Administrators- Discussion of how the RTC supports itself (financially, grants, community or other means?). What kinds of things are being done? Who is involved?

Tutors- Discussion of their knowledge of how the RTC supports itself (financially, grants, community or other means). What is their role in the management or running of any RTC business? What do others do as part of this?

Students- Their own history (of education/working). Discussion of their knowledge of how the RTC supports itself (financially, grants, community or other means). What is their role in running of any RTC business/upkeep?

Community members- Their own history (of education/working). Discussion of their knowledge of how the RTC supports itself (financially, grants, community or other means). What role do they personally play in this? What role does the community play in this? (Workers, consumers, no role, etc.)

\section{Causes/Purpose of RTC Business model}

Administrators- Discussion of why the RTC supports itself through these ways. What do they see as the purpose(s) of the RTC/business(es)? (This might mix in with the topic before this to some extent)

Tutors- Discussion of what they see as the purpose(s) of the work/RTC that they are involved in. How does the business affect their work and is it helpful (feeds a little into other topics of discussion too)?

Students- Discussion of what they see as the purpose of the RTC for them. What do you get out of the RTC/its business? Are your skills relevant to your work in the business and your future plans?

Community members- Discussion of what they see as the purpose of the RTC and its business. How is the business used and/or useful for the community?

\section{Impacts on the community}

This and the previous discussion points are likely to feed into each other.

Administrators- What opportunities do see for young people and the community that have occurred in the last 5 years? For the RTC? How have the START trainings impacted on your own work? Do you do things differently? How? Why?

Tutors- What opportunities do see for young people and the community that have occurred in the last 5 years? Discussion of personal/community 'development'/change. How have the START trainings impacted/changed your teaching (do you teach differently? How? Why?)

Students- What impact has being part of the RTC had on you? Could they do more? How do the RTCs help you now and can they help you when you have finished your course? What are the opportunities in the community? What would you like to see? 
Community members- How does the RTC and its business involve/connect with the community? Could they do more? How? Examples of the impact that it has had on the community? What are the opportunities in the community?

\section{RTC Finances/Sustainability}

Administrators- This is primarily a financial discussion directed at administration/tutors (how money is managed/used at present, how/if business is recorded, if they are trying to continue it regularly or only sometimes).

Tutors- This is primarily a financial discussion directed at administration/tutors (how money is managed/used at present, how/if business is recorded, if they are trying to continue it regularly or only sometimes).

This section for students and community members will feed into the community impact section

Students- Are you doing anything now alongside the RTC work? Do you have plans for when you finish schooling? How do people support themselves and their families here? What are the main ways people earn cash? Other than cash, how do people feed their family, provide housing etc...

Community members- How do people support themselves and their families here? What are the main ways people earn cash? Other than cash, how do people feed their family, provide housing etc...

\section{Other forms of Support}

Administrators- Discussion of other forms of support the RTC receives (external community, government, START programme). Discussion of what has been used in the past (successfully/unsuccessfully? Why?)

Tutors- Apart from the RTC businesses, how do you and others in the community support yourselves (and your families)? Discussion of any other forms of support that people are aware/can/can't access

Students- Apart from the RTC businesses, how do you and others in the community support yourselves (and your families)? Discussion of any other forms of support that people are aware/can/can't access

Community members- Apart from the RTC businesses, how do you and others in the community support yourselves (and your families)? Discussion of any other forms of support that people are aware/can/can't access

Is there anything else you would like to add? 